Review

\title{
Design of metal-organic frameworks (MOFs)-based photocatalyst for solar fuel production and photo-degradation of pollutants
}

\author{
Xiaoxue Zhao, Jinze Li, Xin Li, Pengwei Huo *, Weidong Shi \# \\ Institute of Green Chemistry and Chemical Technology, School of Chemistry and Chemical Engineering, Jiangsu University, Zhenjiang 212013, Jiangsu, \\ China
}

\section{A R T I C L E I N F O}

Article history:

Received 18 August 2020

Accepted 21 September 2020

Available online 22 November 2020

\section{Keywords:}

Design

Metal organic framework

Photocatalytic performance

Degradation of organic pollutants

$\mathrm{CO}_{2}$ reduction

$\mathrm{H}_{2}$ production

\begin{abstract}
A B S T R A C T
Metal organic frameworks (MOFs) is a research hotspot in the solar fuel production and photo-degradation of pollutants field due to high surface area, rich metal/organic species, large pore volume, and adjustability of structures and compositions. Therefore, in this review, we first summarized the design factors of photocatalytic materials based on MOF from the perspective of "star" MOF. The modification strategies of MOFs-based photocatalysts were discussed to improve its photocatalytic activity and specific applications were summarized as well, including photocatalytic $\mathrm{CO}_{2}$ reduction, photocatalytic water splitting and photo-degradation of pollutants. Finally, the advantages and disadvantages of MOFs-based photocatalysts were discussed, the current challenges were highlighted, and suggestions for future research directions were proposed.
\end{abstract}

(C) 2021, Dalian Institute of Chemical Physics, Chinese Academy of Sciences. Published by Elsevier B.V. All rights reserved.

\section{Introduction}

Metal organic frameworks (MOFs) are assembled by coordination effect between metal ions/clusters and organic ligands. Other forces such as $\pi-\pi$ stacking, hydrogen bonds and van der Waals forces also have a significant effect in the formation of three-dimensional (3D) MOFs. MOFs have a large specific surface area, uniform distribution of pores and great porosity. On account of the wonderful properties of MOFs, MOFs have been applied diffusely in varieties of fields, such as catalytic reactions (including photocatalysis, electrocatalysis, photoelectric catalysis and chemical catalysis) [1-4], gas adsorption [5] and selective separation [6], biomedicine [7], chemical sensors [8] and so on (Fig. 1(a)). In the past ten years, various applications of MOF materials have developed by rapidly, especially in the field of catalysis, which has received more attention and popularity (Fig. 1(b)) [9-15].

MOFs are diverse in structure and wide in variety. There are currently thousands of MOFs reported in synthesis, and new reports are constantly emerging [16]. These different kinds of MOFs have own unique inorganic and organic components, crystal types, pore sizes, etc., and can be applied in different fields according to needs. Firstly, MOFs can be easily imported into functional components [17]. With the previous modification of organic ligands, MOFs can be easily introduced into heteroatom rings [18,19], phosphate groups [20], hydroxyl groups [21], halogen atoms [22,23], chiral molecules [24-26], biomacromolecule frameworks [27-29], metal ions [30-33], etc. In addition, nanoparticles can also be easily introduced into the cavity of MOFs or reduced in the skeleton [34]. The introduction of these functionalized components enhances the original functions of MOFs or gives them new functions. Secondly, some

\footnotetext{
* Corresponding author. Tel/Fax: +86-511-88790885; E-mail: huopw@mail.ujs.edu.cn

\# Corresponding author. E-mail: swd1978@ujs.edu.cn

This work was supported by the National Natural Science Foundation of China (22078131, 21776117).

DOI: 10.1016/S1872-2067(20)63715-9 | http://www.sciencedirect.com/science/journal/18722067 | Chin. J. Catal., Vol. 42, No. 6, June 2021
} 


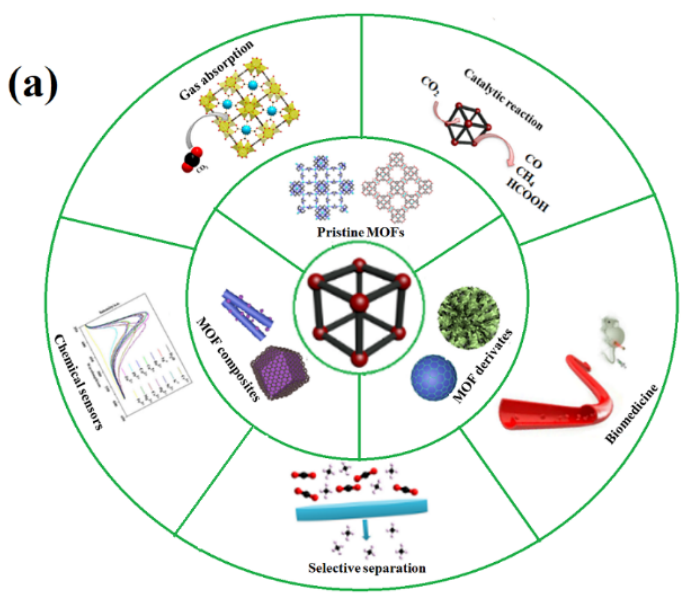

(b)

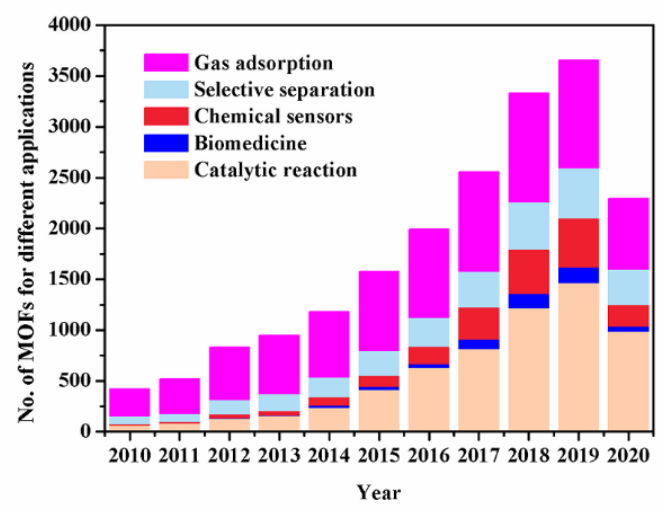

Fig. 1. (a) Applications of MOFs; (b) Number of papers for different applications of MOF reported during 2010-2020.

types of MOFs have been found to have properties similar to semiconductors. In the photocatalytic reaction, because of the relatively short transmission distance from carriers to the surface of the hole in entire structure, the high porosity of MOFs makes for the separation of electrons and holes. Thirdly, the Lewis acid and optical properties of MOFs can be used to catalyze the corresponding reactions because of the structural characteristics of metal nodes $[35,36]$.

On the grounds of the differences of metal ions/metal clusters and linkers, there are several types of MOF: MIL (Materials of Institute Lavoisier) series, IRMOF (Isoreticular Metal-Organic Frameworks) series, ZIF (Zeolitic imidazolate framework) series, UiO (University of Oslo) series, PCN (Porous Coordination Network) series, etc. MILs series were discovered and successfully prepared by Ferey's team, in which MIL-100 [37] is rigid cage structure with large cage pore structure. In 2002, the Yaghi research team modified the structure of MOF-5 to obtain a series of MOFs, namely IRMOFs [38]. The successful preparation of IRMOFs realizes the transition of the MOFs material from microporous material to mesoporous material. Zeolitic imidazolate frameworks (ZIFs) can be summarized as typical silica-alumina molecular sieve structures [39]. UiO series materials are a new class of zirconium ( $\mathrm{Zr}$ )-based MOFs that have received wide attention [40]. Taking UiO-66 as an example, UiO-66 with octahedral 3D microporous structure is composed of 1,4-benzene-dicarboxylate and $\left[\mathrm{Zr}_{6} \mathrm{O}_{4}(\mathrm{OH})_{4}\right]$. PCN contains cubic octahedral nanopores and forms a $\mathrm{Cu}$-BTC pore cage-channel topology in space [41,42]. In addition, the design and modification strategy of MOF structure has become a development trend. For example, modification of ligands or metal centers could improve visible-light absorption. The amino group in UiO-66- $\mathrm{NH}_{2}$ acts as auxochromic, shifting the absorption wavelength of UiO-66 [43]. It is an ideal modification strategy to construct heterojunctions by MOFs and other semiconductors. More content will be discussed in detail below.

Here, we aim to introduce different types of MOF materials and the design and modification of MOFs-based photocatalysts. We also discussed the role of MOFs-based photocatalysts in different photocatalytic applications and hope to provide more opinions for the design of MOFs-based photocatalysts.

\section{Fundamentals of MOFs-based photocatalysts}

\subsection{Advantages of MOFs photocatalytic material}

The organic linkers of MOFs tend to have large $\pi$-conjugated systems, and there is a tendency for electron transfer between ligands and metals. Solvent molecules with reversible coordination on metal nodes also contain potential sites for substrate binding activity [44]. In addition, if MOFs itself has metal ligands with photocatalytic performance, then the ligands themselves can generate photogenerated electrons for photocatalytic reactions. On the whole, MOFs have the following advantages as photocatalysts: (1) the porous structure of MOFs: the porous structure of MOFs exposes more active sites and facilitates; (2) crystalline nature of MOFs [45]: MOF with ordered crystal structure can separate electron-hole pairs; (3) the well-defined and tailorable MOF structures [46]: optical absorption of MOFs are enhanced by introducing a long-wavelength absorbing group into the MOFs as an organic bridging ligand; (4) the recyclability of MOFs: MOFs are easy to separate and recycle from the reaction system, which is beneficial to prolong life of the catalyst and avoid pollution.

\subsection{Classifications of MOFs-based photocatalytic material}

\subsubsection{UiO-MOFs Photocatalysts}

Lillerud et al. [47] first reported the UiO series (UiO- $X, X=$ $66,67,68$ ) in 2008. UiO series MOF are 3D porous material constructed by $\mathrm{Zr}^{4+}$ and dicarboxylic acid ligand. Although the ligands are different in length, UiO-66, UiO-67, and UiO-68 have the same network structure (Fig. 2). The redox potential energy of the ligand in UiO-66 is lower than that of the metal cluster, so the electrons of the ligand cannot be transferred to the metal cluster, so UiO-66 cannot be excited under visible light $[48,49]$. However, the band gap can be adjusted by altering the substituents of the ligand, thereby changing the absorption range of light. The redox potential, electron density and electronegativi- 

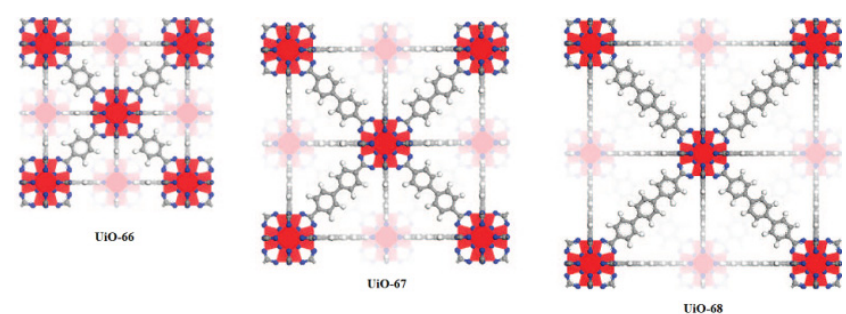

Fig. 2. The structures of UiO-66, UiO-67 and UiO-68. Reprinted with permission from Ref. [47]. Copyright (2008) American Chemical Society.

ty of photocatalysts can be accurately regulated through introducing electron-absorbing/electron-giving groups, which in theory can also promote charge separation and change the band gap [50].

The introduction of electron-donating groups that are not involved in coordination in the MOF can adjust the electronegativity of the photocatalyst, resulting in the LMCT of electrons. For example, amino-modified MOFs can effectively broaden the light absorption range, thereby improve photocatalytic activity. Wei et al. [51] studied the band gap changes of UiO-68 caused by different functional groups. The electron group increased the absorption of visible light. From this point of view, the electron-donating groups greatly influence the photochemical properties. Hence, Li et al. [52] studied the effects of electron-donating groups in UiO-66-X. And zeta potential of UiO-66-X followed the order of $-\mathrm{OH}>-\mathrm{NH}_{2}>-\mathrm{COOH}>-\mathrm{NO}_{2}>-\mathrm{H}$ in water at $\mathrm{pH}=7.08$ on account of adjustment of UIO-66-X electronegativity by electron donating groups. The above results provided strong electron-donating groups freely interact with benzene ring [53]. However, Chen and his colleagues [54] found that $-\mathrm{NH}_{2}$ and $-\mathrm{SH}$ modified MOF, which were also electron-donating groups, had almost opposite degradation behavior. Hence, it is improper to explain this phenomenon with the electron effects theory. The author found suitable potential relationship enables the electrons transfer from the excited $\mathrm{RhB}$ to UiO-66-(SH) 2. Hence, it is also important for photocatalytic reactions to attach importance to the potential relationship between dyes and semiconductors and the efficiency of electron separation.

\subsubsection{ZIF-MOFs photocatalysts}

The ZIF is a class of MOF materials formed by Yaghi group. It is a series of 3D porous materials self-assembled by nitrogen ligand and divalent metal ion $\left(\mathrm{Zn}^{2+}\right.$ or $\left.\mathrm{Co}^{2+}\right)$ in tetrahedral coordination. Because the angle of its metal-N-N-metal secondary structure is somewhat similar to that of $\mathrm{Si}-\mathrm{O}-\mathrm{Si}$ in zeolite molecular sieves with $145^{\circ}$ coordination angle and topological structure (Fig. 3(a)), it is called zeolitic imidazolate framework [55-58]. ZIF not only has good thermal stability, but also has adjustable topology structure. ZIF-8 and ZIF-67 are two widely used materials in photocatalysis field. Nevertheless, the large band gap (5.1 eV) of ZIF-8 limits its photocatalytic activity under visible light. The photocatalytic performance of ZIF-8 in visible light is limited to a certain extent, mainly due to the influence of its large band gap (5.1 eV). In contrast, ZIF-67 can

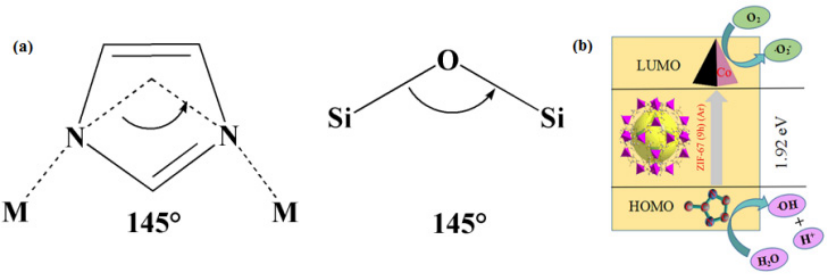

Fig. 3. (a) ZIFs and zeolites have similar bond angles; (b) A schematic illustration of photocatalytic reaction mechanism of ZIF-67(9h)(Ar). Reprinted from Ref. [62]. Copyright (2019) Elsevier.

exhibit multiple absorption bands in the ultraviolet-visible-near-infrared region, mainly because its band gap $(1.98 \mathrm{eV})$ is smaller than ZIF-8 [59,60]. The current research on pure ZIF in photocatalysis is not extensive and focuses on the degradation of pollutants. ZIF-8 not only decompose MB (82.3\%) under UV light, but also works at different $\mathrm{pH}$ values (pH = 4-12) [61]. Additionally, ZIF-67(9h)(Ar) showed photocatalytic activity with 75\% Methyl Orange (MO) degradation, 85\% Methylene Blue (MB) degradation, and 54\% Rhodamine B $(\mathrm{RhB})$ degradation [62]. In the process of degradation, $\mathrm{e}^{-}$ transfers from $\mathrm{N}$ to Co (Fig. 3(b)). Then, $\mathrm{H}_{2} \mathrm{O}$ was oxygenated into the $\bullet \mathrm{OH}$ active species. Oxygen adsorbed on ZIF-67(9h) (Ar) surface combined with $\mathrm{e}^{-}$in the LUMO to form $\bullet \mathrm{O}_{2}$, which can be further converted to $\bullet \mathrm{OH}$. The formed active radicals can decompose dye molecules rapidly [63,64].

\subsubsection{MIL-MOFs photocatalysts}

MIL series MOFs are competent in efficient photocatalysts because of nontoxic, low cost and high chemical stability $[65,66]$. MIL-100(Fe) can participate in the photocatalytic hydroxylation of benzene. When $\mathrm{H}_{2} \mathrm{O}_{2}$ acted as oxidant, the conversion between $\mathrm{Fe}^{3+}$ and $\mathrm{Fe}^{2+}$ in the $\mathrm{Fe}-\mathrm{O}$ cluster leads to the reduction of $\mathrm{H}_{2} \mathrm{O}_{2}$ to $\bullet \mathrm{OH}$, and $\bullet \mathrm{OH}$ as the active substance can oxidize benzene to phenol. Li et al. [67] first proved that MIL-100(Fe) can be involved in the hydroxylation of benzene to produce phenol. The mechanism was shown in Fig. 4 . The - $\mathrm{OH}$ produced during the conversion of $\mathrm{Fe}^{3+}$ and $\mathrm{Fe}^{2+}$ can convert benzene to hydroxyl cyclohexadiene group. Then, the release of protons and electrons in the hydroxyl cyclohexadiene group to form phenol. Morphology of MIL-100(Fe) also had a great influence on photocatalytic activity. Uniform MIL-100(Fe) nanospheres could transform benzene into phenol with an efficiency of $34.4 \%$ and a selectivity of $98 \%$. Besides benzene

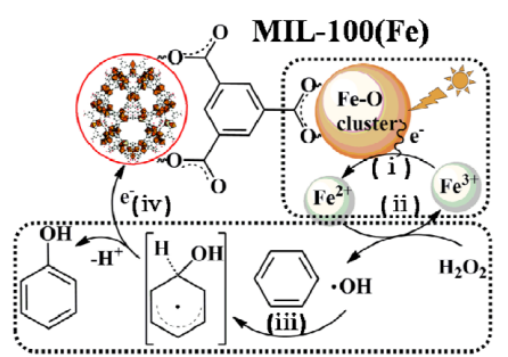

Fig. 4. Mechanism for the photocatalytic hydroxylation of benzene by MIL-100(Fe). Reprinted with permission from Ref. [49]. Copyright (2015) the Royal Society of Chemistry. 
hydroxylation, MIL-100(Fe) also had excellent performance in photocatalytic degradation. Three MIL-100(Fe) were prepared using $\mathrm{FeCl}_{3}, \mathrm{Fe}\left(\mathrm{NO}_{3}\right)_{3}$ and $\mathrm{Fe}_{2}\left(\mathrm{SO}_{4}\right)_{3}$ to degrade Basic Blue 41 [69]. Hereafter, Wang and co-workers reported Fe-MIL-101 can achieve $55.1 \%$ adsorption and $96.6 \%$ degradation efficiency of $\mathrm{TC}$ within $180 \mathrm{~min}$ [70]. In photocatalytic $\mathrm{CO}_{2}$ reduction, Sun et al. adopted solvent-free route for reduction of $\mathrm{CO}_{2}$ by $\mathrm{NH}_{2}$-MIL-101(Fe), which exhibited CO formation rate of 87.6 $\mu \mathrm{mol} \cdot \mathrm{g}^{-1}[71]$.

\subsubsection{PCN-MOF photocatalysts}

PCN materials are mainly the MOF materials which contain the hole cage and 3D orthogonal channel structure by the reaction of the copper and ligands such as tribenzoic acid, 4,4',4"-s-triazine-2,4,6-triyltribenzoate or s-heptazine trebenzoate. And the hole cage and channel are interlinked through a window with a small diameter. Porphyrins are a class of heterocyclic compounds with large conjugated systems, which are formed by the attachment of a methine group of the alpha carbon atoms of four pyrroles. MOF with porphyrin becomes excellent photocatalysts because the presence of porphyrins raises the light absorption and increases the photoelectron-hole separation rate, and have large specific surface area and a porous structure [72,73].

PCN-22 was provided by $\mathrm{Ti}_{6} \mathrm{O}_{6}(\mathrm{OiPr})_{6}(\mathrm{abz})_{6}$ cluster, TCPP and benzoic acid [74]. PCN-22/TEMPO system was used for a photocatalyzed alcohol oxidation reaction. The conversion rate of benzyl alcohol to benzaldehyde was up to $28 \%$ with high selectivity (almost 100\%). Jiang's group prepared a stable meso-porous porphyrin MOF, namely $\mathrm{PCN}-222$, by $\mathrm{ZrCl}_{4}$ and $\mathrm{H}_{2} \mathrm{TCPP}$ (tetrakis(4-carboxyphenyl)porphyrin) [75]. PCN-222 was a 3D network formed by $\mathrm{H}_{2} \mathrm{TCPP}$ connecting $\mathrm{Zr}_{6}$ clusters and had a large 1D channel with a diameter of $3.7 \mathrm{~nm}$ (Fig. 5(a)).

It is precisely because $\mathrm{PCN}-222$ has absorption in the range of 200-800 nm that the electrons of PCN-222 can be excited in visible light (Fig. 5(b)). Extremely long-lived electrons in PCN-222 avoid recombination of electron-hole. All in all, large $\pi$-conjugated system MOFs with clear crystal structure can enhance the light absorption of MOFs and increase the number of electron-hole pairs generated under solar illumination, which leads to effective light trapping and expansion of light contact area.

Another typical Zr-MOF was $\pi$-conjugated PCN-136, which had a high $\mathrm{CO}_{2}$ adsorption capacity $\left(61.01 \mathrm{~cm}^{3} \cdot \mathrm{g}^{-1}\right)$ [76]. Inter-
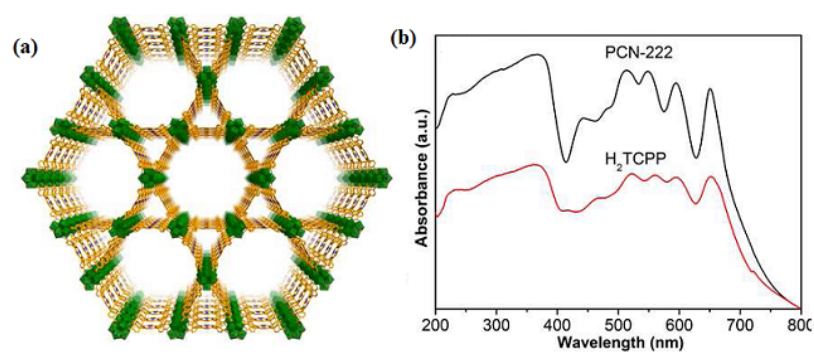

Fig. 5. (a) View of the 3D network of PCN-222; (b) UV-Vis spectra of $\mathrm{H}_{2}$ TCPP and PCN-222. Reprinted with permission from Ref. [75]. Copyright (2015) American Chemical Society. action between the $\mathrm{sp}^{2}$ bond carbon atoms in the hexabenzocoronene fragments and the $\mathrm{CO}_{2}$ molecule may play a vital role in $\mathrm{CO}_{2}$ absorption $[77,78]$. The mechanism of photo-reduction of $\mathrm{CO}_{2}$ by $\mathrm{PCN}-136$ was shown in the Fig. 6. Hexakis(4-carboxyphenyl)hexabenzocoronene) (HCHC) generates electrons under visible light and transfers to $\mathrm{Zr}^{\mathrm{IV}}$-oxo clusters, thereby reducing $\mathrm{Zr}^{\mathrm{IV}}$ to $\mathrm{Zr}^{\mathrm{II}}$. Then, the intermediate $\mathrm{Zr}^{\mathrm{III}}$ as a reaction site reduces $\mathrm{CO}_{2}$ to $\mathrm{HCOO}^{-}$and was oxidized back to Zriv.

By briefly introducing several types of typical MOF, we find that it is feasible to build up the photocatalytic activity of $\mathrm{UiO}$ series MOFs by molecular modification. But the choice of organic ligand modification and replacement of metal center is astricted. ZIF materials with typical silica-aluminum molecular sieve structure can remain stable in boiling alkaline aqueous solution and organic solvent, and are suitable for selectively and efficiently capturing $\mathrm{CO}_{2}$ in automobile exhaust. One of the biggest characteristics of MIL series MOF is that under the stimulation of external factors, the material structure will change between the large hole and the narrow hole. This phenomenon makes the MIL material have certain flexibility when adsorbing polar molecules such as $\mathrm{H}_{2} \mathrm{O}$ and $\mathrm{CO}_{2}$, which is conducive to the selective adsorption of $\mathrm{CO}_{2}$. The porphyrin in PCN is beneficial to the photo-induced electron transfer process and can extend the recombination time of electron-hole in the framework. In the process of synthesizing PCN-MOFs, the function of porphyrin is expanded through modification and other functional methods, so as to be better applied to each field.

\subsection{Design considerations of MOFs-based photocatalytic material}

\subsubsection{Stability}

MOF has good application prospects, but it is not suitable for use under harsh conditions due to stability issues. For example, MOF-5 [79], as an important milestone in MOF research, will gradually decompose after being exposed to moist air. When an MOF is applied to a particular scenario, the integrity of the framework must be guaranteed to achieve the expected function. Acid/alkali, water vapor/liquid water, and water containing coordination anions have different effects on the stability of MOF.

Compared with neutral water molecules, protons and hydroxide ions are more destructive to the structure of MOFs. In addition, the chemical conditions of acidic solutions and alka-

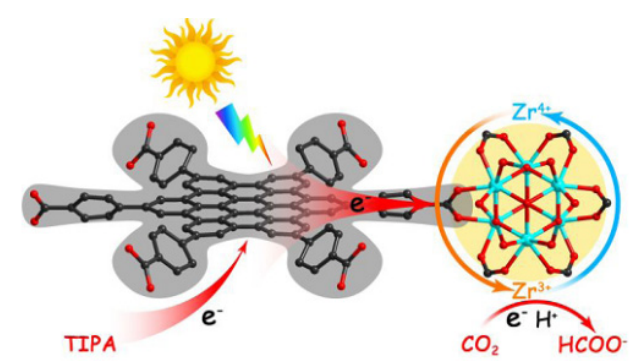

Fig. 6. Mechanism for photocatalytic $\mathrm{CO}_{2}$ reduction over $\mathrm{PCN}-136$ under visible-light irradiation. Reprinted with permission from Ref. [76]. Copyright (2019) American Chemical Society. 
line solutions are different, leading to different stability of MOFs. MOFs composed of high-priced metal ions and carboxyl ligands show good stability in acid solution, but they are not resistant to the destruction of alkaline solutions. A typical example is MOF-545 [80], which is composed of $\mathrm{Zr}^{4+}$ and carboxylic acid. MOF-545 can achieve complete crystallization in $\mathrm{HCl}$. However, when MOF-545 was placed in an alkaline solution, it quickly was dissolved. Although MOFs composed of low-value metal ions and azo linkers can be stable in alkaline solution, they are susceptible to influence in acids. For example, a $\mathrm{Ni}^{2+}$-pyrazole-based MOF-PCN-601 was not affected by saturated $\mathrm{NaOH}$, but decomposed gradually after the solution $\mathrm{pH}$ was less than 4 [81].

The structural collapse of MOFs in water vapor or liquid water is attributed to the strong interaction between metal nodes and water molecules, which leads to the break of coordination bonds and the destruction of the framework $[82,83]$. The direct way to solve such problems is to use carboxylic acid-based ligands and high-valent metal ions, or azo-based ligands and low-valent transition metal ions to construct the framework.

Many coordination anions such as $\mathrm{F}^{-}, \mathrm{PO}_{4}{ }^{3-}$ etc. are usually regarded as hard Lewis bases. In MOFs consisting of high-valent metal ions, carboxylic acid ligands can easily be replaced by these coordination anions in solution as competing species. Using soft metal ions and ligands to construct MOFs is a valid way to surmount the influence of coordination anions on MOFs. So, the strong coordination bond between the metal ion and the ligand is maintained, and the affinity between the metal ion in the framework and the coordination anion in the solution is reduced.

Operation environment, coordination configuration of metal ligands and surface hydrophobicity will affect the stability of MOF. The research on the stability of MOFs enables us to reasonably consider the influence of certain factors, thereby rationally designing a stable frame structure.

\subsubsection{Properties of the metal center}

The structural stability of MOFs is affected by the type, coordination number and oxidation state of metal center. High-valence metal cations usually have richer coordination environment than that of low-valent metal cations, so they have stronger metal-coordination bonds, and can enhance the stability of the framework to some extent by preventing the attack of the guest through inorganic nodes with high connectivity [84-88]. For example, Zhou et al. reported 13 kinds of Zr-MOFs, in which NU-1000 and NU-901 remained structural integrity after immersion in water, acidic solution $(\mathrm{pH}=1)$ and slightly alkaline solution $(\mathrm{pH}=11)$ [89]. Similarly, the tetravalent zirconium ion $\left(\mathrm{Zr}^{4+}\right)$ made $\mathrm{Zr}_{6} \mathrm{O}_{4}(\mathrm{OH})_{4}\left(\mathrm{CO}_{2}\right)_{12}$ stable in water [90]. Kang et al. investigated effect of introducing inert metal ions into the isotypic MOF structure on chemical stability [91]. After 6 hours in $0.07 \mathrm{M} \mathrm{HCl}$ solution, MIL-53(Cr) still maintains its original structure, but MIL-47(V) dissolved. Therefore, MOF containing $\mathrm{Cr}(\mathrm{III})$ or $\mathrm{Rh}(\mathrm{III})$ as the central metal ion will be more stable. The strength of the metal-ligand bond can also be increased by exchanging the metal cation in the MOF. For in- stance, Li et al. found that Ni-doped MOF- 5 not only maintained its crystallinity in moisture, but also had a larger surface area and larger pore size than undoped MOF-5 [92].

\subsubsection{Properties of the ligand}

On the one hand, functionalization of organic ligands with hydrophobic groups can heighten the stability of the frame in water. On the other hand, the alkalinity of the ligand also enhances the strength of the metal-coordination bond. Most metals belong to Lewis acids and can form stronger bonds with basic ligands. Wu et al. functionalized the ligand of MOF, namely Banasorb-22, with a hydrophobic group (R1 = trifluoromethoxy, R2 = H) and tested its hydrothermal stability in water vapor [93]. The PXRD of Banasorb-22 did not change significantly after one week. unfunctionalized MOF, but the surface area of Banasorb-22 decreased from 1113 to $210 \mathrm{~m}^{2} \cdot \mathrm{g}^{-1}$. However, under the same conditions, the surface area of unfunctionalized MOF decreased from 2365 to $50 \mathrm{~m}^{2} \cdot \mathrm{g}^{-1}$ within a few minutes, which confirmed that the hydrophobicity of R1 and R2 successfully improved the stability. Yang's groups reported a super-hydrophobic MOF, which had higher water stability than BPL Carbon and zeolite-5A [94]. $\mathrm{Cu}_{2} \mathrm{~L}$ was reported to maintain structural integrity in boiling organic solvents, $0.001 \mathrm{M} \mathrm{HCl}$ and $0.001 \mathrm{M} \mathrm{NaOH}$ for $24 \mathrm{~h}$, not only due to the hydrophobicity of the MOF channel, but also due to the alkalinity and coordination capacity of pyrazolate ligands [95].

\subsubsection{Composition-dependent band structures}

MOF has an adjustable energy band structure. First of all, a suitable valence band is an indispensable condition for catalytic oxidation of MOF, while a conduction band can determine the feasibility of hydrogen evolution or $\mathrm{CO}_{2}$ reduction [96-98]. Second, it is vital for charge transfer between co-catalyst and MOF to conduct the band alignment. In addition, the proper bandgap displacement of MOF can affect the effective charge separation at the heterojunction $[99,100]$. The modification of organic linkers and metal nodes affects the electronic structure of MOF, and the interaction between organic linkers and metal nodes can alter the position of its orbit and generate new hybrid states. In general, the band gap engineering of MOFs could be studied by altering metal nodes or functionalized organic ligands.

Pham studied the effect of halogen atoms ( $\mathrm{F}, \mathrm{Cl}, \mathrm{Br}$ and I) on the electron band structure of IRMOFs [101]. Introducing halogen atoms can reduce the band gap, and the band gap decreases with the increase of the size of halogen atoms. Iodine can prominently reduce the band gap to $2.65 \mathrm{eV}$. Moreover, Musho et al. [102] confirmed that amino can reduce the bandgap energy of Zr-UiO-66 by combining calculation and UV-vis experiment. On the contrary, nitro reduced the band gap energy of Zr-UiO-66 by a small amount, which can be attributed to the bonding property between the functional group nitrogen and aromatic carbon. Hendon and co-workers analyzed the effect of linker functionalization on the band gap of MIL-125 [103]. After the substitution of 2-aminoterephthalic acid for 1,4-dicarboxybenzene, the movement of N 2P electrons to the aromatic connection unit resulted in a red-shifted band above 
the edge of the MIL-125 valence band, reducing the band gap of MIL-125- $\mathrm{NH}_{2}$ from 3.6 to $2.6 \mathrm{eV}$. The electronic modification of aromatic motifs is local, and the optical properties can be directly controlled by the modification of the valence band, so the optical response of MIL-125 can be adjusted by rational selection of substituents to make it suitable for absorption in the visible light region.

\subsubsection{Promoting effects of adsorption}

The unique characteristics of MOF are porous nature and large specific surface area. The specific surface area of MOFs can be as high as $7000 \mathrm{~m}^{2} \cdot \mathrm{g}^{-1}$, and the pore size (usually 0-3 $\mathrm{nm}$, can also be as high as $9.8 \mathrm{~nm}$ ) and specific surface area can be changed by adjusting the size and assembly method of its organic ligands [104]. This determines the advantages of MOF in adsorbing gas, especially the adsorption of $\mathrm{CO}_{2}$, which is very conducive to the later $\mathrm{CO}_{2}$ photoreduction.

Since $\mathrm{CO}_{2}$ is an acid gas, the basicity of MOF itself is beneficial to enhance the adsorption capacity of $\mathrm{CO}_{2}$. Before designing the MOF structure, changing the surface properties can achieve the $\mathrm{CO}_{2}$ adsorption we need [105]. The surface properties of MOF can be modified by two methods, one is the use of amine-functionalized ligands during the synthesis of MOF, and the other is the post-synthetic modification of MOF by impregnation. For instance, the maximum $\mathrm{CO}_{2}$ absorption of $\mathrm{NH}_{2}$-MIL-125(Ti) was $132.2 \mathrm{~cm}^{3} \cdot \mathrm{g}^{-1}$, while MIL-125(Ti) was only $\mathrm{cm}^{3} \cdot \mathrm{g}^{-1}$, because $-\mathrm{NH}_{2}$ enhanced the interaction between $\mathrm{CO}_{2}$ and the functionalized aromatic molecules [106]. Similarly, $\mathrm{NH}_{2}$-UiO-66(Zr) showed higher $\mathrm{CO}_{2}$ adsorption capacity than Ui0-66(Zr) [107]. Therefore, better $\mathrm{CO}_{2}$ adsorption performance resulted in more reduction products. It is worthwhile mentioning that copper organic complexes have advantages in $\mathrm{CO}_{2}$ capture and activation. $\mathrm{Cu}$ porphyrin-based MOF ( $\left.\mathrm{S} \mathrm{Cu}\right)$ exhibited better performance in capturing $\mathrm{CO}_{2}$ and converting $\mathrm{CO}_{2}$, compared with sample without $\mathrm{Cu}$ [108]. The presence of $\mathrm{Cu}$ induced the chemisorption of $\mathrm{CO}_{2}$ on $\mathrm{S} \mathrm{Cu}$ and realized the activation of $\mathrm{CO}_{2}$, thereby improving the $\mathrm{CO}_{2}$ capture ability and higher photoreduction efficiency.

\subsubsection{Selectivity consideration}

The well-defined channels and pores of MOF limit the size and shape selection of reactants, giving MOF unique advantages in selective catalysis. The uniform pore structure of the MOF can act as a molecular sieve, allowing substrates/products with a smaller pore size than the MOF to enter and exit. The ZIF-8 has adjustable bore diameter from 11.6 to $3.4 \AA$ [109]. Wang's groups [110] reported ZnO@ZIF-8 with size selective photocatalysis properties. The shell was composed of a ZIF-8 polyhedron with uniform thickness of about $30 \mathrm{~nm}$. In order to penetrate the ZIF-8 shell, the reactant molecules must pass via the pores of the ZIF-8 skeleton with a size of $3.4 \AA$, so $\mathrm{CrO}_{4}{ }^{2-}$ ions with a diameter of $4 \AA$ A can penetrate into the ZIF-8 shell [111,112]. However, MB molecules with a minimum cross-sectional size of $8 \AA$ cannot enter pores which were smaller than $13 \AA$ [113]. Hence, ZnO@ZIF-8 can selectively reduce $\mathrm{Cr}(\mathrm{VI})$. Zeng et al. [114] prepared CdS@ZIF-8 and the thickness of MOF could be adjusted from $10.2 \pm 5.4$ to $13.6 \pm$
$2.5 \mathrm{~nm}$ by changing the concentration of 2-methylimidazole. Compared with CdS, CdS@ZIF-8 had better selectivity for $\mathrm{H}_{2}$ production, and the mole percentage of CO decreased significantly from $12.5 \%$ to $3.2 \%$. This was mainly because the diameter of $\mathrm{CO}$ is $3.8 \AA$, which was significantly larger than the pore size (3.4 $\AA$ ) of ZIF-8. As a result, CO cannot pass through the pores of ZIF-8, which suppresses the production of $\mathrm{CO}$ and promotes the production of $\mathrm{H}_{2}$.

\subsubsection{Electrical conductivity}

Because of the formation of a coordination bond between the metal ion or cluster and the organic ligand in the MOF, the metal ion or cluster becomes a redox active deactivated ion [115]. Hence, the poor conductivity of MOFs in general is mainly due to the lack of free charge carriers and low energy paths for charge transmission. Without sacrificing its inherent characteristics of high surface area and high porosity, improving the electrical conductivity of MOF can provide opportunities for its electronic applications. The $\pi$-conjugated MOF with a highly dispersed valence/conduction band can achieve band transfer and excellent charge mobility

Effective $\pi-\pi$ stacking path and redox active ligand/mixed metal node can promote discrete delocalization and long-distance charge transmission [116-119]. More than anything, the direct evidence for the semiconductor behavior of MOF is electrical conductivity. MOFs are considered semiconductors if their conductivity was higher than that of an insulator $\left(10^{-10} \mathrm{~S} \cdot \mathrm{cm}^{-1}\right)$.

Ben et al. reported that $\pi-\pi$ stacked conductive MOFs, namely ANMOF-74 [120]. In ANMOF-74, 4,4'-(anthracene-9,10diyl)bis(2-hydroxybenzoic acid) and metal ions formed a porous hexagonal framework. ANMOF-74 had numerous anthracene cores stacked along the c direction, and the interlayer distance was $5.7 \AA$. The conductivity of ANMOF-74 had been increased by a factor of $10^{6}$ because it incorporated a stacked charge transport pathway. Zn2(TTFTB) had excellent intrinsic charge mobility of $0.2 \mathrm{~cm}^{2} /(\mathrm{V} \cdot \mathrm{s})$ [121]. $\mathrm{Zn}_{2}$ (TTFTB) was composed of infinite helical chains whose corners share a pseudo-octahedron and these helical chains were connected together by a helical stack of TTFTB-linkers. Although there was only one kind of intermolecular S•••S contact in $\mathrm{Zn}_{2}$ (TTFTB), it could delocalize part of the charge, thus giving it a higher charge mobility. If the orbitals between metal ions and coordination atoms overlap energetically, an effective charge transfer can be formed in the rigid MOF. Dinca et al. [121] studied the electrical transmission properties of $\mathrm{Fe}_{2}$ (DEBDC) and $\mathrm{Mn}_{2}$ (DEBDC). The difference was that $\mathrm{Fe}_{2}$ (DEBDC) had metal-sulfur chains and $\mathrm{Mn}_{2}$ (DEBDC) had metal-oxygen chain. The enhanced orbital overlaps of MOF and chalcogen atoms reduced the charge jump barrier, so the conductivity of $\mathrm{Fe}_{2}$ (DEBDC) was six orders of magnitude higher than that of $\mathrm{Mn}_{2}$ (DEBDC).

\subsection{Modification strategies of MOFs-based photocatalysts}

\subsubsection{Cocatalyst loading}

There is a problem that photo-excited charge carriers are 
easily recombined in the application process of MOF [123,124]. In order to improve this situation, the surface of MOF can be modified with cocatalyst. Cocatalysts improve the performance of MOF in two ways: one is to boost the separation and transport of charges by forming an interface/barrier between the cocatalyst and MOF, and the other is to serve as a reaction site for consumption of separated charge [125]. These two functions of the co-catalyst emphasize the importance of the interface design for improving the photocatalytic properties [126]. On the one hand, the surface of the cocatalyst is the location of the redox reaction, which largely determines the adsorption and activation ability of the reactant molecules, thus affecting the activity and stability of the photocatalytic reaction $[127,128]$. On the other hand, the interface between the cocatalyst and the MOF is where the charge carriers are transferred and separated, so the interface is the key to preventing electron-hole recombination [129]. For proton reduction cocatalysts, their band gap energy should be lower than that of MOF, so that electrons can flow from the MOF to the cocatalysts, such as noble metals. Not only can they form Schottky junctions with MOF to capture electrons, but they can provide available proton reduction sites because of their low $E_{\mathrm{a}}[130,131]$. In addition to noble metals, conductive materials such as graphene can also be used as a charge bridge.

\subsubsection{Noble metal cocatalyst}

Miao et al. designed the Pt/MIL-125(Ti)/Ag photocatalyst [132]. First, Pt was doped inside of the MOF by hydrothermal method, and then Ag was loaded outside of the MOF by photo-deposition. The design of the metal-MOF double interface in Pt/MIL-125(Ti)/Ag realized the cooperative utilization of schottky junction charge trapping and surface plasmon resonance effect (Fig. 7). Interestingly, Qiu and co-workers found that the special matching crystal plane between the noble metal and Zr-MOF may promote or inhibit the photocatalytic reaction [133]. During the photocatalytic process of aromatic alcohols, $\mathrm{Au} / \mathrm{Zr}-\mathrm{MOF}$ had a promoting effect, while Pt played the opposite role, because the (200) crystal plane of Pt was not conducive to the generation of $\bullet \mathrm{O}_{2}$ - Likewise, the Pt (200) plane had no negative effect on the reduction of $\mathrm{Cr}(\mathrm{VI})$, because the light-induced electrons can directly take part in the reduction

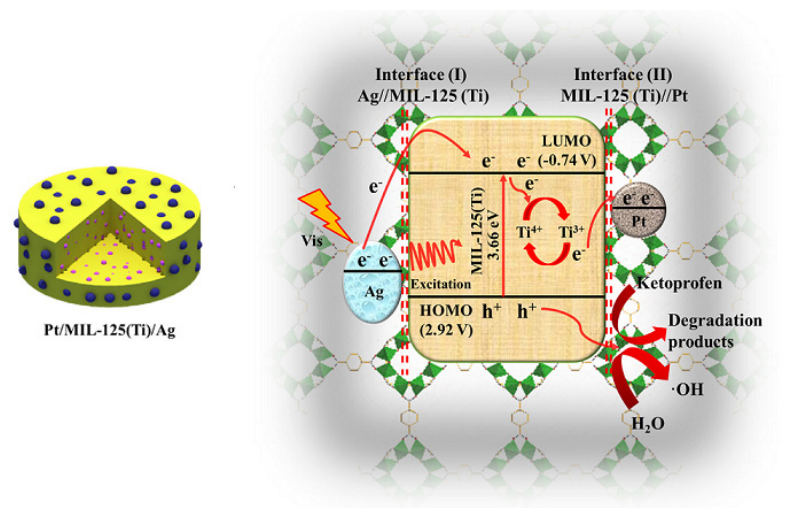

Fig. 7. The mechanism for the photocatalytic process by Pt/MIL-125(Ti)/Ag. Reprinted with permission from Ref. [132]. Copyright (2020) Elsevier. of $\mathrm{Cr}(\mathrm{VI})$. Besides, Pt and $\mathrm{Au}$ also have different influence on promoting the performance of $\mathrm{NH}_{2}$-MIL-125(Ti) photocatalytic reduction of $\mathrm{CO}_{2}$ [134]. The hydrogen overflow from $\mathrm{Pt}$ to the MOFs framework improved the performance of $\mathrm{CO}_{2}$ reduction to form $\mathrm{HCOOH}$ on $\mathrm{Pt} / \mathrm{NH}_{2} \mathrm{MIL}-125$ (Ti). On $\mathrm{Au} / \mathrm{NH}_{2}$-MIL-125(Ti), it was hard to realize the hydrogen overflow from $\mathrm{Au}$ to the MOFs framework. Therefore, Pt/MIL-125- $\mathrm{NH}_{2}$ can promote the production of $\mathrm{HCOOH}$, while $\mathrm{Au} / \mathrm{MIL}-125-\mathrm{NH}_{2}$ inhibited the formation of $\mathrm{HCOOH}$. Shen et al. [135] prepared Pd@UiO-66- $\mathrm{NH}_{2}$ by a simple method. Pd not only enhanced the light absorption intensity, but also effectively separated the photogenerated electron-hole pairs.

\subsubsection{Graphene cocatalyst}

Graphene can act as an electron receiver, receiving photoexcited electrons from semiconductors and inhibiting electron-hole recombination. However, since graphene cannot increase the absorption of visible light [136], graphene needs to be a co-catalyst of MOF with the ability to absorb visible light. Wang et al. [137] assembled UiO-66- $\mathrm{NH}_{2}$ onto graphene with microwave irradiation. The interface of UiO-66- $\mathrm{NH}_{2}$ and graphene in full contact can act as an electron transfer bridge to accelerate the transfer of electrons from UiO-66- $\mathrm{NH}_{2}$ to the UiO-66- $\mathrm{NH}_{2} /$ GR surface. Moreover, the introduction of GR can also inhibit the competitive reaction of hydrogen release, greatly improving the photoreduction $\mathrm{CO}_{2}$ performance of UiO-66-NH2. Liang and co-workers [138] studied the advantages of RGO-MIL-53(Fe) prepared by electrostatic self-assembly method in improving photocatalytic reduction of $\mathrm{Cr}(\mathrm{VI})$. Electrostatic self-assembly increases the interface contact and effectively improved the lifetime of photogenerated charge carriers. The unique 2D structure of GO increased the reaction center and provides more catalytic sites. After 80 minutes of visible light irradiation, the reduction rate of $\mathrm{Cr}(\mathrm{VI})$ can reach $100 \%$. Li et al. [139] came up with a fast microwave-induced route to disperse $\mathrm{NH}_{2}$-MIL-125(Ti) on the graphene layer. The photoluminescence peak of GO/NH2-MIL-125 by microwave treatment was greatly weakened, indicating that graphene can prolong the lifetime of electron holes (Fig. 8). Karthik prepared $\mathrm{NH}_{2}-\mathrm{MIL}-125(\mathrm{Ti}) / \mathrm{rGO}$ with $\pi-\pi$ interaction by wet impregnation method [140]. The separation of charge carriers mediated by $\pi-\pi$ interaction can achieve significant apparent quantum efficiency $(0.66 \%)$. After visible light irradiation, photoexcited electrons were transferred to the titanium-oxygen cluster of MOF through LCCT. In addition, photogenerated electrons moved to graphene through $\pi-\pi$ action, and then reduced hydrogen ions to hydrogen (Fig. 9).

\subsubsection{Heterojunction construction}

On account of the wide band gap and high electron-hole pair recombination rate of MOF, other semiconductor materials are often used together with MOF to build visible light-driven photocatalysts. The interface contact between MOF and semiconductor and the optimization of the system of semiconductor@MOF composite material can boost the photocatalytic performance of MOF-based photocatalysts. Therefore, it is generally believed that the heterojunction can boost the sepa- 


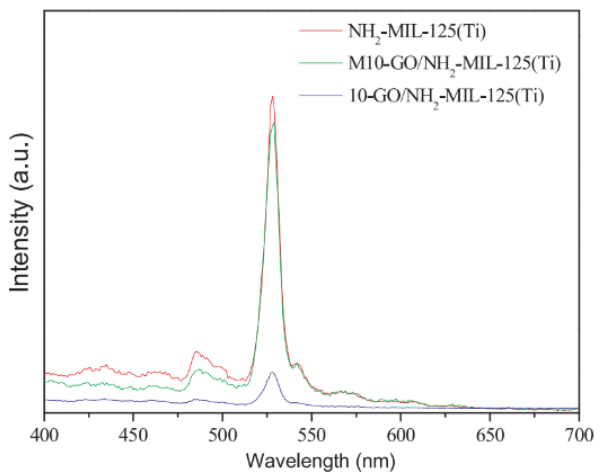

Fig. 8. Photoluminescence (PL) spectra of samples. Reprinted with permission from Ref. [139]. Copyright (2018) Elsevier.

ration of electron-hole pairs, in order to arrive higher photocatalytic activity [141,142]. Then, we will discuss MOF based heterojunctions, including type-II heterojunctions and Z-scheme heterojunctions.

\subsubsection{Type-II heterojunction}

Heterojunction architecture mainly includes the following three types: Type I, II, and III heterojunctions (Fig. 10). In Type I heterojunction, photogenerated electrons and holes are transferred from B to A, respectively. After that, the electrons and holes on A will still recombine, so the photocatalytic activity of the Type I heterojunction catalyst does not improve significantly. Obviously, in the Type II heterojunction, since the CB position of $\mathrm{B}$ is more negative, the photogenic electrons are transferred from $B$ to $A$, and the holes are transferred from $V B$ of $A$ to $B$. And the potential difference between $A$ and $B$ will form an electric field at the interface [143], which can effectively separate photo-generated carriers and enhance photocatalytic activity. However, the band gaps in the Type III heterojunction do not overlap so that there is no electron-hole migration and separation between the two semiconductors. Therefore, Type II heterojunctions are mainly discussed in this section.

Among many semiconductor materials, g- $\mathrm{C}_{3} \mathrm{~N}_{4}$ has the advantages of visible light response, low cost, chemical stability and non-toxicity. In addition, considering the appropriate energy level and band structure, there are studies to use g- $\mathrm{C}_{3} \mathrm{~N}_{4}$

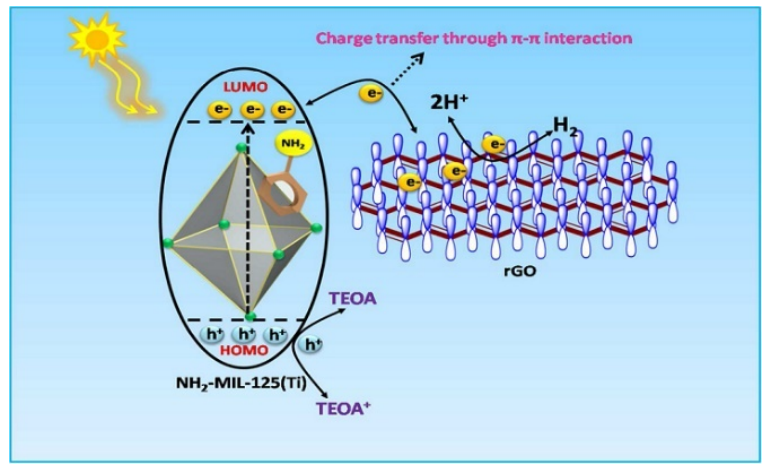

Fig. 9. Possible mechanism for photocatalytic $\mathrm{H}_{2}$ production. Reprinted with permission from Ref. [140]. Copyright (2018) American Chemical Society.
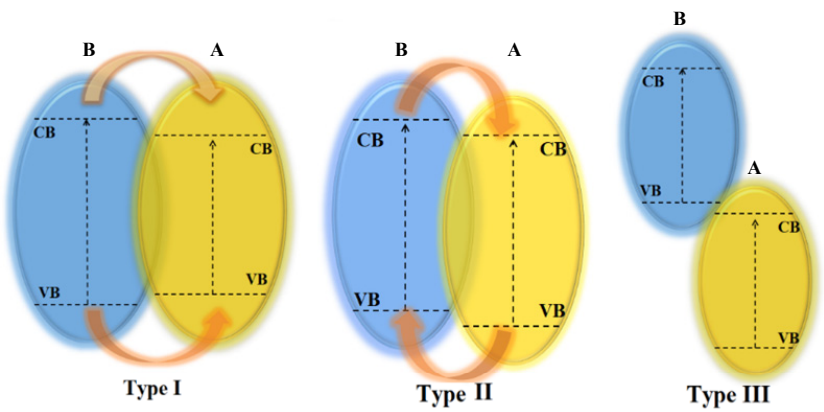

Fig. 10. Different heterojunction types.

and MOF to construct highly efficient Type-II heterojunction photocatalysts. For instance, the degradation efficiency was greatly improved compared to UiO-66 and g- $\mathrm{C}_{3} \mathrm{~N}_{4}$ alone via adding $\mathrm{g}-\mathrm{C}_{3} \mathrm{~N}_{4} / \mathrm{UiO}-66$ prepared by solvothermal to the $\mathrm{RhB}$ solution [144]. Zhang et al. [145] prepared a visible light-responsive photocatalyst, namely g- $\mathrm{C}_{3} \mathrm{~N}_{4} / \mathrm{MIL}-53(\mathrm{Fe})$. g- $\mathrm{C}_{3} \mathrm{~N}_{4}$ acted as the carrier for the establishment of heterojunction, and prevented the recombination of photoinduced charge carriers, thus accelerating the photocatalytic efficiency of $\mathrm{Cr}(\mathrm{VI})$ reduction. Zhong et al. [146] prepared PCN-222/g- $\mathrm{C}_{3} \mathrm{~N}_{4}$ by one-pot solvothermal. Both PCN-222 and g- $\mathrm{C}_{3} \mathrm{~N}_{4}$ can be excited in visible light and produced photogenic electron-hole pairs. Photogenerated electrons tended to transfer from g- $\mathrm{C}_{3} \mathrm{~N}_{4}$ to PCN-222 and the deep electron trap state of PCN-222 can greatly reduce the recombination of electron-hole pairs. A heterojunction, g- $\mathrm{C}_{3} \mathrm{~N}_{4} / \mathrm{PDI} @ \mathrm{NH}_{2}-\mathrm{MIL}-53$ (Fe) was synthesized through thermal condensation, surface growth technology and solvothermal methods [147]. Because PDI had a strong electron affinity, it made the redox potential of g- $\mathrm{C}_{3} \mathrm{~N}_{4}$ moved forward to achieve the purpose of matching band bands [148]. Energy band matching is beneficial to the formation of heterojunction, the separation of charge and the process of photodegradation (Fig. 11).

In addition to $\mathrm{g}-\mathrm{C}_{3} \mathrm{~N}_{4}$, there are many other semiconductor materials, such as $\mathrm{CdS}, \mathrm{TiO}_{2}, \mathrm{Bi}_{2} \mathrm{WO}_{6}$, etc. are also suitable for forming heterojunction with MOF. For example, Liu et al. [149] evenly distributed $\mathrm{CdS}$ nanoparticles on the surface of UiO-66- $\mathrm{NH}_{2}$ to form a close contact heterojunction interface. The strong photocurrent indicated a decrease in the recombination rate of the interface charge. UiO-66- $\mathrm{NH}_{2}$ also played a vital role in reducing the arc radius of the multi-component photocatalyst, indicating a more efficient charge transfer process. Within $40 \mathrm{~min}, 1.5-\mathrm{CdS} / \mathrm{UiO}-66-\mathrm{NH}_{2}$ showed the highest

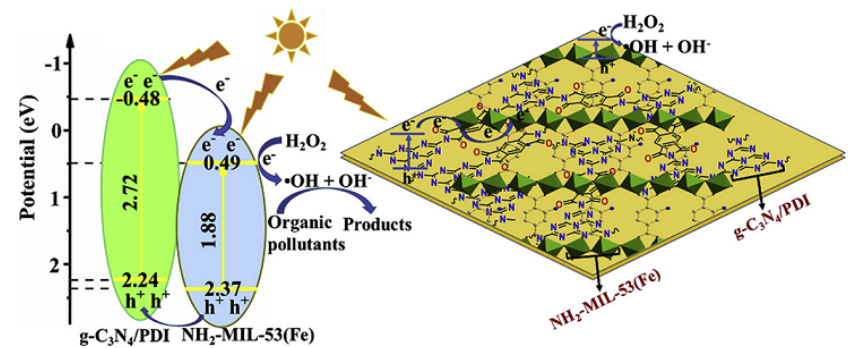

Fig. 11. Photocatalytic mechanism of the g- $\mathrm{C}_{3} \mathrm{~N}_{4} / \mathrm{PDI} / \mathrm{NH}_{2}-\mathrm{MIL}-53(\mathrm{Fe})$. Reprinted with permission from Ref. [148]. Copyright (2019) Elsevier. 

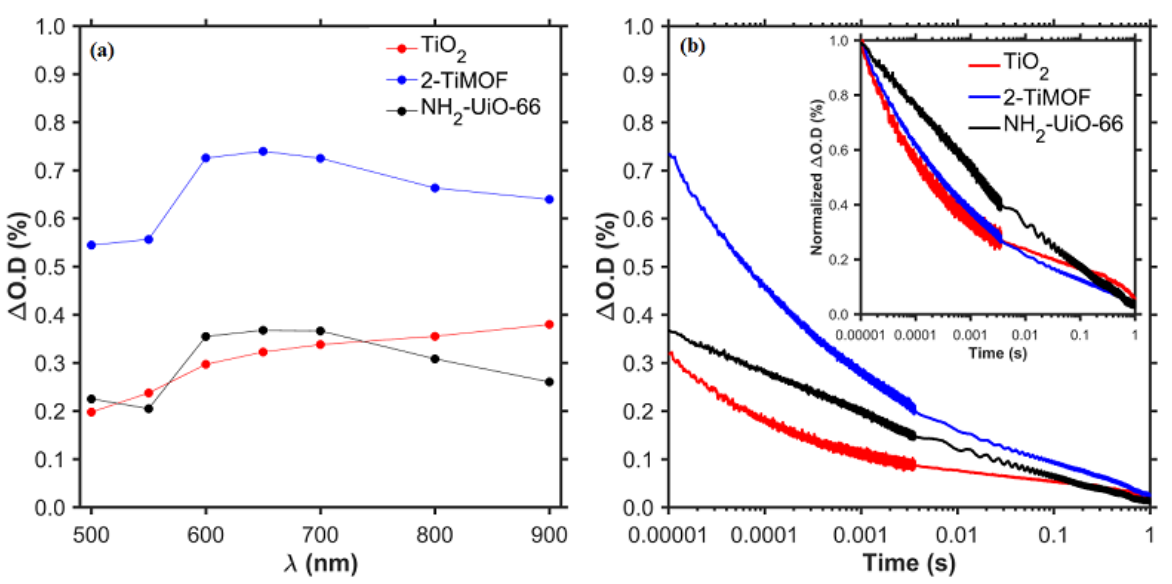

Fig. 12. Transient absorption spectroscopy study of $\mathrm{TiO}_{2}, \mathrm{NH}_{2}$-UiO-66 and $\mathrm{TiO}_{2} / \mathrm{NH}_{2}$-UiO-66 composite (2-TiMOF). Reprinted with permission from Ref. [150]. Copyright (2017) Elsevier.

photocatalytic degradation rate $(92.5 \%)$ and excellent photostability. Petit and co-workers reported a dual-functional $\mathrm{TiO}_{2} / \mathrm{NH}_{2}$-UiO-66 nanocomposite for capturing and photocatalytic reduction of $\mathrm{CO}_{2}$ [150]. Since the $\mathrm{CB}$ potential of $\mathrm{NH}_{2}$-UiO-66 was more negative than that of $\mathrm{TiO}_{2}$, combined with Eg value and XPS results, it was confirmed that a Type-II heterojunction was formed. And the transient absorption spectrum proved that the effective charge transfer can increase the charge generation, thereby generating more photo-excited electrons (Fig. 12). In addition, $\mathrm{Bi}_{24} \mathrm{O}_{31} \mathrm{Br}_{10}$ is also a semiconductor material that can effectively utilize solar energy. Wang's group [151] composited $\mathrm{Bi}_{24} \mathrm{O}_{31} \mathrm{Br}_{10}$ nanosheets with BUC-21 by ball milling. The obtained BB-100 had the same polyhedral structure as the original BUC-21. DFT calculation results and Hirshfeld analysis showed that $\mathrm{Bi}_{24} \mathrm{O}_{31} \mathrm{Br}_{10}$ had a strong chemical interaction on BUC-21, and photogenerated electrons were transferred from BUC-21 to $\mathrm{Bi}_{24} \mathrm{O}_{31} \mathrm{Br}_{10}$.Therefore, BUC-21/ $\mathrm{Bi}_{24} \mathrm{O}_{31} \mathrm{Br}_{10}$ composites exhibited high photocatalytic removal of $\mathrm{Cr}(\mathrm{VI})$ under white light (Fig. 13).

\subsubsection{Z-scheme heterojunctions}

Z-scheme heterojunction catalysts have the same band structure type as Type-II heterojunction catalysts, but with very different charge carrier transfer modes (Fig. 14). In Z-scheme heterojunction, the photo-generated electrons in $\mathrm{CB}$

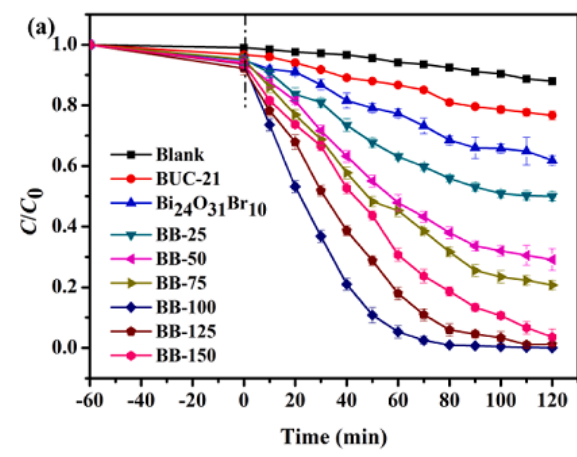

of $\mathrm{A}$ have strong reduction ability while the holes in $\mathrm{VB}$ of $\mathrm{B}$ have strong oxidation ability. Meanwhile, the $\mathrm{e}^{-}$in $\mathrm{CB}$ of $\mathrm{B}$ and $\mathrm{h}^{+}$in VB of A own weak redox capacity. Therefore, the most obvious feature of Z-type heterojunction photocatalyst is the high separation efficiency of photo-generated carriers with strong redox capacity. The Z-scheme heterojunction is divided into direct Z-scheme and indirect Z-scheme. The biggest difference between the two is whether there is a carrier transfer mediator. In direct Z-scheme heterojunction, where two semiconductors are in direct contact, carrier transfer is driven by an internal electric field, while indirect Z-scheme requires electronic conductor (Ag, graphene, etc.) to facilitate charge carrier transfer.

Wang et al. [152] constructed the UiO-66- $\mathrm{NH}_{2} / \mathrm{Ag}_{2} \mathrm{CO}_{3}$ $\mathrm{Z}$-scheme heterojunction. The electrons in the HOMO of UiO-66- $\mathrm{NH}_{2}$ were excited to the LUMO under visible light, thereby forming holes in the HOMO. The photo-generated electrons in the $\mathrm{CB}$ of $\mathrm{Ag}_{2} \mathrm{CO}_{3}$ were transferred to HOMO and consumed holes. Therefore, the electron transfer distance was effectively shortened, which had excellent $\mathrm{Cr}(\mathrm{VI})$ reduction performance (Fig. 15). In addition to this, HPW (phosphotungstic acid)-anchored UiO-66, namely HPW@UiO-66 [153], exhibited better activity than the original UiO-66 and HPW, mainly due to exciton splitting caused by the interaction of Zr-O-W. HPW@UiO-66 contained favorable edge potential and

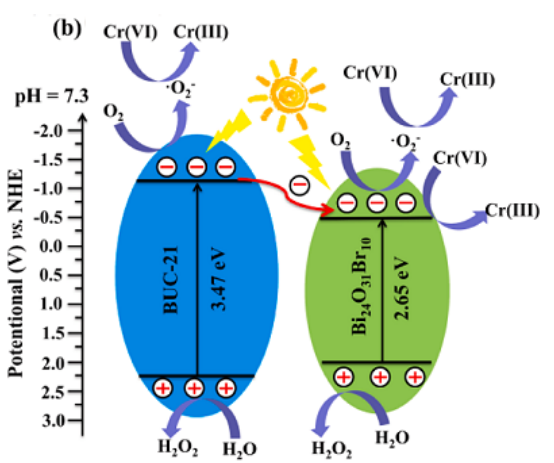

Fig. 13. (a) Photoreduction of the $\mathrm{Cr}(\mathrm{VI})$ at $\mathrm{pH}=2$ using various photocatalysts; (b) Illustration of plausible mechanism of photocatalysis reduction of Cr(VI) over BB-100 under white light. Reprinted with permission from Ref. [151]. Copyright (2020) Elsevier. 


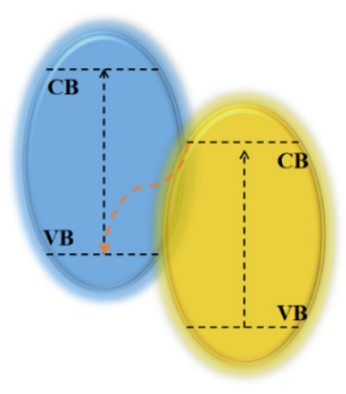

direct Z-scheme

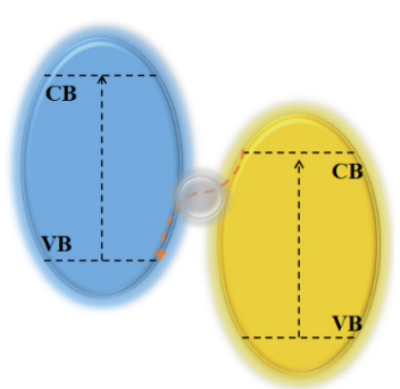

indirect $\mathrm{Z}$-scheme
Fig. 14. The charge transfer in Z-scheme photocatalytic mechanism systems.

reduced the process of charge recombination by heterojunction. $\mathrm{CdLa}_{2} \mathrm{~S}_{4}$ has suitable conduction band energy levels to generate hydrogen [154]. Through energy level analysis, the band position of MIL-88A(Fe) matched the band position of $\mathrm{CdLa}_{2} \mathrm{~S}_{4}$ very well, which meant that $\mathrm{CdLa}_{2} \mathrm{~S}_{4}$ and MIL-88A(Fe) could form a Z-scheme heterojunction [155]. The optimal $\mathrm{H}_{2}$ release rate of $\mathrm{CdLa}_{2} \mathrm{~S}_{4} / \mathrm{MIL}-88 \mathrm{~A}(\mathrm{Fe})$ was approximately 7.74 times that of the original $\mathrm{CdLa}_{2} \mathrm{~S}_{4}$. The photogenerated electrons of MIL-88A(Fe) migrated to VB of $\mathrm{CdLa}_{2} \mathrm{~S}_{4}$ through the solid-solid interface, and then recombined with $\mathrm{h}^{+}$in $\mathrm{VB}$ of $\mathrm{CdLa}_{2} \mathrm{~S}_{4}$.

Zeng et al. [156] formed yolk-shell structure with $\mathrm{Ag}_{3} \mathrm{PO}_{4}$ and MIL-53(Fe) to improve the photocatalytic performance. After the introduction of $\mathrm{Ag}_{3} \mathrm{PO}_{4}$, the absorption range of $\mathrm{Ag}_{3} \mathrm{PO}_{4} @ M I L-53(\mathrm{Fe})$ was expanded. And MIL-53(Fe) could decompose $\mathrm{H}_{2} \mathrm{O}_{2}$ produced by $\mathrm{Ag}_{3} \mathrm{PO}_{4}$, thus reducing $\mathrm{h}^{+}$consumption and producing more active species to participate in photocatalytic reactions. $\mathrm{NH}_{2}-\mathrm{MIL}-125$ is composed of $\mathrm{Ti}_{8} \mathrm{O}_{8}$ ring clusters and 2-amino-terephthalic acid and had abundant amino groups on the surface. $\mathrm{Hu}$ et al. prepared $\mathrm{TiO}_{2} @ \mathrm{NH}_{2}$-MIL-125 by in-situ self-assembly method [157]. During the self-assembly process, an obvious interface was formed between $\mathrm{TiO}_{2}$ and $\mathrm{NH}_{2}$-MIL-125 (Fig. 16(a)). Because the close connection between the two phases promoted the interfacial charge transfer, the composites prepared by in-situ self-assembly method had higher activity than that of mechanical mixing method and the solvent evaporation method (Fig. 16(b)).

In the indirect Z-scheme heterojunction, it is very important

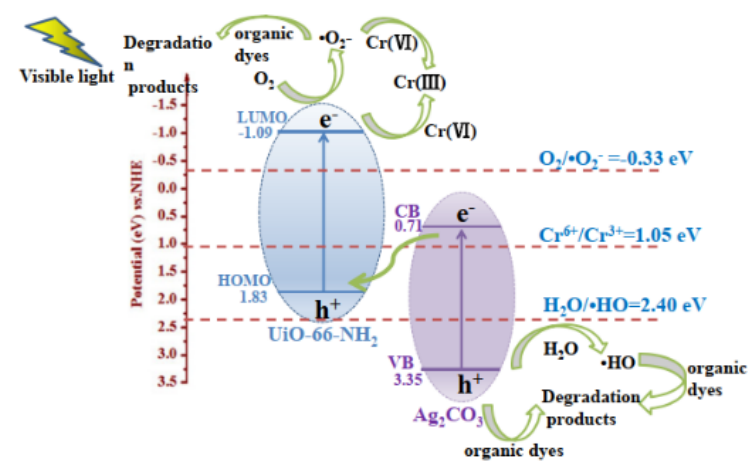

Fig. 15. The charge transfer in UiO-66- $\mathrm{NH}_{2} / \mathrm{Ag}_{2} \mathrm{CO}_{3}$. Reprinted with permission from Ref. [152]. Copyright (2019) Elsevier.
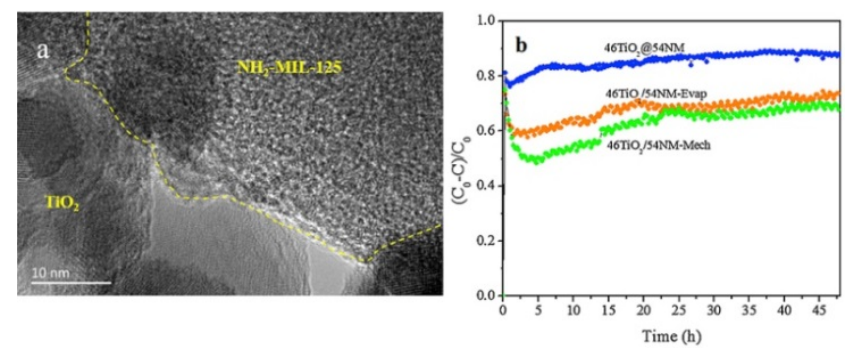

Fig. 16. (a) HR-TEM images $46 \mathrm{TiO}_{2} @ 54 \mathrm{NM}$; (b) Photocatalytic activities of 46 $\mathrm{TiO}_{2} @ 54 \mathrm{NM}, 46 \mathrm{TiO}_{2} / 54 \mathrm{NM}-\mathrm{Mech}$ and 46 $\mathrm{TiO}_{2} / 54 \mathrm{NM}$-Evap. Reprinted with permission from Ref. [157]. Copyright (2019) Elsevier.

to choose the right electron conductor, because it can not only transfer photo-charge carriers effectively, but also improve the stability of photocatalyst [158]. Ag can act as a charge transport bridge to promote carrier separation and maintain strong carrier redox capacity, and the SPR of Ag can improve light absorption. In addition, r-GO has a large surface area, excellent electrical conductivity, a special layered structure and high chemically stable carbon dots. Therefore, Ag and r-GO are good electron mediators.

If $\mathrm{Ag}_{3} \mathrm{PO}_{4}$ and $\mathrm{AgI}$ are exposed to sunlight, $\mathrm{Ag}^{+}$react with $\mathrm{e}^{-}$ and then reduce to metal $\mathrm{Ag}$ that constructs indirect Z-scheme heterojunction as an electron conductor. $\mathrm{Ag}_{3} \mathrm{PO}_{4}$ were adhered to the surface of MIL-53(Fe) [159]. After visible light irradiation, $\mathrm{Ag}$ appeared at the interface of MIL-53(Fe) and $\mathrm{Ag}_{3} \mathrm{PO}_{4}$. The Fermi level of $\mathrm{Ag}$ was between $\mathrm{CB}$ of $\mathrm{Ag}_{3} \mathrm{PO}_{4}$ and $\mathrm{VB}$ of MIL-53(Fe) [160]. Photo-generated electrons on CB of $\mathrm{Ag}_{3} \mathrm{PO}_{4}$ migrated to the Ag through the Schottky barrier, then transferred to the VB of MIL-53(Fe) and reacted with the holes. Strong reducing electrons accumulated on the $\mathrm{CB}$ of the MIL-53(Fe) to form an electron-rich region. The holes left on the $\mathrm{VB}$ of $\mathrm{Ag}_{3} \mathrm{PO}_{4}$ would form a hole-rich region. The resulting Z-electron migration system effectively promoted the electron-hole separation. This reasonably explained the excellent photocatalytic performance and light stability of the composite. Jiang and co-workers prepared $\mathrm{AgI} / \mathrm{UiO}-66\left(\mathrm{NH}_{2}\right)$ composite by ion exchange precipitation method [161]. A small amount of Ag nanoparticles appeared at the initial stage of the photocatalytic process, which resulted in the transformation of $\mathrm{AgI} / \mathrm{UiO}-66\left(\mathrm{NH}_{2}\right)$ type-II heterojunction to the $\mathrm{AgI} / \mathrm{Ag} /$ UiO-66( $\left.\mathrm{NH}_{2}\right)$ Z-scheme heterojunction (Fig. 17). AgI/UiO66( $\left.\mathrm{NH}_{2}\right)$ composites significantly improved the photocatalytic performance, and the optimal TC removal rate was 3.8 times than that of UiO-66 $\left(\mathrm{NH}_{2}\right)$ and 2.1 times than that of AgI.

Akbarzadeh et al. [162] synthesized novel $\mathrm{Ag}_{3} \mathrm{VO}_{4} / \mathrm{Cu}-\mathrm{MOF} / \mathrm{rGO}$ heterojunction for photocatalytic degradation of acid blue 92. During degradation, rGO was used as a supporting matrix for $\mathrm{Ag}_{3} \mathrm{VO}_{4}$ and $\mathrm{Cu}-\mathrm{MOF}$ and as a charge carrier from $\mathrm{Ag}_{3} \mathrm{VO}_{4}$ to $\mathrm{Cu}-\mathrm{MOF}$, and $\mathrm{Ag}_{3} \mathrm{VO}_{4}$ particles were used as photoelectron donors (Fig. 18). The synergistic effect made the composite exhibit improved catalytic activity in the photo-degradation of dye molecules. Liu et al. [163] constructed the three-component Z-scheme heterojunction by using UiO-66- $\mathrm{NH}_{2}$ and $\mathrm{O}-\mathrm{ZnO}$ as photocatalysts and $\mathrm{r}-\mathrm{GO}$ as electronic media. The photo-induced electrons in the $\mathrm{CB}$ of $\mathrm{O}-\mathrm{ZnO}$ were 

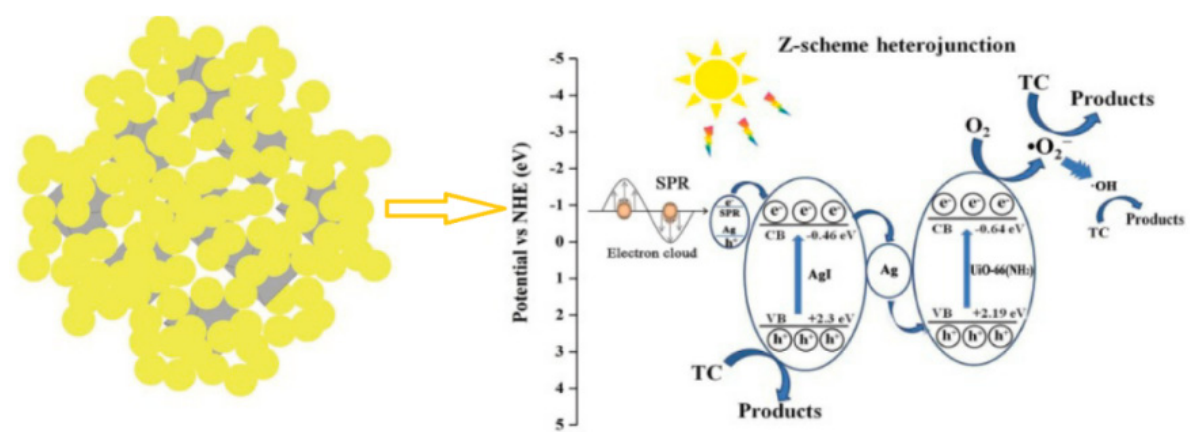

UiO-66(NH2) AgI

Fig. 17. Photocatalytic process for AgI/UiO-66 $\left(\mathrm{NH}_{2}\right)$. Reprinted with permission from Ref. [161]. Copyright (2020) Elsevier.

transferred to $\mathrm{rGO}$ and then recombined with the holes in VB of UiO-66- $\mathrm{NH}_{2}$ to improve the efficiency of charge separation.

\subsubsection{Ligand or metal center modified MOF photocatalysts}

Huang et al. [164] prepared $\mathrm{NH}_{2}-\mathrm{MIL}-125$ (Ti), and then prepared aromatic heterocycle-grafted $\mathrm{NH}_{2}$-MIL-125(Ti) by 2-quinolinecarboxaldehyde and 3-thiophenecarboxaldehyde of introduction. It changed the inherent electronic properties and enhanced the absorption of visible light. Compared with the original MOF, the modified MOF showed enhanced photocatalysis in selective oxidation of benzyl alcohol. ZIF-8 has abundant surface grafting sites, which can be modified by EDA. Hu et al. [165] modified ZIF-8 with EDA, and the results showed that the amine functional group was grafted to the methyl group of the 2-methylimidazole unit, which expanded visible light absorption and enhanced the photocatalytic reduction activity of $\mathrm{Cr}(\mathrm{VI})$. Huang et al. [166] reported $\mathrm{NH}_{2}-\mathrm{MIL}-125(\mathrm{Ti})$, $\mathrm{CH}_{3}$-MIL-125(Ti) and OH-MIL-125(Ti). MOF with functional linkers extended the absorption range to the visible light region of $550 \mathrm{~nm}$. $\mathrm{NH}_{2}$-MIL-125(Ti) had the highest $\mathrm{N}_{2}$ fixation efficiency, and the reaction rate was $12.3 \mu \mathrm{mol} \cdot \mathrm{g}^{-1} \cdot \mathrm{h}^{-1}$ (Fig. 19).

Moreover, it was found that partial substitution of metal centers may affect the photocatalytic activity to some extent. The bimetallic composition is formed by replacing some metals, which increases the MMCT. Li and co-workers [167] reported Ti substituted UiO-66- $\mathrm{NH}_{2}$. The introduction of Ti played a role in promoting electron transfer. Excited ligand ATA could transfer electrons to $\mathrm{Zr}_{6} \mathrm{O}_{4}(\mathrm{OH})_{4}$ under visible light and $\mathrm{The} \mathrm{Ti}^{3+}$ in the $(\mathrm{Ti} / \mathrm{Zr})_{6} \mathrm{O}_{4}(\mathrm{OH})_{4}$ provided electrons to $\mathrm{Zr}^{4+}$, which improved interface charge transfer efficiency from ATA to Zr-O

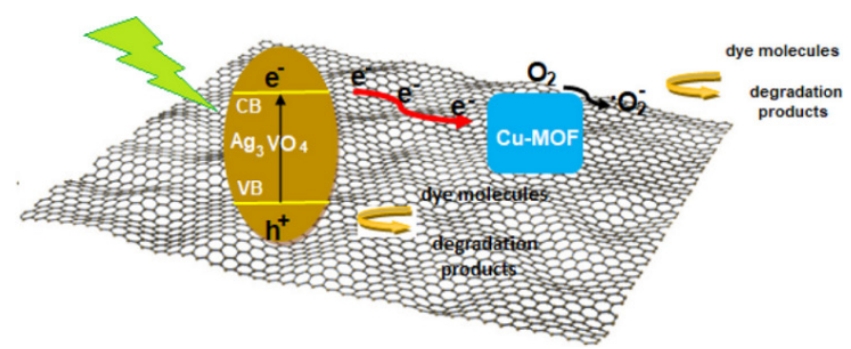

Fig. 18. Proposed photocatalytic mechanism and charge transfer scheme of the $\mathrm{Ag}_{3} \mathrm{VO}_{4} / \mathrm{Cu}-\mathrm{MOF} / \mathrm{rGO}$. Reprinted with permission from Ref. [162]. Copyright (2020) Elsevier. clusters, thereby improving photocatalytic activity. In addition, Zhou et al. [168] adopted microwave method to introduce Ti into UiO-66. The incorporation of Ti can improve the interface charge transfer from photo-excited BDC to Zr-O oxygen cluster [168]. Recently, Wang et al. [169] synthesized bimetallic $\mathrm{NH}_{2}$-MIL-68 $\left(\operatorname{In}_{\alpha} \mathrm{Fe}_{1-\alpha}\right)$. The photo-generated electrons at the center of In(III) could be quickly transferred to Fe(III) through MMCT, which was beneficial to restrain the recombination of photo-generated $\mathrm{e}^{-}$and $\mathrm{h}^{+}$(Fig. 20). Li et al. [170] reported that nanoporous bimetallic MOF (FeCo-BDC). The rich unsaturated metal active sites of Fe(II) and Co(II) in the FeCo-BDC framework contributed greatly to the formation of $\mathrm{SO}_{4}{ }^{\bullet-}$ and $\bullet \mathrm{OH}$, leading to the performance of MB degradation.

\subsubsection{Defect engineering in $M O F$}

Early reports believed that MOF is perfect and orderly, but it was found that defects are common in many MOFs. There may be two types of defects in MOF, namely node defects and extended defects [171]. Node defects are caused by vacancy associated with metal centers or organic ligands, while extended defects are associated with crystal structure defects [171]. By integrating defects into MOF structural design, certain characteristics of MOF can be introduced or changed.
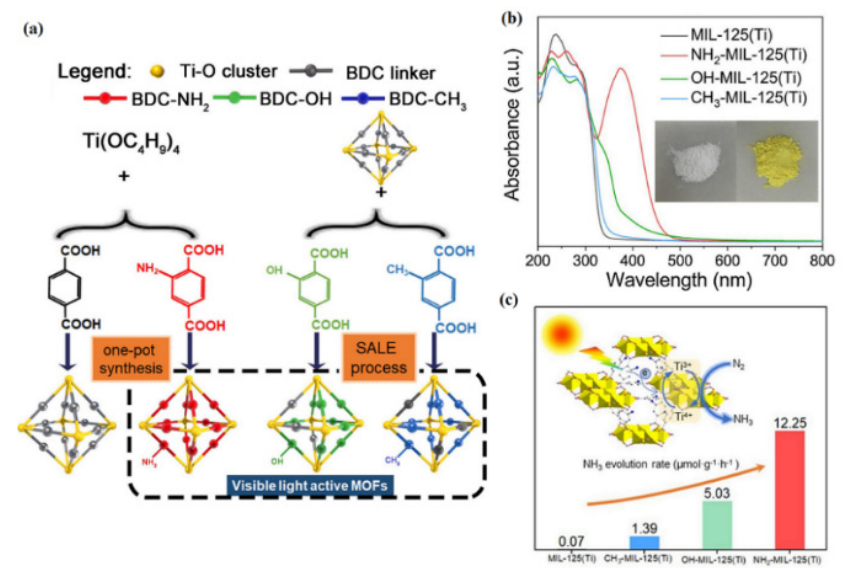

Fig. 19. (a) Schematic diagram of the visible light active MOFs; (b) UV/Vis spectra of the samples; (c) Proposed mechanism for the photocatalytic $\mathrm{N}_{2}$ fixation over $\mathrm{NH}_{2}$-MIL-125(Ti). Reprinted with permission from Ref. [166]. Copyright (2020) Elsevier. 


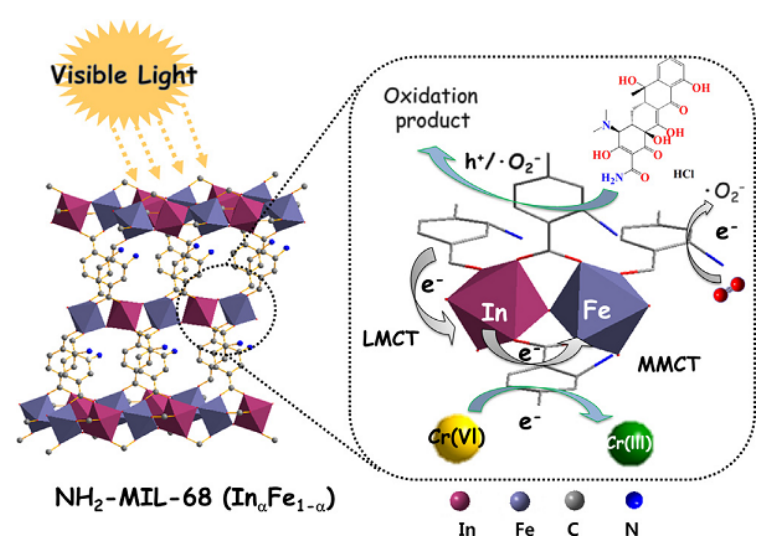

Fig. 20. Photocatalytic mechanism of $\mathrm{Cr}(\mathrm{VI})$ reduction and $\mathrm{TC}-\mathrm{HCl}$ oxidation in water with $\mathrm{NH}_{2}$-MIL-68 $\left(\mathrm{In}_{\alpha} \mathrm{Fe}_{1-\alpha}\right)$. Reprinted with permission from Ref. [169]. Copyright (2020) Elsevier.

Zhu et al. [172] used concentrated $\mathrm{HCl}$ as a regulator and controlled the synthesis temperature to adjust the defects of the $\mathrm{NH}_{2}$-UiO-66. As the temperature increased, the degree of defects was more obvious, and the specific surface area and pore volume were also larger. Avci and colleagues [173] prepared the defect ZIF-8 and ZIF-67. Interestingly, by simply adjusting the $\mathrm{pH}$ of solution, different defect ZIFs morphologies were obtained and the original surface area or porosity was basically maintained. Koo and co-workers [174] reported selective acid etching of MIL-100(Fe) crystals using MOFs window size. When phosphoric acid was used as an etchant, multistage pore MIL-100(Fe) was produced, while keeping microporosity, mesoporous property and skeleton stability. Cai and co-workers [175] prepared UiO-66 with pore defect using monocarboxylic acid regulators. The length of different carboxylic acid regulators regulates the concentration of pore defects in MOFs crystals. When the length of the carboxylic acid regulators was very short (such as acetic acid), almost no mesopores were produced. Nevertheless, as the length of the carboxylic acid regulators increased by degrees, the concentration of crystal defects and the mesopore volume of UiO-66 increased. With dodecanoic acid as the regulator, the pore defect crystal with the highest mesoporosity $(8.6 \mathrm{~nm})$ was obtained. Wu's group [176] reported UiO-66 with missing ligand defects. By accurately adjusting the concentration of acetic acid and the synthesis time, the skeleton density can be effectively reduced, and finally the pore volume and surface area of the defect crystals are greatly increased. De Vos and colleagues prepared the UiO-66 defective crystal [177]. In the presence of hydrochloric acid, the trifluoroacetate was coordinated with the metal center, partially replacing the terephthalic acid ligand. Ui0-66 crystals with larger pores and more unsaturated metal sites can be obtained by thermal activation for the removal of trifluoroacetate groups.

The introduction of defects in MOFs materials provides researchers with some additional applications, such as adjusting porosity, active catalytic sites and other properties. In addition, there are even some properties, such as charge transfer, that may exist only in the defective MOFs but not in the respective parent frameworks. Defects MOFs have the characteristics of enlarged pore size, which is conducive to the adsorption and catalysis of macromolecules; on the other hand, MOFs expose more active sites, accelerate the molecular mass transfer rate, and improve the catalytic performance of the reaction.

\section{Application of MOFs-based photocatalysts}

\subsection{Photocatalytic $\mathrm{CO}_{2}$ reduction}

\subsubsection{Basic process and thermodynamics principle of $\mathrm{CO}_{2}$ reduction}

$\mathrm{CO}_{2}$ is the final product of oxidative degradation of organic fuels, and it is also one of the most stable compounds of carbon. Since the bond energy of $\mathrm{C}=0\left(750 \mathrm{~kJ} \cdot \mathrm{mol}^{-1}\right)$ is higher than the bond energy of $\mathrm{C}-\mathrm{C}\left(336 \mathrm{~kJ} \cdot \mathrm{mol}^{-1}\right), \mathrm{C}-\mathrm{O}\left(327 \mathrm{~kJ} \cdot \mathrm{mol}^{-1}\right)$, and $\mathrm{C}-\mathrm{H}$ $\left(411 \mathrm{~kJ} \cdot \mathrm{mol}^{-1}\right)$, the conversion of $\mathrm{CO}_{2}$ requires higher energy to open $\mathrm{C}=\mathrm{O}$ bond [178]. Compared with the high temperature and high-pressure approach, the process of photocatalytic conversion of $\mathrm{CO}_{2}$ is very mild [179]. As shown in the Fig. 21, photocatalytic reduction of $\mathrm{CO}_{2}$ includes the following five processes: (1) $\mathrm{CO}_{2}$ and $\mathrm{H}_{2} \mathrm{O}$ are adsorbed on the catalyst surface; (2) The catalyst is photoexcited to produce $\mathrm{e}^{-}$and $\mathrm{h}^{+}$; (3) The $\mathrm{e}^{-}$ and $\mathrm{h}^{+}$that did not recombine migrated to the catalyst surface; (4) $\mathrm{e}^{-}$combine with $\mathrm{H}^{+}$to reduce $\mathrm{CO}_{2}$, and at the same time $\mathrm{h}^{+}$is consumed in the oxidation reaction; (5) Desorption of products and re-adsorption of reactants.

The thermodynamics of photocatalytic reduction of $\mathrm{CO}_{2}$ is related to the CB and VB of the catalyst and the Gibbs free energy provided by the light. As shown in Fig. 22, the photocatalyst should have an appropriate position of the $\mathrm{CB}$ and $\mathrm{VB}$ [180]. The VB position is more negative than the oxidation potential of $\mathrm{H}_{2} \mathrm{O}$, and the $\mathrm{CB}$ position is more negative than the reduction potential of $\mathrm{CO}_{2}$, and then induce the photocatalytic reaction. However, since the one-electron reduction reaction of $\mathrm{CO}_{2}$ requires a reduction potential of $-1.90 \mathrm{~V}(v s \mathrm{NHE}, \mathrm{PH}=7)$ and almost no semiconductor material can reach such a negative $\mathrm{CB}$ potential, the photocatalytic reduction of $\mathrm{CO}_{2}$ reaction is a multi-electron and multi-step reaction process. In the presence of water, different $\mathrm{CO}_{2}$ reduction products can be obtained

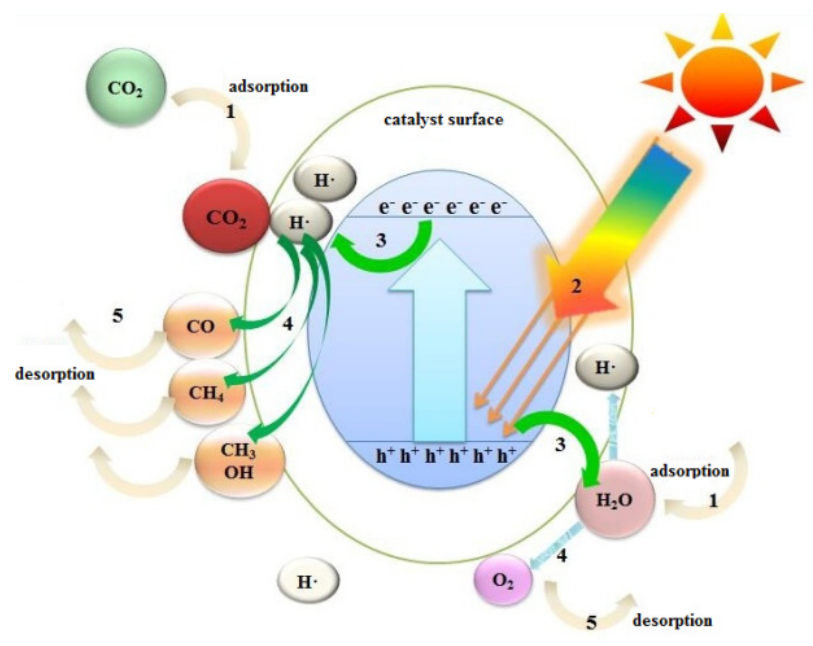

Fig. 21. Schematic illustration of the main five steps in photocatalytic $\mathrm{CO}_{2}$ reduction. 


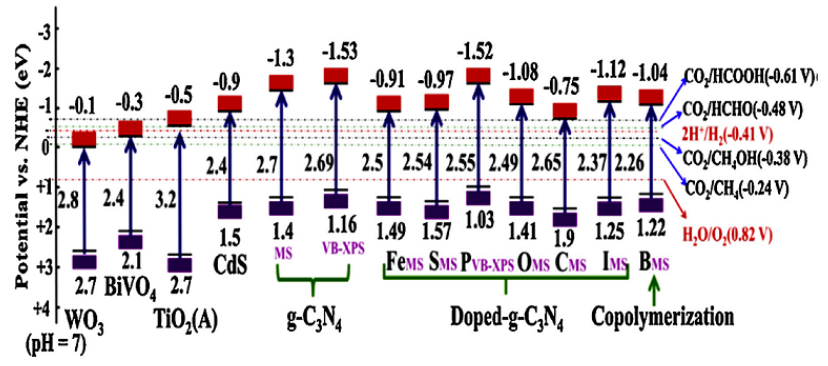

Fig. 22. Bandgap energy, $C B$ and VB potential of various photocatalysts. Reprinted with permission from Ref. [180]. Copyright (2018) Elsevier.

according to the reduction potential and the number of electron transfers (Table 1) [181,182].

\subsubsection{Selectively photocatalytic $\mathrm{CO}_{2}$ reduction}

In the process of photocatalytic $\mathrm{CO}_{2}$ reduction, different kinds of products will be obtained, such as $\mathrm{CO}, \mathrm{HCOOH}, \mathrm{CH}_{4}$ and $\mathrm{CH}_{3} \mathrm{OH}$, when the catalyst gets different numbers of electrons and protons.

Selectivity of products can theoretically be changed by adjusting one or more of the following factors, such as the photoexcitation properties, the adsorption/activation of $\mathrm{CO}_{2}$, the adsorption/desorption of intermediates, the energy band structure, catalytic active sites, and the separation efficiency of photogenerated carriers $[183,184]$. The properties of light excitation involve photon energy and light intensity. The photon energy can be used to judge whether the catalyst can receive the excited photons from the perspective of thermodynamics. The light intensity will change the number of photogenerated electrons and holes, which will influence the reaction rate and product selectivity in terms of kinetics [185]. The conduction band position of the catalyst determines the reduction ability of photogenerated electrons. When the photo-generated electron density on the surface of the catalyst is higher, the rate of the multi-electron reduction reaction can be accelerated, and a higher reduced product can be obtained. The high yield of the target product can be improved by the adsorption/resolution of the reactants or intermediates. Photoreduction of $\mathrm{CO}_{2}$ is a multi-step surface catalytic reaction, so different active sites can regulate the selectivity of products [186]. Therefore, in this section, different products of MOF-based photocatalysts in photocatalytic reduction of $\mathrm{CO}_{2}$ are summarized in Table 2 and the product selectivity of photoreduction $\mathrm{CO}_{2}$ was summarized by analyzing experimental conditions, light source and products. It is also a difficult task to develop MOF that responds to visible light. Therefore, it would be a wise choice to modify the MOF or separate electrons and holes with a sacrificial agent.

Table 1

Reduction potentials of some reactions related to $\mathrm{CO}_{2}$ reduction.

\begin{tabular}{lc}
\hline Reactions & $E_{\text {redox }}^{0} /(\mathrm{V} v s \mathrm{NHE})$ \\
\hline $\mathrm{CO}_{2}+2 \mathrm{H}^{+}+2 \mathrm{e}^{-} \rightarrow \mathrm{HCOOH}$ & $-0.61 \mathrm{~V}$ \\
$\mathrm{CO}_{2}+2 \mathrm{H}^{+}+2 \mathrm{e}^{-} \rightarrow \mathrm{CO}+\mathrm{H}_{2} \mathrm{O}$ & $-0.53 \mathrm{~V}$ \\
$\mathrm{CO}_{2}+4 \mathrm{H}^{+}+4 \mathrm{e}^{-} \rightarrow \mathrm{HCHO}+\mathrm{H}_{2} \mathrm{O}$ & $-0.48 \mathrm{~V}$ \\
$\mathrm{CO}_{2}+6 \mathrm{H}^{+}+6 \mathrm{e}^{-} \rightarrow \mathrm{CH}_{3} \mathrm{OH}+\mathrm{H}_{2} \mathrm{O}$ & $-0.38 \mathrm{~V}$ \\
$\mathrm{CO}_{2}+8 \mathrm{H}^{+}+8 \mathrm{e}^{-} \rightarrow \mathrm{CH}_{4}+\mathrm{H}_{2} \mathrm{O}$ & $-0.24 \mathrm{~V}$ \\
\hline
\end{tabular}

\subsubsection{Selective formation of $\mathrm{HCOOH}$}

$\mathrm{Li}$ et al. [106] prepared $\mathrm{NH}_{2}$-MIL-125(Ti) using amine-modified terephthalic acid as a linker. Amino functionalization not only enhanced the visible light absorption capacity, but also had a higher $\mathrm{CO}_{2}$ adsorption capacity (132.2 $\left.\mathrm{cm}^{3} \cdot \mathrm{g}^{-1}\right)$ than MIL-125(Ti) (98.6 $\left.\mathrm{cm}^{3} \cdot \mathrm{g}^{-1}\right)$. Therefore, $\mathrm{NH}_{2}$-MIL-125(Ti) exhibited significant $\mathrm{CO}_{2}$ reduction performance and had a high $\mathrm{HCOOH}$ production rate. Yang and co-workers [187] designed the Eu-Ru(phen)3-MOF catalyst, and generation rate of $\mathrm{HCOO}^{-}$was $102.4 \mu \mathrm{mol} \cdot \mathrm{h}^{-1} \cdot \mathrm{g}^{-1}$. Time-resolved emission spectra and ultrafast transient absorption spectroscopy confirmed that charge transfer from $\mathrm{Ru}$ to Eu-O clusters in a time range of 1 to 300 ns. EPR studied implied $\mathrm{Eu}(\mathrm{III})$ clusters became active catalytic centers for $\mathrm{CO}_{2}$ photoreduction when Eu(III) accepted photoexcitation electrons from metal ligand (Fig. 23). Mahmoud et al. [188] reported the incorporation of the photoactive bis(4'-(4-carboxyphenyl)-terpyridine)ruthenium(II)(Ru(cptpy) 2) strut into a Zr-MOF (MOF). The obtained MOF manifested highly efficient $\mathrm{HCOOH}$ reduction activity. Ir unit has efficient light collection ability. Therefore, Ir-CP, based on Ir, was widely absorbed in the UV-visible region and had a long lifetime excitation state [189]. Clearly, the Ir-CP showed much higher yields of HCOO- in the heterogeneous photocatalytic system.

Porphyrin is an important photosensitive organic compound, which can broaden the light absorption of MOF materials to the entire visible light region. Liu et al. [190] reported that Rh-PMOF-1 as an effective and highly selective photocatalyst. $\mathrm{HCOOH}$ and $\mathrm{CO}$ were two-electron reduction products of $\mathrm{CO}_{2}$ reduction. But Rh-PMOF-1 had a good adsorption capacity for $\mathrm{CO}$, and the strong interaction between $\mathrm{CO}$ and $\mathrm{Rh}$ atoms makes $\mathrm{CO}_{2} \cdot-$ easier to combine with hydrogen atoms to form HCOO-. Recently, PCN-138 was proposed for $\mathrm{CO}_{2}$-to- $\mathrm{HCOOH}$ conversion [17]. Benefiting from the coexistence of the photosensitive porphyrin fragment and the $\mathrm{Zr}$-oxo center, PCN-138 used for the conversion of $\mathrm{CO}_{2}$-to-HCOOH had high photocatalytic activity. Similar behaviors had been seen in PCN-222 [75] and PCN-136 [76] where are porphyrin-based MOF.

Xing et al. [191] prepared microporous Zr-based MOF (NNU-28) through selecting organic ligand derived from an anthracene group. The NNU-28 not only had excellent chemical stability and thermal stability, but also exhibited efficient capture of $\mathrm{CO}_{2}$ and wide range response to visible light. NNU-28 had a higher $\mathrm{HCOOH}$ generation rate $\left(183 \mu \mathrm{mol} \cdot \mathrm{h}^{-1} \cdot \mathrm{mmol}_{\mathrm{MOF}}{ }^{-1}\right)$ because of dual photocatalytic pathways of anthracene-based organic ligands and Zr-O clusters. In another work, Dong et al. [192] mimicked the photosynthesis using NNU-31-Zn for $\mathrm{CO}_{2}$-to-HCOOH conversion. NNU-31-Zn had significant light absorption efficiency in the visible light range, which was attributed to the effective charge transfer of the TCA ligand to the transition metal center, thereby promoting further photocatalytic reactions.

2,3-Dihydroxyterephthalic acid (catbdc) was introduced in UiO-66 via post-synthetic exchange and then $\mathrm{Cr}$ (III) was incorporated into the catbdc site, which was UiO-66-CrCAT (Fig. 24) [193]. The combination of $\mathrm{Cr}(\mathrm{III})$ to catbdc resulted in LMCT. UiO-66-CAT generated electron-hole pairs without photosensi- 
Table 2

Performances of some MOF-based photocatalysts for photocatalytic $\mathrm{CO}_{2}$ reduction.

\begin{tabular}{|c|c|c|c|c|c|}
\hline Photocatalyst & Light & Sacrificial agent & Products & Yield $\left(\mu \mathrm{mol} \cdot \mathrm{g}^{-1} \cdot \mathrm{h}^{-1}\right)$ & Ref. \\
\hline $\mathrm{NH}_{2}-\mathrm{MIL}-125(\mathrm{Ti})$ & Visible light & MeCN/TEOA & $\mathrm{HCOOH}$ & 16.28 & [106] \\
\hline Eu-Ru(phen $)_{3}-\mathrm{MOF}$ & Visible light & TEOA & $\mathrm{HCOOH}$ & 102.47 & [187] \\
\hline AUBM-4 & Visible light & $\mathrm{MeCN} / \mathrm{TEOA}$ & $\mathrm{HCOOH}$ & 366 & [188] \\
\hline Ir-CP & Visible light & MeCN/TEOA & $\mathrm{HCOOH}$ & 158.3 & [189] \\
\hline Rh-PMOF-1(Zr) & Visible light & MeCN/TEOA & $\mathrm{HCOOH}$ & 33.8 & [190] \\
\hline PCN-138 & Visible light & TIPA & $\mathrm{HCOOH}$ & 6.6 & [17] \\
\hline PCN-222 & Visible light & TEOA & $\mathrm{HCOOH}$ & 60 & [75] \\
\hline PCN-136 & Visible light & TIPA & $\mathrm{HCOOH}$ & 46.29 & [76] \\
\hline NNU-28 & Visible light & MeCN/TEOA & $\mathrm{HCOOH}$ & 149.88 & [191] \\
\hline NNU-31-Zn & Visible light & - & $\mathrm{HCOOH}$ & 26.3 & [192] \\
\hline UiO-66-CrCAT & Visible light & MeCN/TEOA & $\mathrm{HCOOH}$ & 1724.3 & [193] \\
\hline UiO-66-NH $/ 2.0 \mathrm{GR}$ & Visible light & TEOA & $\mathrm{HCOOH}$ & 443.75 & [137] \\
\hline CdS/ZIF-8 & Visible light & $\mathrm{MeCN}$ & $\mathrm{CO}$ & 803.25 & [194] \\
\hline Co-ZIF-67@ @-TiO & Visible light & MeCN/TEOA & $\mathrm{CO}$ & 7300 & [195] \\
\hline $\mathrm{TiO}_{2} / \mathrm{C} @ Z \mathrm{ZnCo}-\mathrm{ZIF}-\mathrm{L}$ & UV-vis light & - & $\mathrm{CO}$ & 28.6 & [196] \\
\hline $\mathrm{PCN}-250-\mathrm{Fe}_{2} \mathrm{Mn}$ & Visible light & MeCN/TIPA & $\mathrm{CO}$ & 21510 & [9] \\
\hline MIL-101-EN & Visible light & - & $\mathrm{CO}$ & 47.2 & [197] \\
\hline MOF-Ni & Visible light & MeCN/TIPA & $\mathrm{CO}$ & 371.6 & [198] \\
\hline $\mathrm{NH}_{2}-\mathrm{MIL}-101(\mathrm{Fe}) / \mathrm{g}-\mathrm{C}_{3} \mathrm{~N}_{4}$ & Visible light & TEOA & $\mathrm{CO}$ & 22.13 & [199] \\
\hline CdS/MIL-101(Cr) & Visible light & - & $\mathrm{CO}$ & 16.35 & [200] \\
\hline Zn-MOF & Visible light & $\mathrm{MeCN} / \mathrm{MeOH} / \mathrm{TEOA}$ & $\mathrm{CO}$ & - & [201] \\
\hline Co-ZIF-9/CdS & Visible light & MeCN/TEOA & $\mathrm{CO}$ & 1426 & [202] \\
\hline $\mathrm{TiO}_{2} / \mathrm{MOF}$ & Visible light & - & $\mathrm{CO}$ & 4.24 & [150] \\
\hline Co-UiO-67 & Visible light & MeCN/TEOA & $\mathrm{CO}$ & 3292.5 & [203] \\
\hline $\mathrm{PCN}-224(\mathrm{Cu}) / \mathrm{TiO}_{2}$ & Visible light & - & $\mathrm{CO}$ & 37.21 & [204] \\
\hline $\mathrm{CuTCPP} / \mathrm{UiO}-66 / \mathrm{TiO}_{2}$ & Visible light & - & $\mathrm{CO}$ & 31.32 & [205] \\
\hline $\mathrm{Ni}_{3}(\mathrm{HITP})_{2} /\left[\mathrm{Ru}(\mathrm{bpy})_{3}\right] \mathrm{Cl}_{2} \cdot 6 \mathrm{H}_{2} \mathrm{O}$ & Visible light & MeCN/TEOA & $\mathrm{CO}$ & $3.45 \times 10^{4}$ & [206] \\
\hline $\mathrm{Ni}_{3}(\mathrm{HITP})_{2} / \mathrm{rGO}$ & Visible light & $\mathrm{MeCN} / \mathrm{TEOA}$ & $\mathrm{CO}$ & $3.8 \times 10^{4}$ & [207] \\
\hline In-Fe ${ }_{1.91}$ TCPP-MOF & Visible light & Ethyl acetate & $\mathrm{CO}$ & 144.54 & [208] \\
\hline In-Co1.71TCPP-MOF & Visible light & Ethyl acetate & $\mathrm{CO}$ & 38.70 & [208] \\
\hline In-InTCPP-MOF & Visible light & Ethyl acetate & $\mathrm{CO}$ & 22.95 & [208] \\
\hline $\mathrm{Bi}_{2} \mathrm{~S}_{3} / \mathrm{UiO}-66$ & UV-vis light & - & $\mathrm{CO}$ & 25.6 & [209] \\
\hline CdS/ZIF-67 & Visible light & TEOA & $\mathrm{CO}$ & 183.964 & [210] \\
\hline $\mathrm{Zn}_{2} \mathrm{GeO}_{4} / \mathrm{Mg}-\mathrm{MOF}-74$ & UV-vis light & MECN & $\mathrm{CO}$ & 1.45 & [211] \\
\hline HKUST- $1 / \mathrm{TiO}_{2}$ & Visible light & - & $\mathrm{CO}$ & 256.35 & [212] \\
\hline $\mathrm{TiO}_{2} / \mathrm{UiO}-66$ & UV-vis light & - & $\mathrm{CH}_{4}$ & 17.9 & [213] \\
\hline $\mathrm{TiO}_{2} / \mathrm{NH}_{2}-\mathrm{MIL}-125(\mathrm{Ti})$ & Visible light & - & $\mathrm{CH}_{4}$ & 1.18 & [216] \\
\hline $\mathrm{Zn} / \mathrm{PMOF}$ & UV light & - & $\mathrm{CH}_{4}$ & 8.69 & [217] \\
\hline $\mathrm{S}_{\mathrm{Cu}}$ & Visible light & TEA & $\mathrm{CH}_{3} \mathrm{OH}$ & $262.6 \mathrm{ppm} \cdot \mathrm{g}^{-1} \cdot \mathrm{h}^{-1}$ & [108] \\
\hline NNU-13 & Visible light & TEOA & $\mathrm{CH}_{4}$ & 117.33 & [218] \\
\hline NNU-14 & Visible light & TEOA & $\mathrm{CH}_{4}$ & 52 & [219] \\
\hline
\end{tabular}

tizer in visible light. UiO-66-CrCAT could reduce $\mathrm{CO}_{2}$ to $\mathrm{HCOOH}$. Wang et al. [137] combined UiO-66- $\mathrm{NH}_{2}$ with graphene to form UiO-66- $\mathrm{NH}_{2} / \mathrm{GR}$ composite structure. UiO-66- $\mathrm{NH}_{2} / 2.0 \mathrm{GR}$ showed excellent $\mathrm{CO}_{2}$ adsorption ability mainly because the $-\mathrm{NH}_{2}$ could absorb $\mathrm{CO}_{2}$ molecules as a basic site. The $\mathrm{CB}$

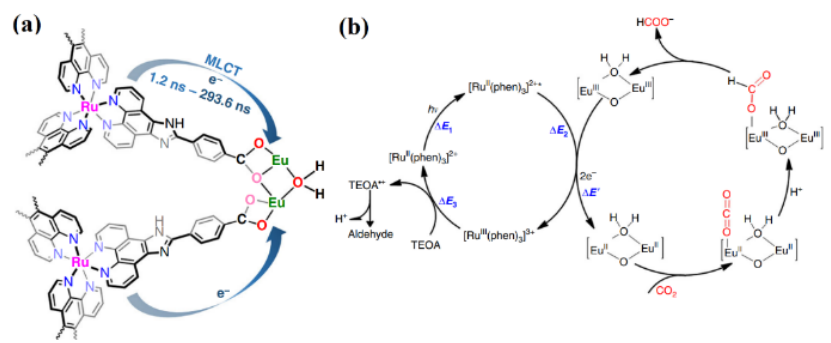

Fig. 23. (a) Schematic light-induced dynamics of Eu-Ru(phen) $)_{3}-M O F$; (b Mechanism of photocatalytic $\mathrm{CO}_{2}$ reduction to $\mathrm{HCOOH}$ over $\mathrm{Eu}-\mathrm{Ru}(\mathrm{phen})_{3}$-MOF. Reprinted with permission from Ref. [187]. Copyright (2018) Nature. position of UiO-66- $\mathrm{NH}_{2} / 2.0 \mathrm{GR}$ was increased from -0.78 to $-0.82 \mathrm{eV}$. And the band gap of UiO-66- $\mathrm{NH}_{2} / 2.0 \mathrm{GR}$ was $2.64 \mathrm{eV}$, which was also beneficial to improve the absorption of light at longer wavelengths. Hence, the relatively negative conduction

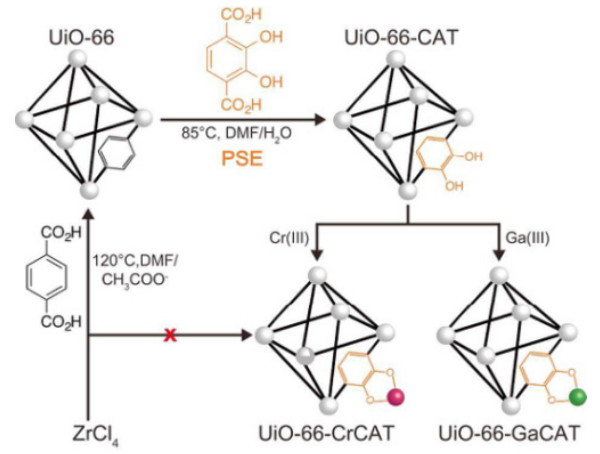

Fig. 24. Preparation of UiO-66-CrCAT photocatalyst by post-synthesis exchange (PSE) and metallization. Reprinted with permission from Ref. [193]. Copyright (2015) the Royal Society of Chemistry. 
band position and low band gap make UiO-66- $\mathrm{NH}_{2} / \mathrm{GR}$ to have a strong capacity to photo-reduce $\mathrm{CO}_{2}$ to $\mathrm{HCOOH}(35.5 \mu \mathrm{mol})$.

\subsubsection{Selective formation of $\mathrm{CO}$}

The process of reducing $\mathrm{CO}_{2}$ to $\mathrm{CO}$ is easier for that to other products because of its lower kinetic barrier. Liu et al. [194] reported that CdS/ZIF-8 for $\mathrm{CO}_{2}$ photoreduction. The $\mathrm{CO}_{2}$ adsorption capacity of CdS/ZIF-8 was about 3.5 times higher than that of CdS, which was due to the high porosity of the deposited ZIF-8. The selectivity of CO was close to $100 \%$, which was attributed to the high $\mathrm{CO}_{2}$ adsorption capacity. Wang et al. studied that integrate the structural of the ZIF-67 and a-TiO 2 [195]. The $\mathrm{TiO}_{2}$ layer not only did not reduce the adsorption capacity of ZIF-67 on $\mathrm{CO}_{2}$, but also provided abundant mesoporous pores for the diffusion of reactant molecules, thus increasing the local $\mathrm{CO}_{2}$ concentration. Recently, Li and co-workers [196] proposed the $\mathrm{TiO}_{2} / \mathrm{C} @ Z n C o-Z I F-L$ composite for selective $\mathrm{CO}_{2}$ photoreduction. $\mathrm{TiO}_{2} / \mathrm{C} @ Z$ ZnCo-ZIF-L exhibited very high selectivity of $99 \%$ for photoreduction of $\mathrm{CO}_{2}$ to $\mathrm{CO}$. $\mathrm{COOH}^{*}$ was an important intermediate for $\mathrm{CO}$ formation. On the one hand, The Lewis acid sites in ZIF-L avail the adsorption/activation of $\mathrm{CO}_{2}$ to $\mathrm{COOH}^{*}$ (Fig. 25(a)), thus selectively promoting the formation of CO. On the other hand, the adsorption energy of CO on $\mathrm{TiO}_{2} / \mathrm{C} @ Z n C o-Z I F-L$ was low, and CO was easy to be desorbed from the active site (Fig. 25(b)). By adjusting the metal ions in metal clusters of MOFs, the active sites can be increased, and the metals with strong affinity to $\mathrm{CO}_{2}$ can inhibit the production of hydrogen generation intermediates and thus improve the selectivity of CO. Dong et al. introduced Mn into PCN-250-Fe3. Compared with single metal PCN-250-Fe3, PCN-250-Fe2 Mn can stably reduce $\mathrm{CO}_{2}$ to $\mathrm{CO}$ [9]. The high $\mathrm{CO}_{2}$ adsorption performance of MOF is mainly established by physical adsorption. If chemical adsorption can be used properly, the affinity of the catalyst for $\mathrm{CO}_{2}$ molecules can be further increased. Xie et al. [197] introduced ethylenediamine into MIL-101-Cr to form abundant $\mathrm{CO}_{2}$ chemisorption sites in the structure. What counts was that this was reversible chemical adsorption of $\mathrm{CO}_{2}$ at lower temperatures, so it will not cause problem of difficult product resolution. The CO selectivity of MIL-101-EN was as high as $96.5 \%$, which was significantly higher than the original MOF. Similar features are found at MOF-Ni [198], $\mathrm{NH}_{2}-\mathrm{MIL}-101(\mathrm{Fe}) / \mathrm{g}-\mathrm{C}_{3} \mathrm{~N}_{4}$ [199], CdS/MIL-101(Cr) [200] and Zn-MOF [201], Co-ZIF-9/CdS [202], etc. In a word, better $\mathrm{CO}_{2}$ adsorption and activation can improve $\mathrm{CO}_{2}$ utilization rate and

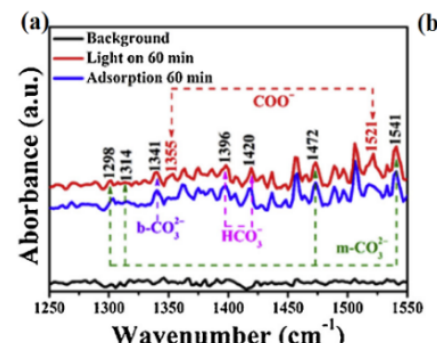

Wavenumber $\left(\mathrm{cm}^{-1}\right)$

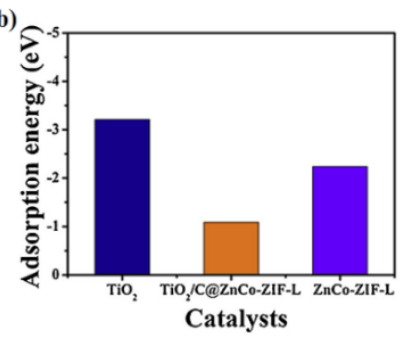

Fig. 25. (a) Before (blue curve) and in (red curve) photocatalytic $\mathrm{CO}_{2}$ reduction; (b) The $\mathrm{CO}$ adsorption energy on $\mathrm{TiO}_{2}$, ZnCo-ZIF-L, and $\mathrm{TiO}_{2} / \mathrm{C} @ Z n C o-Z I F-L$, respectively. Reprinted with permission from Ref. [196]. Copyright (2020) Elsevier. reduce reaction barrier.

$\mathrm{CO}_{2}$ photoreduction is a intricate multi-step process, and a variety of factors play a synergistic role. Crake et al. [150] reported that $\mathrm{NH}_{2}$-UiO-66 modified by $\mathrm{TiO}_{2}$ was used for photocatalytic reduction of $\mathrm{CO}_{2}$. The presence of $\mathrm{TiO}_{2}$ not only prevented the photo-generated charge recombination of $\mathrm{NH}_{2}$-UiO-66, but also generated more photo-excited electrons through effective charge transfer, which made it easy to convert to CO. Gao and co-workers [203] doped Co and Re ions in UiO-67 (Fig. 26(a)). Compared with Re-UiO-67, Co-UiO-67 had a better charge transport ability and reduced the potential barrier for the photo-conversion of $\mathrm{CO}_{2}$ into $\mathrm{CO}$ (Fig. 26(b)). Generally, porphyrin can be used as light-harvesting antennas in photocatalyst. Wang reported that the direct integration of PCN-224(Cu) and $\mathrm{TiO}_{2}$ nanoparticles can achieve CO release rate of $37.21 \mu \mathrm{mol} \cdot \mathrm{g}^{-1} \cdot \mathrm{h}^{-1}$ without co-catalyst or sacrificial agent [204]. Enhanced light absorption and matching band structure improved CO selectivity. The catalyst composed of CuTCPP functionalized UiO-66 and $\mathrm{TiO}_{2}$ can stably and effectively reduce $\mathrm{CO}_{2}$ to $\mathrm{CO}$ under simulated sunlight [205]. CuTCPP can form a favorable LMCT for photocatalytic reactions. The enhanced photon efficiency and the binding affinity of the active site to $\mathrm{CO}_{2}$ molecules affected the product selectivity.

The design of the metal center as an active site is also very effective in controlling product selectivity. Zhu et al. [206] studied the reduction of mixed photocatalytic system under visible light irradiation with ultra-thin conductive nanometer $\left(\mathrm{Ni}_{3}(\mathrm{HITP})_{2}\right)$ as co-catalyst and $\left[\mathrm{Ru}(\mathrm{bpy})_{3}\right] \mathrm{Cl}_{2} \cdot 6 \mathrm{H}_{2} \mathrm{O}$ as photosensitive agent. When photo-excited electrons were transferred to $\mathrm{Ni}_{3}(\mathrm{HITP})_{2}$, the electrons are easily dispersed in the CB of $\mathrm{Ni}_{3}(\mathrm{HITP})_{2}$ due to its conductivity. The electron-rich $\mathrm{Ni}-\mathrm{N}_{4}$ site
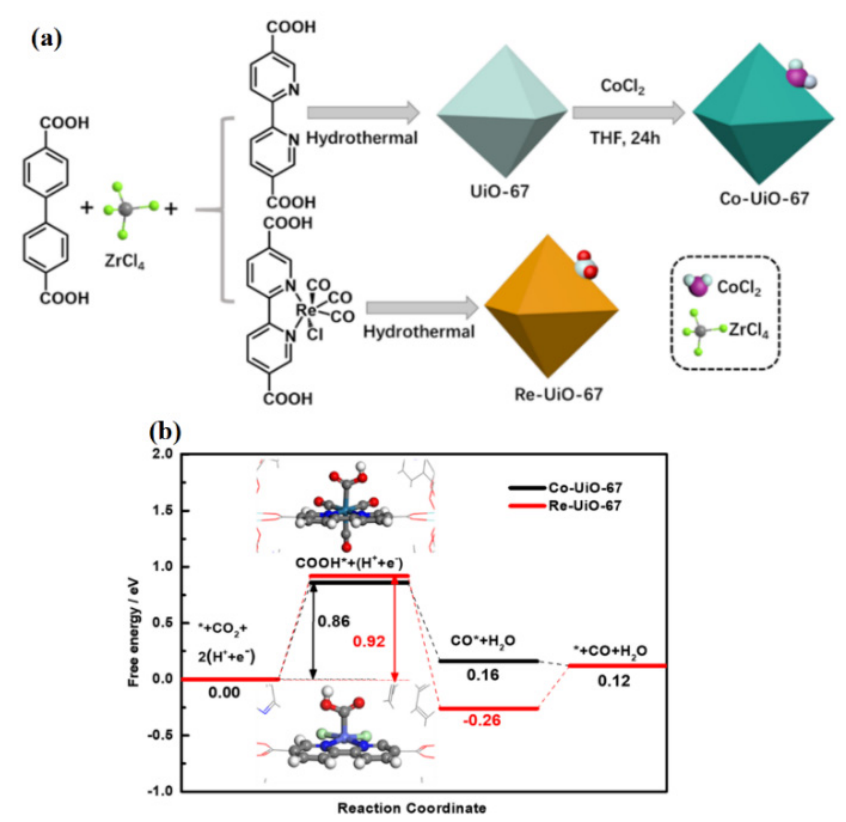

Fig. 26. (a) Synthetic scheme of Co-UiO-67 or Re-UiO-67; (b) Reaction free energy of $\mathrm{CO}_{2}$ reduction to $\mathrm{CO}$ over Co-UiO-67 and Re-UiO-67. Reprinted with permission from Ref. [203]. Copyright (2020) American Chemical Society. 
formed intermediate $\mathrm{COOH}^{*}$ by adsorbing $\mathrm{CO}_{2}$ and $\mathrm{H}^{+}$, and then promoted the two-electron transfer process in the process of releasing water (Fig. 27). Afterwards, this group assembled $\mathrm{Ni}_{3}$ (HITP) 2 and rGO into a heterojunction through coulomb interaction [207]. The rGO acted as an electronic repeater in the electron transfer process. The electrostatic charge transfer and strong $\pi-\pi$ interaction generated in the heterojunction effectively regulated the electronic structure of the metal center in the conductive $\mathrm{Ni}_{3}$ (HITP) 2 (Fig. 28). The enhanced activity of the metal center on account of the electrostatic charge transfer and good energy level alignment synergistically promoted the kinetics of $\mathrm{CO}_{2}$ conversion. Wang et al. [208] studied the synergy between the introduction of different single atoms (In, Co and $\mathrm{Fe}$ ) in the indium-porphyrin structure on the photosensitive porphyrin and the active site. In-Fe1.91TCPP-MOF possessed the high-performance visible-light-driven conversion of $\mathrm{CO}_{2}$ to $\mathrm{CO}$. Iron center was more capable of accepting electrons from the photoexcited MOFs so as to achieve $\mathrm{CO}_{2}$ reduction than cobalt.

Improving the separation efficiency of charge in the photocatalyst is also an important tool for controlling product selectivity. The combination of MOF and some semiconductors can effectively enhance the separation of electron-hole pairs, such as $\mathrm{Bi}_{2} \mathrm{~S}_{3} / \mathrm{UiO}-66$ [209], CdS/ZIF-67 [210], $\mathrm{Zn}_{2} \mathrm{GeO}_{4} / \mathrm{Mg}-\mathrm{MOF}-74$ [211], HKUST-1/ $\mathrm{TiO}_{2}$ [212] and so on. The low content of $\mathrm{Bi}_{2} \mathrm{~S}_{3}$ was assembled into UiO-66 in situ hydrothermally, and a strong interaction was formed between their, which can easily realize electron transfer. And the efficient photo-thermal conversion and heat-assisted charge transfer effect were conducive to the conversion of $\mathrm{CO}_{2}$ to $\mathrm{CO}$. $\mathrm{Zn}_{2} \mathrm{GeO}_{4} / \mathrm{Mg}$-MOF-74 had higher photocatalytic activity than the physical mixture of $\mathrm{Zn}_{2} \mathrm{GeO}_{4}$ and Mg-MOF-74, indicating that the interaction between $\mathrm{Zn}_{2} \mathrm{GeO}_{4}$ and Mg-MOF-74 can promote electron transfer.

\subsubsection{Selective formation of $\mathrm{CH}_{4}$ and $\mathrm{CH}_{3} \mathrm{OH}$}

The process of converting $\mathrm{CO}_{2}$ to $\mathrm{CH}_{4}$ and $\mathrm{CH}_{3} \mathrm{OH}$ requires the transfer of 8-electron and 4-electron, respectively [213]. Hence, there are relatively few works about photoreduction of $\mathrm{CO}_{2}$ to $\mathrm{CH}_{4}$ or $\mathrm{CH}_{3} \mathrm{OH}$ by MOF photocatalysts. In general, the processes of photocatalytic $\mathrm{CO}_{2}$ to $\mathrm{CH}_{4}$ are formaldehyde and carbene pathways, respectively [214]. The formaldehyde pathway has two important characteristics, one is that $\mathrm{H}_{2} \mathrm{CO}$ and $\mathrm{CH}_{3} \mathrm{OH}$ are two kinds of intermediates, and the other is that

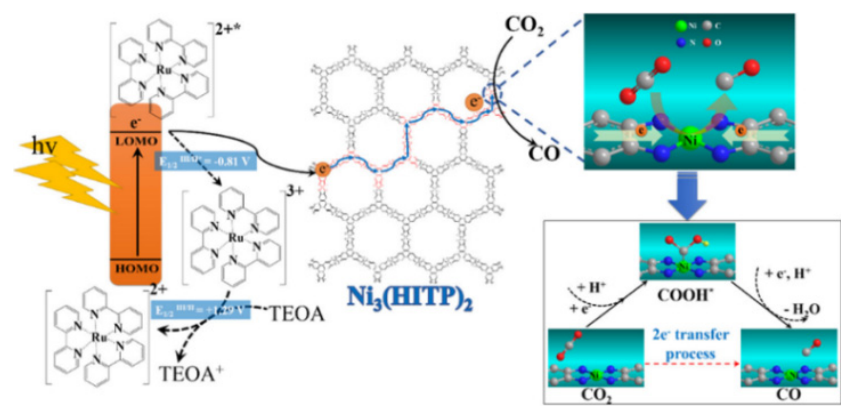

Fig. 27. Mechanism of photocatalytic $\mathrm{CO}_{2}$ reduction to $\mathrm{CO}$ with $\mathrm{Ni}_{3}$ (HITP) $)_{2}$. Reprinted with permission from Ref. [206]. Copyright (2018) Elsevier.
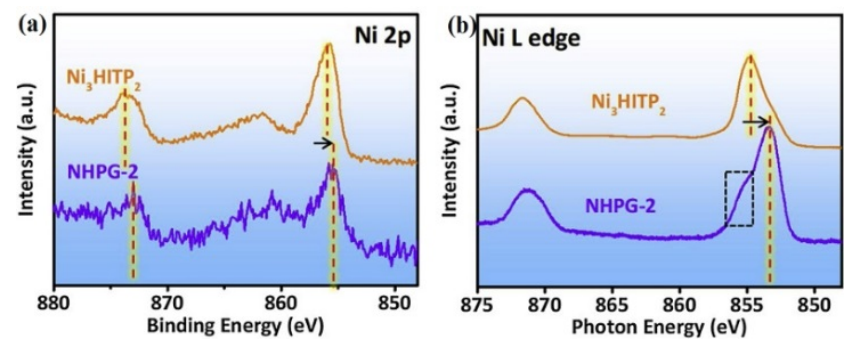

Fig. 28. XPS and XANES analyses of elemental electronic states on $\mathrm{Ni}_{3} \mathrm{HITP}_{2}$ and NHPG-2: (a) high-resolution Ni $2 p$ spectra; (b) Ni L3 edge $\mathrm{X}$-ray absorption near edge structure spectra. Reprinted with permission from [207]. Copyright (2020) Elsevier.

the deoxygenation reaction is always accompanied by the hydrogenation reaction. The carbene pathway also has two important features, that is, $\mathrm{CO}$ is an important intermediate or by-product and the last step of the conversion of $\cdot \mathrm{CH}_{3}$ to $\mathrm{CH}_{3} \mathrm{OH}$ or $\mathrm{CH}_{4}$ is a competitive reaction.

Ma and co-workers designed $\mathrm{TiO}_{2} / \mathrm{UiO}-66$, achieving a high $\mathrm{CH}_{4}$ generation rate of $17.9 \mu \mathrm{mol} \cdot \mathrm{g}^{-1} \cdot \mathrm{h}^{-1}$ because there were adequate active sites and high carbon dioxide absorption of $78.9 \mathrm{~cm}^{3} \cdot \mathrm{g}^{-1}$. In addition, author found that in the absence of water vapor, the yield of $\mathrm{CH}_{4}$ decreased significantly, while the rate of $\mathrm{CO}$ production increased slightly, indicating that water vapor as a proton donor promoted the production of $\mathrm{CH}_{4}$. Hu et al. [216] had a better understanding of the photocatalytic reaction mechanism and intermediates of $\mathrm{TiO}_{2} / \mathrm{NH}_{2}-\mathrm{MIL}-125$ (Ti) through in-situ infrared technology. After light irradiation, the peaks of $\mathrm{Ti}^{4+-} \mathrm{OH}$ and $\mathrm{Ti}^{3+-} \mathrm{OH}$ were reduced, indicating that the -OH may react with $\mathrm{CO}_{2}$ to form $\mathrm{HCO}_{3}^{-}$, and the main adsorption site in the photocatalytic process was the $-\mathrm{OH}$. All of these fully indicated that the pathway to generate $\mathrm{CH}_{4}$ was the formaldehyde pathway.

Sadeghi synthesized Zn/PMOF using tetra (4-carboxyphenyl) porphyrin (TCPP) as ligand and $\mathrm{Zn} / \mathrm{PMOF}$ was capable of reducing $\mathrm{CO}_{2}$ to $\mathrm{CH}_{4}$ in the gas phase $(10.43$ mmol) [217]. Generally, the photo-conversion of $\mathrm{CO}_{2}$ into $\mathrm{CH}_{4}$ with $\mathrm{H}_{2} \mathrm{O}$ was a difficult reaction. There were generally two ways: formaldehyde and carbine. The end product depended on which pathway played the main role. As displayed in Fig. 29, the products produced by the carbene pathway were $\mathrm{CH}_{4}$ and $\mathrm{CH}_{3} \mathrm{OH}$. However, $\mathrm{CH}_{3} \mathrm{OH}$ was adsorbed by the catalyst, and the products produced by the formaldehyde pathway were only $\mathrm{CH}_{4}$. In another work, Liu et al. [108] simulated the photosynthesis of $\mathrm{CO}_{2}-\mathrm{CH}_{3} \mathrm{OH}$ by a copper porphyrin-based MOF $\left(S_{\mathrm{Cu}}\right)$. The $\mathrm{Cu}$ in the porphyrin-based MOF promoted the chemical adsorption and activation of $\mathrm{CO}_{2}$. Chemical adsorption bent linear $\mathrm{CO}_{2}$ molecules and lowered the photoreduction barrier, thereby completing the four-electron reduction process that converts $\mathrm{CO}_{2}$ to $\mathrm{CH}_{3} \mathrm{OH}$. Zhou's group [218] grafted polyoxometalate into two metalloporphyrin coordination frameworks to achieve highly selective reduction of $\mathrm{CO}_{2}-$ to- $\mathrm{CH}_{4}(>96 \%)$. NNU-13 and NNU-14 showed high photocatalytic activity for reduction of $\mathrm{CO}_{2}$ into $\mathrm{CH}_{4}\left(704\right.$ and $312 \mu \mathrm{mol} \cdot \mathrm{g}^{-1}$ ) without photosensitizer and co-catalysts. For most porphyrin-based MOFs, the catalytic active sites are in the porphyrin-centered or 


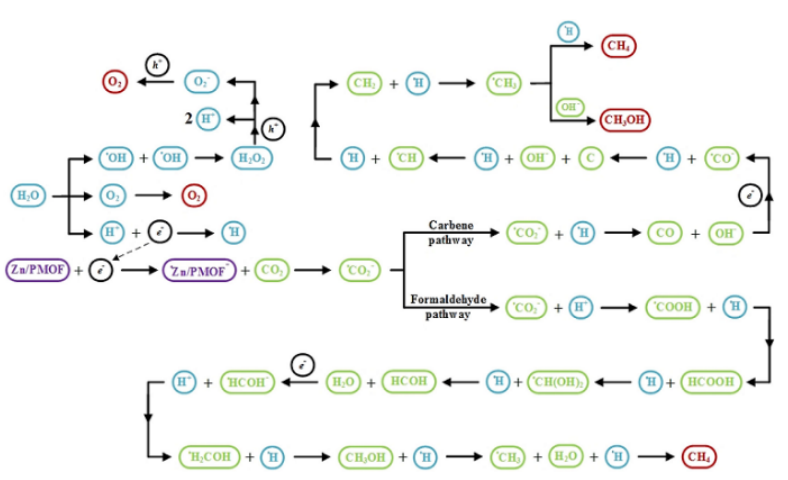

Fig. 29. The reaction pathways of $\mathrm{CO}_{2}$ photoreduction. Reprinted with permission from Ref. [217]. Copyright (2016) Elsevier.

relatively high valence state metal/metal cluster nodes. However, TCPP in NNU-13 and NNU-14 absorbed light and moved the photogenerated electrons to Zn- $\varepsilon$-Keggin (Fig. 30). $\mathrm{Zn}-\varepsilon$-Keggin and TCPP were respectively used as catalysts for $\mathrm{CO}_{2}$ photoreduction, and the electrons enriched on $\mathrm{Zn}-\varepsilon$-Keggin combined with protons in the water to produce $\mathrm{CH}_{4}$, which was an eight-electron transfer product.

\subsection{Photocatalytic water splitting}

Typical photocatalytic water splitting requires at least two components: photosensitizer and catalyst. Photosensitizers absorb photons to produce photogenerated electron-hole pairs, and the catalyst uses the photogenerated electrons for hydrogen production or oxygen production reactions. In addition, the sacrificial agent is also a component that is beneficial to the hydrogen production reaction. The sacrificial agent can consume holes to inhibit photo-generated electrons from recombining with holes. In addition, the co-catalyst can promote carrier separation, inhibit the recombination of photo-generated electron-hole pairs on the surface, and accelerate water decomposition by inhibiting the reverse reaction of $\mathrm{H}_{2}$ and $\mathrm{O}_{2}$. Transition metals, especially noble metals, such as $\mathrm{Pt}, \mathrm{Au}, \mathrm{Ag}$, $\mathrm{Pd}$ and $\mathrm{Ru}$, are considered to be efficient photocatalytic co-catalysts for water decomposition $[219,220]$. Take the noble metal Pt as an example, when the noble metal is loaded on the surface of MOF, the Fermi energy level of the metal is usually lower than that of MOF, and the photogenic electrons on MOF

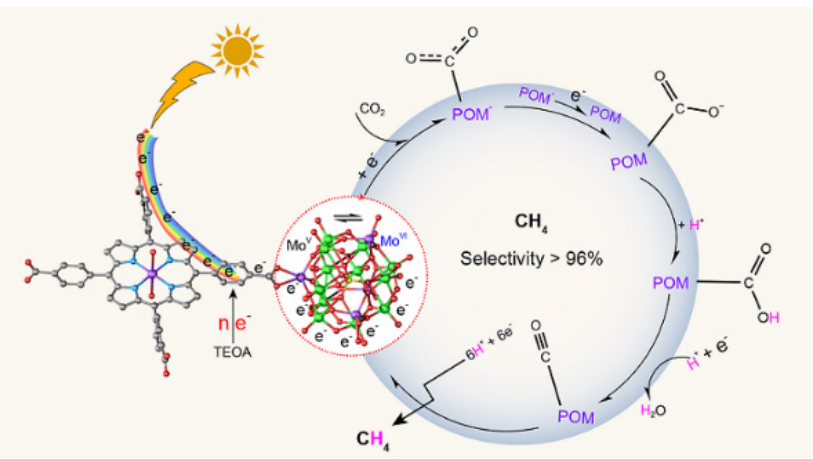

Fig. 30. Proposed mechanism for photocatalytic $\mathrm{CO}_{2}$ reduction. Reprinted with permission from Ref. [218]. Copyright (2019) Oxford University Press. will migrate to the surface of the noble metal and be captured by the precious metal. At the same time, photo-generated holes on the MOF will migrate to surface of noble metal. This process facilitates the efficient separation and transfer of photogenic electron-hole pairs.

The photocatalytic hydrogen production is a reaction of increasing Gibbs free energy [221]. The thermodynamic oxidation and reduction potentials of $\mathrm{O}_{2}$ and $\mathrm{H}_{2}$ are $1.23 \mathrm{eV}$ and $-0.41 \mathrm{eV}$, respectively. In order to achieve water decomposition and make full use of solar energy, the band gap of MOF needs to be between 1.23 and $3.0 \mathrm{eV}$. Moreover, position of the lowest CB level of MOF must be more negative than the potential of $\mathrm{H}^{+} / \mathrm{H}_{2}(0-0.059 \mathrm{pH}, \mathrm{V}$ vs NHE), and the position of the highest VB is more positive than that of $\mathrm{O}_{2} / \mathrm{H}_{2} \mathrm{O}(1.23-0.059 \mathrm{pH}, \mathrm{V}$ vs NHE) [222]. The water splitting involves half-reaction $\mathrm{H}_{2}$ evolution (Eq. (1)) and overall water splitting (Eq. (2)) [223]. Half-reaction $\mathrm{H}_{2}$ evolution needs two electrons, while overall water splitting requires four electrons. Therefore, it is necessary to improve the electron utilization rate in the photocatalytic water splitting system. Hence, the work of photocatalytic hydrogen production with MOF materials is discussed based on half-reaction $\mathrm{H}_{2}$ evolution and overall water splitting. Table 3 shows photocatalytic hydrogen production of MOF-based photocatalysts according to the products and co-catalyst or photosensitizer. In the absence of co-catalysts and photosensitizers, a more effective strategy focuses on the combination of MOF and semiconductor. In most cases, the photosensitizer is not necessary in the process of photocatalytic water splitting of MOF-based photocatalysts, and a higher effect will be obtained when the photosensitizer is present.

$$
\begin{gathered}
\mathrm{H}_{2} \mathrm{O}+\mathrm{h}^{+} \rightarrow 1 / 2 \mathrm{O}_{2}+2 \mathrm{H}^{+} ; 2 \mathrm{H}^{+}+2 \mathrm{e}^{+} \rightarrow \mathrm{H}_{2} \\
2 \mathrm{H}_{2} \mathrm{O} \rightarrow \mathrm{O}_{2}+4 \mathrm{H}^{+} ; 4 \mathrm{H}^{+}+4 \mathrm{e}^{+} \rightarrow 2 \mathrm{H}_{2}+\mathrm{O}_{2}
\end{gathered}
$$

\subsubsection{Overall water splitting}

Only a few reports indicate that MOF can promote photocatalytic overall water splitting [224-227]. Liu and Huang et al. [224] synthesized an aluminum-based MOF bridged by $\mathrm{AlO}_{4}(\mathrm{OH})_{2}$ octahedron and the organic ligand $\mathrm{BDC}-\mathrm{NH}_{2}$, wherein the benzene ring in $\mathrm{BDC}-\mathrm{NH}_{2}$ could be used as $\mathrm{O}_{2}$ production photocatalyst, and the $\mathrm{Ni}^{2+}$ cation was introduced into the pore of MOF for modification through coordination with the amino group. $\mathrm{Ni}^{2+}$ was a highly efficient hydrogen production catalyst, and the obtained MOF could be used in a highly efficient overall water splitting reaction. MIL-125(Ti)- $\mathrm{NH}_{2}$ promoted the photocatalytic overall water splitting into $\mathrm{H}_{2}$ and $\mathrm{O}_{2}$, but its speed depends on the type of co-catalyst [225]. Pt and $\mathrm{RuO}_{x}$ had similar enhancement effects on MIL-125(Ti)-NH when using a single co-catalyst, while MIL-125(Ti)- $\mathrm{NH}_{2}$ showed activity of $141 \mu \mathrm{mol} \cdot \mathrm{g}^{-1}$ (for $\mathrm{H}_{2}$ ) and $61 \mu \mathrm{mol} \cdot \mathrm{g}^{-1}$ (for $\mathrm{O}_{2}$ ) when using $\mathrm{CoO}_{x}$ as co-catalyst. What's more interesting was that when $\mathrm{Pt}$ and $\mathrm{RuO}_{x}$ were acted as co-catalysts in the photocatalytic system, the activity of $\mathrm{H}_{2}$ production and $\mathrm{O}_{2}$ production reached 218 and $85 \mu \mathrm{mol} \cdot \mathrm{g}^{-1}$. Melillo found that collective cooperation of metallic clusters in trimetallic UiO-66(Zr/Ce/Ti) had four electron sites that were beneficial to water oxidation [226]. Therefore, UiO-66 with the polymetallic center could photocatalytic decompose water into $\mathrm{H}_{2}$ and $\mathrm{O}_{2}$ under the sun- 
Table 3

Photocatalytic hydrogen production of MOF-based photocatalysts.

\begin{tabular}{|c|c|c|c|c|c|}
\hline Photocatalyst & Co-catalyst & Photosensitizer & Products & Activity $\left(\mathrm{mmol} \cdot \mathrm{g}^{-1} \cdot \mathrm{h}^{-1}\right)$ & Ref. \\
\hline Al-ATA-Ni MOF & - & - & $\mathrm{H}_{2}$ and $\mathrm{O}_{2}$ & 5.16 and 1.2 & {$[224]$} \\
\hline MIL-125(Ti)- $\mathrm{NH}_{2}$ & - & - & $\mathrm{H}_{2}$ and $\mathrm{O}_{2}$ & 0.002 and 0.001 & {$[225]$} \\
\hline MIL-125(Ti)- $\mathrm{NH}_{2}$ & $\mathrm{CoO}_{x}$ & - & $\mathrm{H}_{2}$ and $\mathrm{O}_{2}$ & 0.007 and 0.003 & {$[225]$} \\
\hline MIL-125(Ti)- $\mathrm{NH}_{2}$ & $\mathrm{Pt}$ & - & $\mathrm{H}_{2}$ and $\mathrm{O}_{2}$ & 0.003 and 0.001 & {$[225]$} \\
\hline MIL-125(Ti)- $\mathrm{NH}_{2}$ & $\mathrm{RuO}_{X}$ & - & $\mathrm{H}_{2}$ and $\mathrm{O}_{2}$ & 0.003 and 0.001 & {$[225]$} \\
\hline MIL-125(Ti)- $\mathrm{NH}_{2}$ & $\mathrm{Pt} / \mathrm{RuO}_{X}$ & - & $\mathrm{H}_{2}$ and $\mathrm{O}_{2}$ & 0.01 and 0.004 & {$[225]$} \\
\hline UiO-66(Zr/Ce/Ti) & - & - & $\mathrm{H}_{2}$ and $\mathrm{O}_{2}$ & 0.009 and 0.003 & {$[226]$} \\
\hline $\mathrm{MoS}_{2} / \mathrm{UiO}-66-\mathrm{NH}_{2}$ & - & - & $\mathrm{H}_{2}$ and $\mathrm{O}_{2}$ & 25.65 and 13.18 & {$[227]$} \\
\hline Ru-MIL-125-NH ${ }_{2}$ & - & - & $\mathrm{H}_{2}$ & 0.426 & {$[229]$} \\
\hline $\mathrm{UiO}-67-\mathrm{Ce}$ & - & - & $\mathrm{H}_{2}$ & 10.784 & {$[230]$} \\
\hline MIL-125-NH $\mathrm{N}_{2} @ \mathrm{TiO}_{2}$ & - & - & $\mathrm{H}_{2}$ & 0.496 & {$[231]$} \\
\hline $\mathrm{TiO}_{2} @ \mathrm{NH}_{2}-\mathrm{MIL}-125$ & - & - & $\mathrm{H}_{2}$ & 0.44 & {$[232]$} \\
\hline $\mathrm{NH}_{2}$-MIL-125(Ti)/RGO & - & - & $\mathrm{H}_{2}$ & 0.091 & {$[140]$} \\
\hline $\mathrm{ZnIn}_{2} \mathrm{~S}_{4} @ \mathrm{NH}_{2}-\mathrm{MIL}-125(\mathrm{Ti})$ & - & - & $\mathrm{H}_{2}$ & 2.204 & {$[233]$} \\
\hline $\mathrm{Ti}_{3} \mathrm{C}_{2} @ \mathrm{UiO}-66-\mathrm{NH}_{2}$ & - & - & $\mathrm{H}_{2}$ & 0.204 & {$[240]$} \\
\hline $\mathrm{Ti}_{3} \mathrm{C}_{2} / \mathrm{TiO}_{2} / \mathrm{UiO}-66-\mathrm{NH}_{2}$ & - & - & $\mathrm{H}_{2}$ & 1.980 & {$[241]$} \\
\hline $\mathrm{CdS}$ QD/UiO-66-(SH) 2 & - & - & $\mathrm{H}_{2}$ & 15.32 & {$[242]$} \\
\hline $\mathrm{NH}_{2}$-UiO-66-d/ZnIn $\mathrm{S}_{4}$ & - & - & $\mathrm{H}_{2}$ & 7.3 & {$[243]$} \\
\hline $\mathrm{CdLa}_{2} \mathrm{~S}_{4} / \mathrm{MIL}-88 \mathrm{~A}(\mathrm{Fe})$ & - & - & $\mathrm{H}_{2}$ & 7.677 & {$[155]$} \\
\hline CdS/ZIF-67 & - & - & $\mathrm{H}_{2}$ & 3.08 & {$[244]$} \\
\hline $\mathrm{CdS} / \mathrm{Ni}-\mathrm{MOF}$ & - & - & $\mathrm{H}_{2}$ & 2.508 & {$[245]$} \\
\hline $3 \mathrm{Cu} / \mathrm{BiOI} / 4 \mathrm{MOF}$ & - & - & $\mathrm{H}_{2}$ & 0.269 & {$[246]$} \\
\hline Cu0@HKUST-1 & - & - & $\mathrm{H}_{2}$ & 0.667 & {$[247]$} \\
\hline UNiMOF/gC $/ \mathrm{N}_{4}$ & - & - & $\mathrm{H}_{2}$ & 0.4 & {$[248]$} \\
\hline $\mathrm{Zn}_{0.2} \mathrm{Cd}_{0.8} \mathrm{~S} @ \mathrm{~h}-\mathrm{MOF}-5$ & - & - & $\mathrm{H}_{2}$ & 15.08 & {$[249]$} \\
\hline $\mathrm{Zn}_{0.5} \mathrm{Cd}_{0.5} \mathrm{~S} / \mathrm{ZIF}-67$ & - & - & $\mathrm{H}_{2}$ & 23.264 .6 & {$[250]$} \\
\hline $\mathrm{CFB} / \mathrm{NH}_{2}-\mathrm{MIL}-125$ (Ti) & $\mathrm{Pt}$ & - & $\mathrm{H}_{2}$ & 1.123 & {$[251]$} \\
\hline Pt@UiO-66- $\mathrm{NH}_{2}$ & $\mathrm{Pt}$ & - & $\mathrm{H}_{2}$ & 0.257 & {$[252]$} \\
\hline $\mathrm{Pt} / \mathrm{UiO}-66-\mathrm{NH}_{2}$ & Pt & - & $\mathrm{H}_{2}$ & 0.05 & {$[252]$} \\
\hline $\mathrm{ZnIn}_{2} \mathrm{~S}_{4} @ \mathrm{NH}_{2}-\mathrm{MIL}-53$ & $\mathrm{Pt}$ & - & $\mathrm{H}_{2}$ & 26.95 & [253] \\
\hline Bi-TBAPy & $\mathrm{Pt}$ & - & $\mathrm{H}_{2}$ & 0.14 & {$[254]$} \\
\hline ZIF-8/g-C $\mathrm{C}_{3} \mathrm{~N}_{4}$ & $\mathrm{Pt}$ & - & $\mathrm{H}_{2}$ & 0.31 & {$[255]$} \\
\hline Pt@PMOF & $\mathrm{Pt}$ & - & $\mathrm{H}_{2}$ & 8.52 & {$[256]$} \\
\hline $\mathrm{NH}_{2}$-MIL-125/TiO $2 / \mathrm{CdS}$ & $\mathrm{Pt}$ & - & $\mathrm{H}_{2}$ & 2.997 & {$[257]$} \\
\hline $\mathrm{NH}_{2}$-MIL-125(Ti)/CTF-1 & $\mathrm{Pt}$ & - & $\mathrm{H}_{2}$ & 0.36 & {$[258]$} \\
\hline g- $\mathrm{C}_{3} \mathrm{~N}_{4} /$ UMOFNs & $\mathrm{Pt}$ & - & $\mathrm{H}_{2}$ & 1.91 & {$[259]$} \\
\hline g-C $\mathrm{C}_{3} \mathrm{~N}_{4} @ \mathrm{TiATA} / \mathrm{Pt}$ & $\mathrm{Pt}$ & - & $\mathrm{H}_{2}$ & 0.265 & {$[260]$} \\
\hline $\mathrm{CdS} / \mathrm{UiO}-66$ & $\mathrm{Pt}$ & - & $\mathrm{H}_{2}$ & 47 & {$[261]$} \\
\hline BP/R-Ti-MOFs/Pt & $\mathrm{Pt}$ & - & $\mathrm{H}_{2}$ & 1.24 & {$[262]$} \\
\hline UiO-66/CdS & $\mathrm{MoS}_{2}$ & - & $\mathrm{H}_{2}$ & 32.5 & {$[263]$} \\
\hline $\mathrm{UiO}-66(\mathrm{COOH})_{2} / \mathrm{ZnIn}_{2} \mathrm{~S}_{4}$ & $\mathrm{MoS}_{2}$ & - & $\mathrm{H}_{2}$ & 18.794 & {$[264]$} \\
\hline $\mathrm{NH}_{2}$-MIL-125(Ti)@ZnIn $\mathrm{S}_{4} / \mathrm{CdS}$ & $\mathrm{CdS}$ & - & $\mathrm{H}_{2}$ & 2.367 & {$[265]$} \\
\hline $\mathrm{UiO}-66-\mathrm{NH}_{2}$ & $\mathrm{Pt}$ & Calix-3 & $\mathrm{H}_{2}$ & 0.516 & {$[266]$} \\
\hline UiO-66 & $\mathrm{Pt}$ & ErB & $\mathrm{H}_{2}$ & 0.46 & {$[267]$} \\
\hline UiO-66 & $\mathrm{NiS}_{2}$ & ErB & $\mathrm{H}_{2}$ & 1.84 & {$[268]$} \\
\hline g- $\mathrm{C}_{3} \mathrm{~N}_{4} / \mathrm{UiO}-66$ & $\mathrm{Ni}_{2} \mathrm{P}$ & EY & $\mathrm{H}_{2}$ & 2 & {$[269]$} \\
\hline Pt-SACs/MBT & $\mathrm{Pt}$ & EY & $\mathrm{H}_{2}$ & 68.33 & {$[270]$} \\
\hline g-C $\mathrm{C}_{3} \mathrm{~N}_{4} @ Z \mathrm{ZIF}-67 / \mathrm{NiS}_{\mathrm{x}}$ & $\mathrm{NiS}_{x}$ & EY & $\mathrm{H}_{2}$ & 2.77 & {$[271]$} \\
\hline g- $\mathrm{C}_{3} \mathrm{~N}_{4} / \mathrm{ZIF}-67 / \mathrm{MoS}_{2}$ & $\mathrm{MoS}_{2}$ & EY & $\mathrm{H}_{2}$ & 4.0125 & {$[272]$} \\
\hline $\mathrm{MoS}_{2} \mathrm{QDs} / \mathrm{UiO}-66-\mathrm{NH}_{2} / \mathrm{GO}$ & $\mathrm{MoS}_{2}$ & EY & $\mathrm{H}_{2}$ & 2.074 & {$[273]$} \\
\hline
\end{tabular}

light. $\mathrm{Zr}^{4+}$ and $-\mathrm{NH}_{2}$ in UiO-66- $\mathrm{NH}_{2}$ can be used as Lewis acid sites and base sites, respectively, so they can be used as bifunctional acid-base catalysts. Subudhi et al. prepared $\mathrm{MoS}_{2}$-modified UiO-66- $\mathrm{NH}_{2}$ [227]. UiO-66- $\mathrm{NH}_{2}$ provided active sites and photocatalytic hydrogen production sites.
Both $\mathrm{MoS}_{2}$ and UiO-66- $\mathrm{NH}_{2}$ had suitable edge potentials. Under the appropriate potential of the heterojunction, effective charge separation and maximum interface contact make the composite material have excellent photocatalytic activity for the redox reaction of water. 


\subsubsection{Half-reaction $\mathrm{H}_{2}$ evolution}

The photocatalytic overall water splitting is in line with atomic economy. However, the current photocatalytic total water splitting efficiency is still very low. Compared with total water splitting, hydrogen production reaction involving two electrons is easier to achieve. In the photocatalytic hydrogen production system, it is very difficult to decompose pure water directly using catalyst, because $\mathrm{e}^{-}$and $\mathrm{h}^{+}$are easy to recombine. For the sake of reducing the difficulty of water splitting and improve the activity, researchers will introduce sacrificial agents into the system of photocatalytic hydrogen production. The sacrificial agent plays a role in consuming holes, and can effectively improve the separation efficiency of photo-generated electrons and holes, thereby improving the reaction activity of photocatalytic hydrogen production. More importantly, the catalytic activity for photocatalytic hydrogen production is closely related to the band gap, the ability to absorb visible light, the composition and number of active sites/co-catalysts, and the charge transfer ability. Therefore, the presence of co-catalyst or photosensitizer is also a way to improve the photocatalytic hydrogen production activity over MOFs-based photocatalysts.

\subsubsection{No photosensitizers and co-catalysts in reaction system}

When there are only photocatalysts and sacrificial agents in the reaction system, the first thing to consider is how to increase the light absorption range and ensure the reduction ability of photogenerated electrons [228]. As is known to all, the MIL-125- $\mathrm{NH}_{2}$ has no $\mathrm{H}_{2}$ production ability. However, Ru-MIL-125- $\mathrm{NH}_{2}$ exhibited excellent photocatalytic activity, which was much higher than those of the MIL-125- $\mathrm{NH}_{2}$ and the $\mathrm{Ru}$ loaded MIL-125- $\mathrm{NH}_{2}$ [229]. Coordination of $\mathrm{Ru}$ to MIL-125- $\mathrm{NH}_{2}$ changed the electronic structures of the MIL-125- $\mathrm{NH}_{2}$ cluster. With the increase of $\mathrm{Ru}$ ions, the HOMO/LUMO gap of Ru-MIL-125- $\mathrm{NH}_{2}$ continued to decrease, which was close to water splitting (Fig. 31). In conclusion, $\mathrm{Ru}$ coordination alters the energy and composition of frontier molecular orbitals and enhances the visible light absorption capacity. An et al. [230] replaced part of bpydc with bpydc-Ce to form UiO-67-Ce. In general, charge transfer in MOF is caused by LMCT. In UiO-67-Ce, the existence of Ce promoted energy transfer and weakened the LMCT process, opening up a new energy transfer channel from bpdc to bpydc-Ce. Similarly, Ce also acts as an active site for hydrogen release.

In addition to doping in the MOF structure, it is an effective approach for high-efficiency hydrogen production to improve

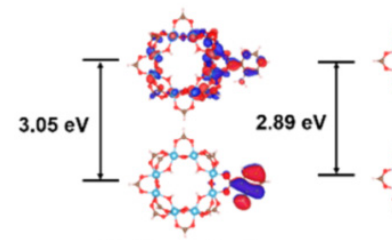

No $\mathrm{H}_{2}$ production

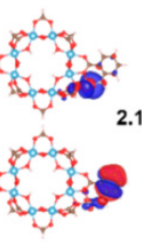

$2.10 \mathrm{eV}$

TOF $=426 \mu \mathrm{mol} \mathrm{h}^{-1} \mathrm{~g}^{-1}$

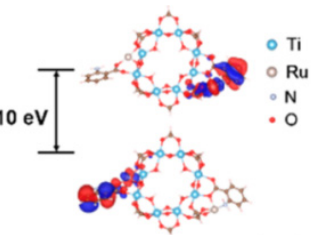

Fig. 31. Frontier molecular orbitals and HOMO/LUMO gaps of $\mathrm{Ti}_{8} \mathrm{O}_{8}(\mathrm{OH})_{4}(\mathrm{COOH})_{11}\left(\mathrm{COOC}_{6} \mathrm{H}_{5} \mathrm{NH}_{2}\right), \mathrm{Ti}_{8} \mathrm{O}_{8}(\mathrm{OH})_{4}(\mathrm{COOH})_{11}\left(\mathrm{COOC}_{6} \mathrm{H}_{5} \mathrm{NH}_{2}\right)$ $\mathrm{Ru}$ and $\mathrm{Ti}_{8} \mathrm{O}_{8}(\mathrm{OH})_{4}(\mathrm{COOH})_{10}\left(\mathrm{COOC}_{6} \mathrm{H}_{5} \mathrm{NH}_{2}\right)_{2} \mathrm{Ru}_{2}$. Reprinted with permission from Ref. [229]. Copyright (2019) American Chemical Society. the separation and transfer efficiency of photogenerated charges through heterojunctions. Band matching is the prerequisite for constructing heterojunction. The conduction band of $\mathrm{TiO}_{2}$ and $\mathrm{NH}_{2}-\mathrm{MIL}-125$ (Ti) matched well in energy levels, so Zhang et al. [231] and Sun et al. [232] prepared heterogeneous structures of $\mathrm{TiO}_{2}$ and $\mathrm{NH}_{2}$-MIL-125(Ti) by different methods. Zhang et al. [231] controlled the internal and external decomposition of MIL-125- $\mathrm{NH}_{2}$ through the post solvothermal route, thus forming MIL-125- $\mathrm{NH}_{2} @ \mathrm{TiO}_{2}$ core-shell particles. The $\mathrm{TiO}_{2}$ shell prepared by this method has ultra-thin characteristics, which was beneficial to the exposure of unsaturated titanium-oxo clusters. At this time, MIL-125- $\mathrm{NH}_{2}$ also improved the light absorption characteristics of $\mathrm{TiO}_{2}$. It is obvious that the voids and mesopores formed during the synthesis process provided more active sites and accelerated the charge transfer to promote photocatalytic activity. Sun and co-workers etched $\mathrm{NH}_{2}$-MIL-125(Ti) from the inside out to get $\mathrm{TiO}_{2} / \mathrm{NH}_{2}-\mathrm{MIL}-125$ (Ti) via selective wet-chemical etching (Fig. 32(a)). $\mathrm{NH}_{2}$-MIL-125(Ti) transferred photoexcited electrons to $\mathrm{TiO}_{2}$, and then $\mathrm{Ti}^{3+}$ in $\mathrm{TiO}_{2}$ acted as the active site for $\mathrm{H}_{2} \mathrm{O}$ reduction during the mutual transformation of $\mathrm{Ti}^{3+}$ and $\mathrm{Ti}^{4+}$ (Fig. 32(b)). Since it is self-sacrificial hydrolysis in situ, photo-generated carriers migrated smoothly through the interface of $\mathrm{TiO}_{2}$ and $\mathrm{NH}_{2}-\mathrm{MIL}-125$ (Ti). Graphene has high conductivity and excellent electron mobility, the non-covalently connected $\mathrm{NH}_{2}$-MIL-125(Ti)/rGO promoted the separation of photogenerated electron-hole pairs through $\pi-\pi$ interaction [140]. Liu et al. [233] reported that the coupling of $\mathrm{NH}_{2}$-MIL-125(Ti) and $\mathrm{ZnIn}_{2} \mathrm{~S}_{4}$ enabled the photoexcited electrons on CB of $\mathrm{ZnIn}_{2} \mathrm{~S}_{4}$ to be transferred quickly to the LUMO of $\mathrm{NH}_{2}-\mathrm{MIL}-125$ (Ti), so as to effectively separate the photogenerated electron-hole pairs.

Two-dimension ternary transition metal carbide and carbon nitride, namely MXenes, have good Fermi level, excellent conductivity and carrier transfer properties [234,235]. The combination of MXenes and MOF is expected to accelerate the transfer of photogenic electrons. If a multilayer two-dimensional material is cut into a single layer, a large

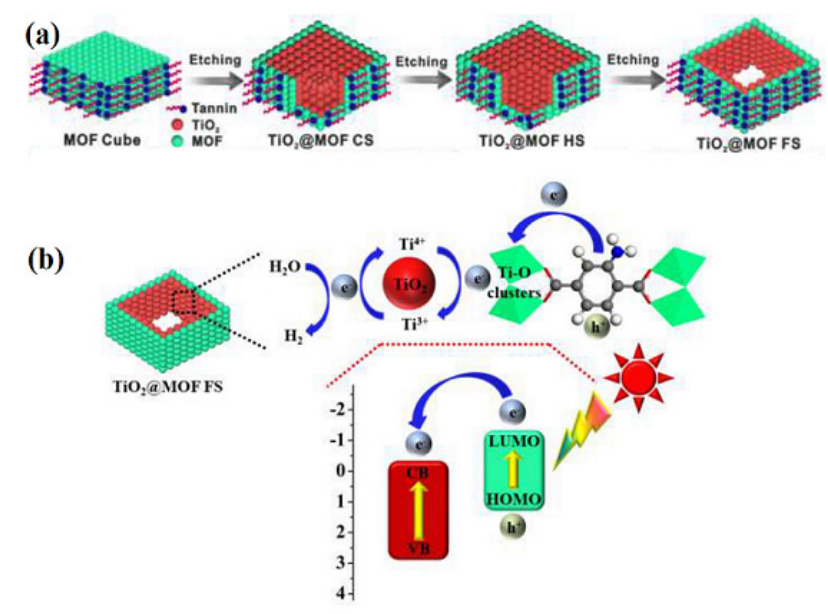

Fig. 32. (a) Synthetic process of monodisperse $\mathrm{TiO}_{2} @ M O F$ FS; (b) Schematic illustration for the enhanced photocatalytic process of $\mathrm{TiO}_{2} @$ MOF FS. Reprinted with permission from Ref. [232]. Copyright (2020) Elsevier. 
number of exposed active sites may be provided [235-239]. Zhao's group [240] prepared $\mathrm{Ti}_{3} \mathrm{AlC}_{2}$ into $\mathrm{Ti}_{3} \mathrm{C}_{2}$ nanosheets, and then combined $\mathrm{Ti}_{3} \mathrm{C}_{2}$ nanosheets with UiO-66- $\mathrm{NH}_{2}$ to obtain different proportions of TU (Fig. 33(a)). Hydrogen evolution rate of TU-10 reached a maximum of $204 \mu \mathrm{mol} \cdot \mathrm{g}^{-1} \cdot \mathrm{h}^{-1}$. Moreover, the concentration of $\mathrm{Ti}_{3} \mathrm{C}_{2}$ nanosheet determined the activity of photocatalytic hydrogen production, because the construction of schottky barrier on the edge of $\mathrm{Ti}_{3} \mathrm{C}_{2}$ nanosheet and the exposed active sites accelerate the separation and transfer of charge carriers in space (Fig. 33(b)). And O-terminated $\mathrm{Ti}_{3} \mathrm{C}_{2}$ possessed favorable Fermi level relatively low Gibbs free energy. After that, Zhao et al. improved the synthesis process which $\mathrm{Ti}_{3} \mathrm{C}_{2} \mathrm{~T} x$ after annealing treatment not only retained the original morphology but also formed $\mathrm{TiO}_{2}$ (Fig. 33(c)) [241]. As expected, the photocatalytic activity of $\mathrm{Ti}_{3} \mathrm{C}_{2} / \mathrm{TiO}_{2} / \mathrm{UiO}-66-\mathrm{NH}_{2}$ was not only higher than that of UiO-66- $\mathrm{NH}_{2}$, but also much higher than that of TU-10 mentioned above. Three contact interfaces were formed in the composite materials due to the addition of $\mathrm{TiO}_{2}$ components (Fig. 33(d)). Under the excitation of visible light, UiO-66- $\mathrm{NH}_{2}$ generated photogenic electron hole pairs. There were two ways for $\mathrm{e}^{-}$in the $\mathrm{CB}$ of UiO-66- $\mathrm{NH}_{2}$ to transfer to $\mathrm{Ti}_{3} \mathrm{C}_{2}$, which were directly migrated to $\mathrm{Ti}_{3} \mathrm{C}_{2}$ (pathway I) or indirectly migrated $\mathrm{Ti}_{3} \mathrm{C}_{2}$ through $\mathrm{TiO}_{2}$ (pathway III). In addition, photogenic electrons at $\mathrm{CB}$ of $\mathrm{TiO}_{2}$ can also be transferred to $\mathrm{Ti}_{3} \mathrm{C}_{2}$ (pathway II) due to the interaction between $\mathrm{TiO}_{2}$ and $\mathrm{Ti}_{3} \mathrm{C}_{2}$ interface. Semiconductor@MOF heterojunctions like $\mathrm{CdS} \quad \mathrm{QD} / \mathrm{UiO}-66-(\mathrm{SH})_{2} \quad$ [242], $\mathrm{NH}_{2}$-UiO-66-d/ZnIn $\mathrm{S}_{4}$ [243], CdLa $\mathrm{S}_{4} / \mathrm{MIL-88A(Fe)} \mathrm{[155],}$ CdS/ZIF-67 [244], CdS/Ni-MOF [245], 3Cu/BiOI/4MOF [246], CuO@HKUST-1 [247], UNiMOF/ $/ \mathrm{gC}_{3} \mathrm{~N}_{4} \quad$ [248], $\mathrm{Zn}_{0.2} \mathrm{Cd}_{0.8} \mathrm{~S} @$ h-MOF-5 [249], Zn ${ }_{0.5} \mathrm{Cd}_{0.5} \mathrm{~S} / \mathrm{ZIF}-67$ [250] have been prepared and rebealed great advantages because of their synergistic effect.

\subsubsection{Co-catalysts in the reaction system}

The co-catalyst in the reaction system can be used as an active site for hydrogen production. The co-catalyst can effectively extract photogenic carriers and reduce the hydrogen evolution potential, so as to improve the activity and stability of photocatalyst by inhibiting carrier recombination or photoetching. At present, noble metals such as $\mathrm{Pt}, \mathrm{Pd}, \mathrm{Au}$, and $\mathrm{Ag}$ have been developed as co-catalysts for most photocatalysts. Among them, $\mathrm{Pt}$ is the most effective hydrogen production promoter, mainly because it has the largest work function and the lowest hydrogen evolution overpotential. Zhou et al. [251] synthesized CFB/NH2-MIL-125(Ti) (CFB: g- $\mathrm{C}_{3} \mathrm{~N}_{4}$ functionalized by benzoic acid) and $\mathrm{Pt}$ nanoparticles were deposited on CFB/NH2-MIL-125(Ti) as cocatalysts. They proposed that the electron transfer follows the LCCT process, that was, the CB of the Ti-O cluster accepted the effective charge transfer from the excited 2-aminoterephthalic acid. The photogenerated electrons on the $\mathrm{CB}$ of CFB combined with the holes on the VB of $\mathrm{NH}_{2}$-MIL-125(Ti) through benzoic acid. Pt acted as a co-catalyst to accept electrons from Ti-O clusters and undergo photolysis of water to produce hydrogen (Fig. 34). As a co-catalyst, Pt has a good auxiliary effect on the separation and transfer of photogenerated electrons and holes. Does the relative position of $\mathrm{Pt}$ and MOF have different effects? Jiang's research group [252] selected UiO-66- $\mathrm{NH}_{2}$ as the model and synthesized Pt@UiO-66- $\mathrm{NH}_{2}$ and Pt/UiO-66- $\mathrm{NH}_{2}$ with the same content of $\mathrm{Pt}$ and the same Pt size. Compared with UiO-66- $\mathrm{NH}_{2}$, both Pt@Ui0-66- $\mathrm{NH}_{2}$ and Pt/UiO-66- $\mathrm{NH}_{2}$ showed significantly improved but different hydrogen production performance. The electron transport distance in the Pt@UiO-66- $\mathrm{NH}_{2}$ material was greatly shortened, which was more conducive to the separation of electrons and holes, so it shows a higher light conversion efficiency than Pt/UiO-66- $\mathrm{NH}_{2}$.
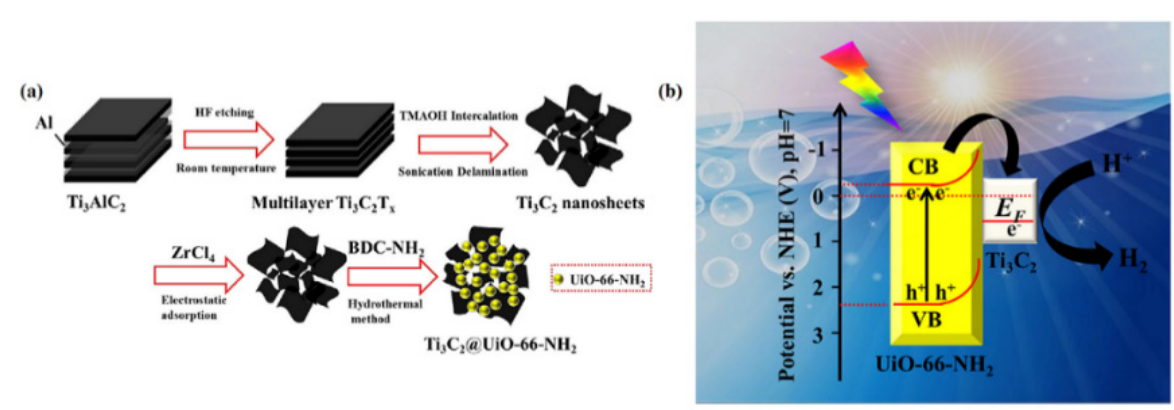

(c)
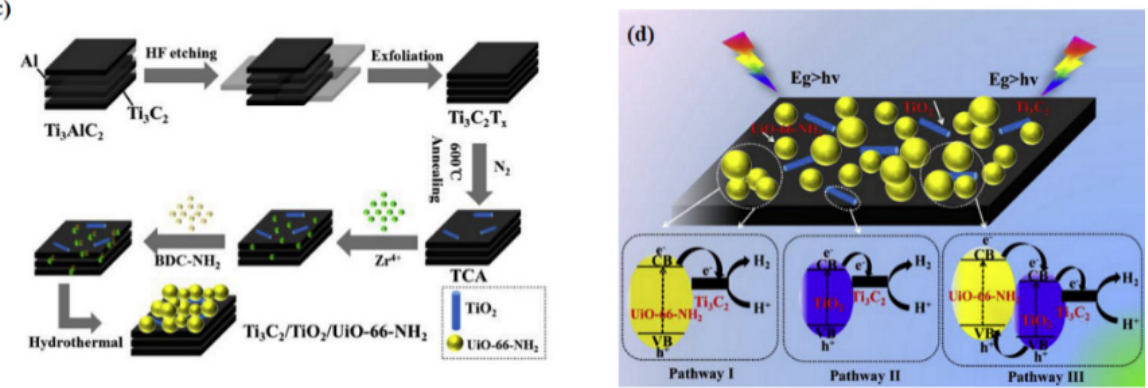

Fig. 33. (a) Schematic chart for the fabrication of $\mathrm{Ti}_{3} \mathrm{C}_{2} / \mathrm{UiO}-66-\mathrm{NH}_{2}$; (b) Energy level structure diagram of $\mathrm{Ti}_{3} \mathrm{C}_{2} / \mathrm{UiO}^{-66}-\mathrm{NH}_{2}$ for photocatalytic $\mathrm{HER}$ process, Reprinted from Ref. [240], Copyright (2019), with permission from Elsevier; (c) Schematic chart for the fabrication of $\mathrm{Ti}_{3} \mathrm{C}_{2} / \mathrm{TiO}_{2} / \mathrm{UiO}-66-\mathrm{NH}_{2}$; (d) The charge-transfer pathways for $\mathrm{Ti}_{3} \mathrm{C}_{2} / \mathrm{TiO}_{2} / \mathrm{UiO}-66-\mathrm{NH}_{2}$. Reprinted with permission from Ref. [241]. Copyright (2019), Elsevier. 


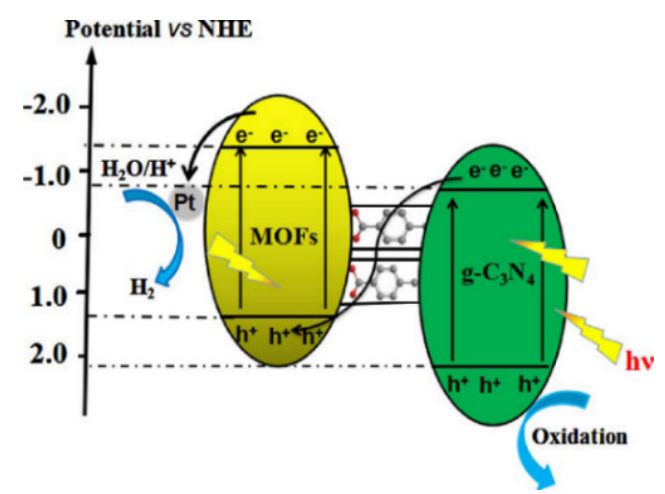

Fig. 34. Photocatalytic mechanism of the charge transfer for hydrogen evolution over the 10CFBM. Reprinted with permission from Ref. [251]. Copyright (2018) Elsevier.

At present, most researches mainly focus on loading Pt on the surface of the catalyst by light deposition. $\mathrm{ZnIn}_{2} \mathrm{~S}_{4} @ \mathrm{NH}_{2}-\mathrm{MIL}-53\left(\mathrm{Fe} / \mathrm{Co}_{0.75}\right)$ [253], Bi-TBAPy [254], ZIF-8/g- $\mathrm{C}_{3} \mathrm{~N}_{4}$ [255], Pt@PMOF [256], NH2-MIL-125/TiO $2 / \mathrm{CdS}$ [257], $\mathrm{NH}_{2}-\mathrm{MIL}-125$ (Ti)/CTF-1 [258], g-C $\mathrm{N}_{3} / \mathrm{UMOFNs} \mathrm{[259],}$ $\mathrm{gC}_{3} \mathrm{~N}_{4} @ \mathrm{TiATA} / \mathrm{Pt}$ [260], CdS/UiO-66 [261], BP/R-Ti-MOFs/Pt [262], were known to be reported. In 2015, Zhou and colleagues [261] reported a CdS/UiO-66 hybrid catalyst deposited with $0.5 \mathrm{wt} \%$ Pt for photocatalytic hydrogen production. Since UiO-66 cannot be excited in visible light, electrons would be transferred from CdS to Pt on the surface of UiO-66. Wang et al. [256] developed that ultra-thin porphyrin-based MOF (PMOF) nanosheets, in which porphyrin-based ligands and Ti-oxo clusters acted as light collectors and catalytic centers, respectively. During the LMCT process, the electron transfer kinetics from the porphyrin-based ligand to the Ti-oxo cluster was greatly promoted from the donor to the acceptor. Based on this, the hydrogen evolution rate of $8.52 \mathrm{mmol} \cdot \mathrm{h}^{-1} \cdot \mathrm{g}^{-1}$ was obtained on the PMOF with a loading of $3 \mathrm{wt} \%$ Pt as a cocatalyst. The introduction of $\mathrm{Ti}^{4+}$ into the Ti-based MOF can induce a continuous vacancy band of electronic states below the edge of the CB, which is beneficial to the photocatalytic reaction. Liu and co-workers [262] reported Ti-MOF with loading Pt encapsulated black phosphorus (BP/R-Ti-MOFs/Pt). Hybridization of $\mathrm{BP}$ with Ti-MOFs reduces the valence state of Ti at the heterogenous interface, rendering BP/R-Ti-MOFs/Pt with enhanced photocatalytic activity.

However, the use of precious metal cocatalysts is limited by resource shortage and high price. So, other co-catalysts such as $\mathrm{MoS}_{2}$ and CdS also were introduced into the photocatalytic hydrogen production system. Shen reported that $\mathrm{MoS}_{2} / \mathrm{UiO}-66 / \mathrm{CdS}$, the best hydrogen release rate reached $\mu \mathrm{mol} \cdot \mathrm{h}^{-1}$ when the loading content of $\mathrm{MoS}_{2}$ was $1.5 \mathrm{wt} \%$. The photogenerated electrons of CdS had two transfer paths (Fig. 35(a)). One was directly transferred to the co-catalyst $\mathrm{MoS}_{2}$ nanometer sheet, so as to react with the $\mathrm{H}_{2} \mathrm{O}$ on the edge of $\mathrm{MoS}_{2}$ to form $\mathrm{H}_{2}$. The other one was to transfer to UiO-66, and then to $\mathrm{MoS}_{2}$ to generate $\mathrm{H}_{2}$. The effective separation and consumption of holes could inhibit the photocorrosion of CdS and enhance the light stability. More importantly, the performance of the obtained $\mathrm{MoS}_{2} / \mathrm{UiO}-66 / \mathrm{CdS}$ was even better than that of
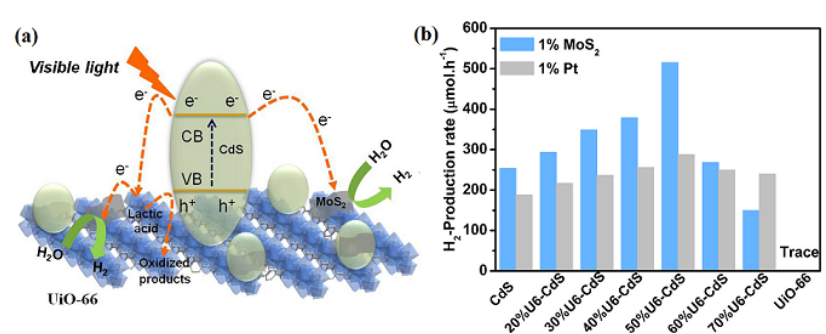

Fig. 35. (a) Charge transfer path of $\mathrm{MoS}_{2} / \mathrm{UiO}-66 / \mathrm{CdS}$; (b) The rate of $\mathrm{H}_{2}$ production over samples loaded with $1 \mathrm{wt} \% \mathrm{MoS}_{2}$ or Pt. Reprinted with permission from Ref. [263]. Copyright (2015) Elsevier.

Pt/UiO-66/CdS under the same reaction conditions (Fig. 35(b)). Mu prepared UiO-66-(COOH $)_{2} / \mathrm{ZnIn}_{2} \mathrm{~S}_{4}$ decorated with $\mathrm{MoS}_{2}$ co-catalyst by reflux and hydrothermal methods and the composite photocatalyst displayed efficient properties for hydrogen evolution under visible light irradiation, in which the rate of hydrogen evolution is $18.794 \mathrm{mmol} \cdot \mathrm{h}^{-1} \cdot \mathrm{g}^{-1}$ [264]. $\mathrm{MoS}_{2}$ as a co-catalyst played a vital role in charge transfer, which mainly depended on the CB and VB potential of $\mathrm{MoS}_{2}$ being, respectively. When $\mathrm{MoS}_{2}$ was combined with $\mathrm{ZnIn}_{2} \mathrm{~S}_{4}$, electrons would migrate from $\mathrm{ZnIn}_{2} \mathrm{~S}_{4}$ to $\mathrm{MoS}_{2}$. The photogenerated holes in the VB of UiO-66-(COOH $)_{2}$ could be captured by the sacrificial agent, so as to achieve the purpose of separating charges. Zhang et al. [265] reported $\mathrm{NH}_{2}$-MIL-125(Ti)@ZnIn $2 \mathrm{~S}_{4} / \mathrm{CdS}$ hierarchical tandem heterojunctions photocatalyst. As showed in Fig. 36, $\mathrm{NH}_{2}$-MIL-125(Ti) provided a cycle of $\mathrm{Ti}^{3+}$ and $\mathrm{Ti}^{4+}$ to promote the generation of hydrogen. $\mathrm{ZnIn}_{2} \mathrm{~S}_{4}$ enhanced the photocatalytic performance of $\mathrm{H}_{2}$ generation by electron enrichment. Core-shell structure formed by $\mathrm{ZnIn}_{2} \mathrm{~S}_{4}$ and $\mathrm{NH}_{2}$-MIL-125(Ti) improved the stability and integrity of $\mathrm{NH}_{2}$-MIL-125(Ti). The participation of catalyst CdS can form double electron transfer and inhibit the corrosion of CdS. In conclusion, the load of the co-catalyst on the surface of MOF can reduce the reaction activation energy and provide an effective active site for photocatalytic hydrogen production, thus improving the catalytic reaction rate on the surface of MOF. At the same time, the co-catalyst provides a new transfer channel for photogenic carriers, promotes the transfer of photogenic carriers from MOF to the co-catalyst, and effectively improves the separation efficiency of photogenic carriers.

\subsubsection{Photosensitizers in the reaction system}

It is a relatively mature technology to utilize dye as a photo-

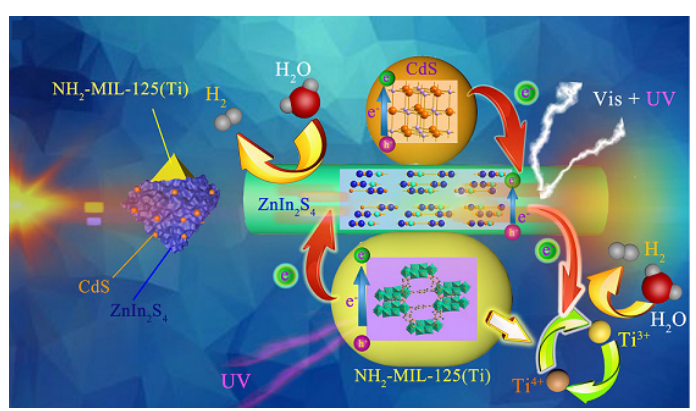

Fig. 36. The mechanism of photocatalytic hydrogen production of $\mathrm{NH}_{2}$-MIL-125(Ti)@ZnIn $2 \mathrm{~S}_{4} / \mathrm{CdS}$. Reprinted with permission from Ref. [265]. Copyright (2020) Elsevier. 
sensitizer for effective visible light response. There will also be strong $\pi-\pi$ stacking and van der Waals interactions between MOF and dyes containing benzene rings, which is very crucial for effective electron transfer in dye-sensitized photocatalytic systems. The photocatalytic hydrogen production mechanism of dye-sensitized MOF in the presence of sacrificial agent and co-catalyst is shown in the Fig. 37 . When the energy of the incident light is higher than the band gap of the dye, the electrons will be excited from the HOMO to the LUMO of dye. The photogenerated electrons are then transferred to co-catalyst and the LUMO of MOF. The electrons in the LUMO state migrate to the co-catalyst, and finally the electrons on the surface of the co-catalyst participate in the reduction of water. Oxidized dye molecules return to their original state by acquiring electrons from the sacrificial agent. Therefore, in the dye-sensitized MOF photocatalytic system, the following prerequisites are required to achieve high catalytic activity and hydrogen production stability: (1) the dye molecules have a wide spectral absorption range and a high molar extinction coefficient; (2) the lowest unoccupied molecular orbital of the dye is more negative than the conduction band position of the MOF, and the highest occupied molecular orbital is more positive than the redox potential of the sacrificial agent; (3) the stability and cost of the dye should also be considered.

Cone-calixarene-based dye (Calix-3) can prevent dye aggregation. Each Calix-3 molecule with four light collection units not only ensure electron transfer between dye and MOF but also provide a high extinction coefficient. Chen et al. [266] reported Calix-3-sensitized Pt@UiO-66- $\mathrm{NH}_{2}$. The hydrogen bond and the $\pi$ - $\pi$-interaction of between Calix-3 and UiO-66- $\mathrm{NH}_{2}$ promoted the transfer of electrons from the excited Calix- 3 to UiO-66- $\mathrm{NH}_{2}$, and finally the electrons were transferred to the $\mathrm{Pt}$ surface to produce $\mathrm{H}_{2}$. Erythrosin B (ErB) is also often used as a photosensitizer for UiO-66 [267,268].

Jin's group [269] first synthesized g- $\mathrm{C}_{3} \mathrm{~N}_{4} / \mathrm{UiO}-66$ by hydrothermal method, and then modified g- $\mathrm{C}_{3} \mathrm{~N}_{4} / \mathrm{UiO}-66$ with $\mathrm{Ni}_{2} \mathrm{P}$ and finally sensitized the material with EY to expand the absorption spectrum. When the amount of $\mathrm{Ni}_{2} \mathrm{P}$ was $50 \%$ of the total weight, the photocatalytic activity was the highest (Fig. 38(a)). The photocatalytic reaction process was shown in Fig. 38(b). The binding site on UiO-66 was occupied by $\mathrm{Ni}_{2} \mathrm{P}$ and g- $\mathrm{C}_{3} \mathrm{~N}_{4}$ and formed an active surface with varying degrees of unsaturation. The excited dye molecules provided energy for valence electrons after visible light irradiation. The electrons traveled from UiO-66 to the valence band of $\mathrm{Ni}_{2} \mathrm{P}$, and the free release of valence electrons on $\mathrm{Ni}_{2} \mathrm{P}$ produced reducibility. The

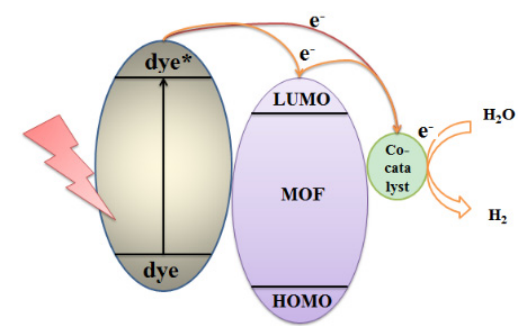

Fig. 37. Mechanism of dye-sensitized MOFs for photocatalysis for $\mathrm{H}_{2}$ production. g- $\mathrm{C}_{3} \mathrm{~N}_{4}$ could absorb electrons and have oxidation property because of valence electron detachment. Effective hydrogen release was obtained through this special charge transfer structure. In view of the fact that ethylene diamine tetraacetic acid (EDTA) ligand can effectively capture single metal ions, Li et al. [270] prepared MOF-808-EDTA (MBT), which was used to encapsulate Pt single atom. Under the condition that triethanolamine (TEOA) and EY were used as electron donors and photosensitizers, the photocatalytic hydrogen evolution activity of the catalyst was measured under visible light and near infrared light. The photocatalyst exhibited remarkable photocatalytic hydrogen production. This MOF photocatalytic system using EY dye sensitization also includes g- $\mathrm{C}_{3} \mathrm{~N}_{4} @ Z \mathrm{ZIF}-67 / \mathrm{NiS}_{X}$ [271], g- $\mathrm{C}_{3} \mathrm{~N}_{4} / \mathrm{ZIF}-67 / \mathrm{MoS}_{2}$ [272], and $\mathrm{MoS}_{2}$ QDs/UiO-66- $\mathrm{NH}_{2} / \mathrm{GO}$ [273].

\subsection{Photocatalytic degradation of organic pollutants}

\subsubsection{Mechanisms of MOFs photocatalytic degradation of organic pollutants}

There are two principles for using MOF as a photocatalysts to degrade organic pollutants. One is semiconductor theory [274]: when the MOFs material is irradiated, photogenic electrons jump from the VB to the $\mathrm{CB}$, resulting in holes $\left(\mathrm{h}^{+}\right)$in the VB. $\mathrm{h}^{+}$have strong oxidation, which can directly oxidize, degrade and adsorb small organic molecules located on the surface or react with $\mathrm{H}_{2} \mathrm{O}$ molecules and $\mathrm{OH}^{-}$to form hydroxyl radicals $(\bullet \mathrm{OH})$ with higher oxidation potential. $\bullet \mathrm{OH}$ can directly oxidize and degrade organic pollutants. $\mathrm{O}_{2}$ can capture $\mathrm{e}^{-}$to form superoxide free radicals $\left(\bullet \mathrm{O}_{2}-\right)$ that degrade organic pollutants.

The other is HOMO-LUMO theory. Under light irradiation, the organic ligands in MOF absorb light and are excited to generate electrons, which are then transferred from HOMO to LUMO, and then to the surface of the metal-oxo cluster, which is known as LMCT (Fig. 39) [275,276]. When the central metal is reduced to a lower valence state, electrons are excited from the ligand donor orbital to the metal acceptor orbital, thus absorbing low-energy photons. What happened at this time was LMCT. MOF can make use of LMCT to achieve excellent optical tenability. The absorption band of LMCT can be regulated by the substitution group on the ligand aromatic ring. The substituents with stronger electron donors can reduce the energy of LMCT transition to a greater extent and make the absorption

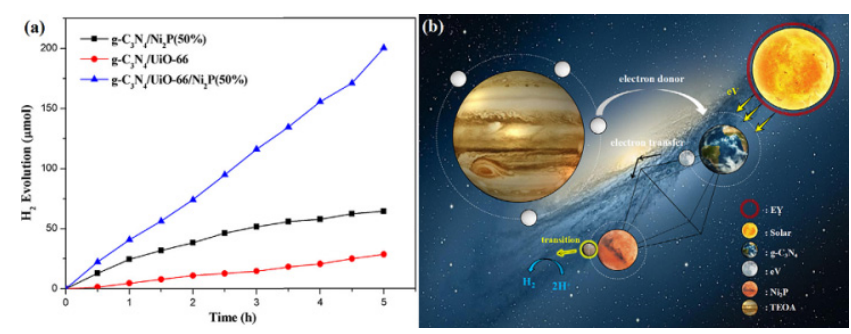

Fig. 38. (a) Hydrogen production of photocatalysts with different contents of $\mathrm{Ni}_{2} \mathrm{P}$; (b) The photocatalytic hydrogen production mechanism by the EY sensitized g- $\mathrm{C}_{3} \mathrm{~N}_{4} / \mathrm{UiO}-66 / \mathrm{Ni}_{2} \mathrm{P}$. Reprinted with permission from Ref. [269]. Copyright (2018) Elsevier. 


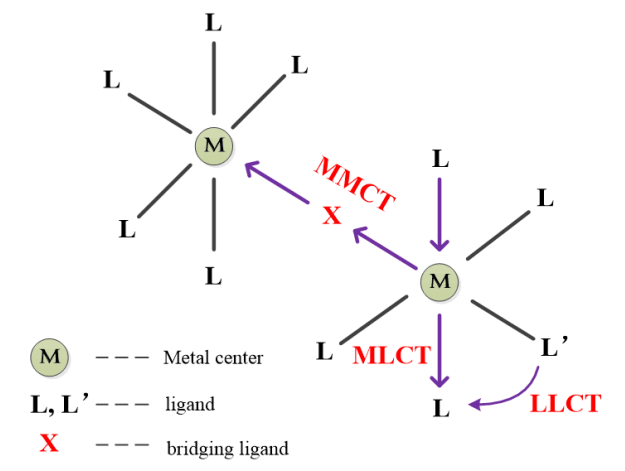

Fig. 39. Simplified schematic for the charge-transfer transitions.

of light move to a longer wavelength. [277,278]. In addition, the uncoordinated $d$ orbital of metal ions is lower than the LUMO of ligand, which can also narrow the LMCT transition energy gap [277]. Unlike LMCT, the occurrence of MLCT is based on the fact that the metal center is oxidized to a higher valence state and the ligand provides a fairly stable empty orbital. Electrons are excited from the local orbital of the occupying metal to the local orbital of the empty ligand, resulting in the absorption of long-wavelength light. When two metals with different valence states are coupled with a ligand, the electronic transition mode is MMCT. So MMCT typically occurs in poly-nuclear complexes. LLCT occurs when the donor and recipient ligands coexist. The two kinds of ligand interact with each other through the metal center to undergo oxidation and reduction, respectively. At this time, it shows the LLCT light absorption in the long wavelength region. However, LLCT actually coexists with LMCT, and the research on LLCT in MOF photocatalysts is still insufficient.

\subsubsection{Typical reactive species}

After light irradiation, photocatalysts are activated and redox environments are established in the reaction system. Hydroxyl radicals are produced throughout the process, and hydroxyl radicals can degrade various pollutants into non-toxic products. What counts is that the holes in the VB are powerful oxidants and the electrons in the CB are powerful reductants [279]. Photogenerated electrons react with oxygen to form superoxide radicals, and holes can directly oxidize pollutants. It is generally believed that electrons do not directly participate in photocatalytic reactions, but act indirectly in the form of free radicals produced by electrons. Therefore, the most important of the photodegradation pollutants is to oxidize pollutants and reduce oxygen at the same time to avoid the accumulation of electrons in CB. Table 4 lists some of MOF-based photocatalysts, which exhibited good photocatalytic performances for the degradation of organic pollutants. Combining the active species in the degradation process to determine the key to photodegradation efficiency is also the focus of further research.

\subsubsection{Reduction induced degradation}

In the process of MOF photodegradation of pollutants, electrons participate in the reduction reaction as a reducing agent. However, since electrons cannot directly participate in photocatalysis, they react with molecular oxygen in solution to form
$\mathrm{O}_{2}{ }^{--}$. In general, $\mathrm{O}_{2}{ }^{--}$are difficult to diffuse into the solution and can only react with pollutants adsorbed on the surface of MOFs-based photocatalysts [280]. The reduction reaction can be expressed as:

$$
\begin{aligned}
& \text { MOFs-based photocatalysts }+h v \rightarrow \text { MOFs-based } \\
& \text { photocatalysts }\left(\mathrm{e}^{-\mathrm{CB}}+\mathrm{h}^{+\mathrm{VB}}\right) \\
& \text { MOFs-based photocatalysts }\left(\mathrm{e}^{-\mathrm{CB}}\right)+\mathrm{O}_{2} \rightarrow \mathrm{O}_{2} \cdot- \\
& \mathrm{O}_{2} \cdot-\text { Organic pollutant } \rightarrow \mathrm{CO}_{2}+\mathrm{H}_{2} \mathrm{O}+\ldots
\end{aligned}
$$

Zhang et al. [281] discuss the performance of Photodegradation MO and TCH after the $\operatorname{In}_{2} \mathrm{~S}_{3}$ introduced UiO-66. Since $\mathrm{In}_{2} \mathrm{~S}_{3}$ was responsive to visible light, the response of $\mathrm{In}_{2} \mathrm{~S}_{3} / \mathrm{UiO}-66$ composite to visible light was significantly improved. Compared with the $\mathrm{CB}$ of UiO-66, $\mathrm{In}_{2} \mathrm{~S}_{3}$ had a more negative $C B$ position, which enabled the electrons on $\operatorname{In}_{2} \mathrm{~S}_{3}$ to be transferred to UiO-66 (Fig. 40). On the other hand, the Есв of UiO-66 became distinctly more negative than that of $\mathrm{E}_{0}\left(\mathrm{O}_{2} / \mathrm{O}_{2}{ }^{--}\right)(-0.046 \mathrm{eV}$ vs. NHE). Hence, the electrons on the $\mathrm{CB}$ of UiO-66 reacted with oxygen to form $\mathrm{O}_{2}{ }^{\bullet-}$, and $\mathrm{O}_{2}{ }^{\bullet-}$ participated in the degradation of MO and TCH. Li and coworkers reported the degradation of $\mathrm{BPA}$ by $\mathrm{S}-\mathrm{TiO}_{2} / \mathrm{UiO}-66-\mathrm{NH}_{2}$ under LED lights [282]. The degradation rate was optimal at $\mathrm{pH}=6$, and the important role of $\mathrm{O}_{2}{ }^{--}$in the degradation process was proved by ESR. The photocatalytic activity of $\mathrm{TiO}_{2} / \mathrm{UiO}-66-\mathrm{NH}_{2}$ was improved, but C-dots have up-conversion PL performance, which can improve light utilization, such as C-dots/ $\mathrm{TiO}_{2} / \mathrm{UiO}-66-\mathrm{NH}_{2}$ [283].

Akbarzadeh et al. [162] uses $\mathrm{Cu}-\mathrm{MOF} / \mathrm{rGO}$ as a co-catalyst to synthesize $\mathrm{Ag}_{3} \mathrm{VO}_{4} / \mathrm{Cu}-\mathrm{MOF} / \mathrm{rGO}$ composite materials. The degradation rate constants of $\mathrm{Ag}_{3} \mathrm{VO}_{4} / \mathrm{Cu}-\mathrm{MOF} / \mathrm{rGO}$ were 2.5 times and 4.7 times higher than that of $\mathrm{Ag}_{3} \mathrm{VO}_{4}$ and $\mathrm{Cu}-\mathrm{MOF} / \mathrm{rGO}$, respectively. $\mathrm{Ag}_{3} \mathrm{VO}_{4}$ particles were used as photoelectron donors, and rGO was used as charge carrier from $\mathrm{Ag}_{3} \mathrm{VO}_{4}$ to $\mathrm{Cu}-\mathrm{MOF}$, and support matrix for $\mathrm{Ag}_{3} \mathrm{VO}_{4}$ and $\mathrm{Cu}-\mathrm{MOF}$. However, because of p-phthaloquinone, the photodegradation of AB92 molecules was inhibited, proving the main role of $\mathrm{O}_{2}{ }^{--}$ in the degradation process. In addition, Manteghi reported $\mathrm{MOF} / \mathrm{CuWO}_{4}$ composites for MB degradation [284]. The structure of MOF provided an effective matrix for the transfer of electron-hole pairs, and there was no significant performance degradation after six cycles of reaction, which may be put down to the adsorption of degradation intermediates on the surface of $\mathrm{MOF} / \mathrm{CuWO}$.

Due to the special structure of MOF, it is often used as the outer shell of nanoparticles, but there is a problem that MOF will reduce the light absorption capacity of the internal catalyst. So, $\mathrm{Li}$ et al. [285] reported the uniform growth of $\mathrm{TiO}_{2}$ nanospheres on the surface of ZIF-8. ZIF-8 and $\mathrm{TiO}_{2}$ were connected by $\mathrm{N}-\mathrm{Ti}-\mathrm{O}$, and the interaction between the two narrowed the band gap of ZIF-8@ $\mathrm{TiO}_{2}$ and produced subenergy levels. In addition, Due to the presence of chemical bonds, this became another transport path for carriers. The large band gap of ZIF-8 makes it regarded as an insulator, but the coupling of $\mathrm{AgBr}$ and ZIF-8 can improve the charge separation efficiency. He et al. [286] prepared AgBr/ZIF-8 by deposition method. Since the CB position of ZIF-8 was $-1.0 \mathrm{~V}$, the electrons of $\mathrm{AgBr}$ cannot directly migrate to ZIF-8. The AgBr decomposed into Ag in a small amount, and Ag acted as an electronic bridge to make the 
Table 4

Photocatalytic degradation of organic pollutants over MOF-based photocatalysts.

\begin{tabular}{|c|c|c|c|c|c|}
\hline Photocatalyst & Light & Pollutants & Reactive species & Activity (\%) & Ref. \\
\hline $\mathrm{In}_{2} \mathrm{~S}_{3} / \mathrm{UiO}-66$ & Visible light & $\begin{array}{c}\mathrm{MO} \\
\mathrm{TCH}\end{array}$ & $\mathrm{O}_{2} \cdot-$ & $\begin{array}{l}96.2 \\
84.8\end{array}$ & [281] \\
\hline $\mathrm{S}-\mathrm{TiO}_{2} / \mathrm{UiO}-66-\mathrm{NH}_{2}$ & Visible light & $\mathrm{BPA}$ & $\mathrm{O}_{2} \cdot-$ & 97.5 & {$[282]$} \\
\hline C-dots $/ \mathrm{TiO}_{2} / \mathrm{UiO}-66-\mathrm{NH}_{2}$ & Visible light & KET & $\mathrm{O}_{2} \cdot-$ & 90 & [283] \\
\hline $\mathrm{Ag}_{3} \mathrm{VO}_{4} / \mathrm{Cu}-\mathrm{MOF} / \mathrm{rGO}$ & Visible light & AB92 & $\mathrm{O}_{2} \cdot-$ & - & [162] \\
\hline $\mathrm{MOF} / \mathrm{CuWO}{ }_{4}$ & Visible light & $\begin{array}{c}\mathrm{MB} \\
4-\mathrm{NP}\end{array}$ & $\mathrm{O}_{2} \cdot-$ & $\begin{array}{l}98 \\
81\end{array}$ & [284] \\
\hline ZIF-8@ $\mathrm{TiO}_{2}$ & UV-vis light & $\mathrm{TC}$ & $\mathrm{O}_{2} \cdot-$ & 90 & [285] \\
\hline $\mathrm{AgBr} / \mathrm{ZIF}-8$ & Visible light & MB & $\mathrm{O}_{2} \cdot-$ & 99.5 & [286] \\
\hline $\mathrm{NH}_{2}-\mathrm{MIL}-125(\mathrm{Ti}) / \mathrm{BiOCl}$ & Visible light & $\begin{array}{c}\text { TC } \\
\text { BPA }\end{array}$ & $\mathrm{O}_{2} \cdot-$ & $\begin{array}{l}78 \\
65\end{array}$ & [287] \\
\hline CdS/MIL-53(Fe) & Visible light & RhB & $\mathrm{O}_{2} \cdot-$ & 92.5 & [288] \\
\hline $\mathrm{NH}_{2}-\mathrm{MIL}-68\left(\mathrm{In}_{\alpha} \mathrm{Fe}_{1-\alpha}\right)$ & Visible light & $\mathrm{TC}$ & $\mathrm{O}_{2} \cdot-$ & 72 & [169] \\
\hline MIL-125(Ti)/g- $\mathrm{C}_{3} \mathrm{~N}_{4}$ & UV-vis light & Cefixime & $\mathrm{O}_{2} \cdot-$ & - & [289] \\
\hline $\mathrm{TiO}_{2} @ \mathrm{MIL}-101(\mathrm{Cr})$ & UV light & BPA & $\mathrm{O}_{2} \cdot-$ & 99.4 & [290] \\
\hline MIL-68(In)-NH $2 / \mathrm{GrO}$ & Visible light & AMX & $\mathrm{h}^{+}$ & 93 & [291] \\
\hline g- $\mathrm{C}_{3} \mathrm{~N}_{4} / \mathrm{MIL}-68(\mathrm{In})-\mathrm{NH}_{2}$ & Visible light & IBP & $\mathrm{h}^{+}$ & 93 & [292] \\
\hline CQDs/NH $2-M I L-125$ & Visible light & $\mathrm{RhB}$ & $\mathrm{h}^{+}$ & 100 & [293] \\
\hline Pt/MIL-125(Ti)/Ag & Visible light & KP & $\bullet \mathrm{OH}$ & 95.5 & {$[132]$} \\
\hline Ag NPs@MIL-100(Fe)/GG & Visible light & MB & $\bullet \mathrm{OH}$ & 100 & [294] \\
\hline Ag/AgCl@MIL-88A(Fe) & Visible light & IBP & $\mathrm{h}^{+}$ & 100 & [295] \\
\hline $\mathrm{TiO}_{2}-\mathrm{MIL}-101(\mathrm{Cr})$ & Visible light & $\mathrm{TC}$ & $\mathrm{h}^{+}$ & 99.7 & [296] \\
\hline $\mathrm{TiO}_{2} @ M I L-100(\mathrm{Fe})$ & Visible light & MB & $\mathrm{h}^{+}$and $\bullet \mathrm{OH}$ & 100 & [297] \\
\hline MIL-53(Al)/ZnO & UV light & TMP & $\bullet \mathrm{OH}$ & 93.5 & [298] \\
\hline $\mathrm{UiO}-66-\mathrm{NH}_{2} / \mathrm{Bi}_{2} \mathrm{WO}_{6}$ & Visible light & $\mathrm{RhB}$ & $\mathrm{h}^{+}$ & 100 & [299] \\
\hline $\mathrm{CoTiO}_{3} / \mathrm{UiO}-66-\mathrm{NH}_{2}$ & Visible light & NFX & $\bullet \mathrm{OH}$ & 90.13 & [300] \\
\hline $\mathrm{NH}_{2}-\mathrm{UiO}-66 / \mathrm{ZnIn}_{2} \mathrm{~S}_{4}$ & UV-vis light & MG & $\mathrm{h}^{+}$ & 98 & [301] \\
\hline MWCNT/N-TiO $2 / \mathrm{UiO}-66-\mathrm{NH}_{2}$ & Visible light & KET & $\bullet \mathrm{OH}$ & 96 & {$[302]$} \\
\hline $\mathrm{Cu}-\mathrm{NH}_{2}-\mathrm{MIL}-125(\mathrm{Ti})$ & Visible light & $\begin{array}{c}\text { MO } \\
\text { Phenol }\end{array}$ & $\mathrm{h}^{+}$and $\bullet \mathrm{OH}$ & $\begin{array}{l}86.9 \\
63.5\end{array}$ & [303] \\
\hline CdS/MIL-53(Fe) & Visible light & KTC & $\bullet \mathrm{OH}$ & 80 & [304] \\
\hline $\mathrm{In}_{2} \mathrm{~S}_{3} / \mathrm{MIL}-100(\mathrm{Fe})$ & Visible light & $\mathrm{TC}$ & $\mathrm{h}^{+}$ & 88 & [305] \\
\hline $\mathrm{Ag}_{3} \mathrm{VO}_{4} @ \mathrm{MIL}-125-\mathrm{NH}_{2}$ & UV-vis light & MB & $\bullet \mathrm{OH}$ & 95.2 & [306] \\
\hline $\mathrm{Ag}_{3} \mathrm{PO}_{4} @ U M O F N s$ & Visible light & $\begin{array}{c}\text { Phenol } \\
\text { BPA }\end{array}$ & $\mathrm{h}^{+}$ & $\begin{array}{l}100 \\
98.9\end{array}$ & [307] \\
\hline UMOFN $/ \mathrm{Ag}_{3} \mathrm{PO}_{4}$ & Visible light & 2-CP & $\mathrm{h}^{+}$ & 一 & [308] \\
\hline
\end{tabular}

electron transmission between AgBr and ZIF-8 smooth. On the other hand, MB also had a sensitizing effect. Therefore, the electrons accumulated in the CB of ZIF-8 fully reacted with

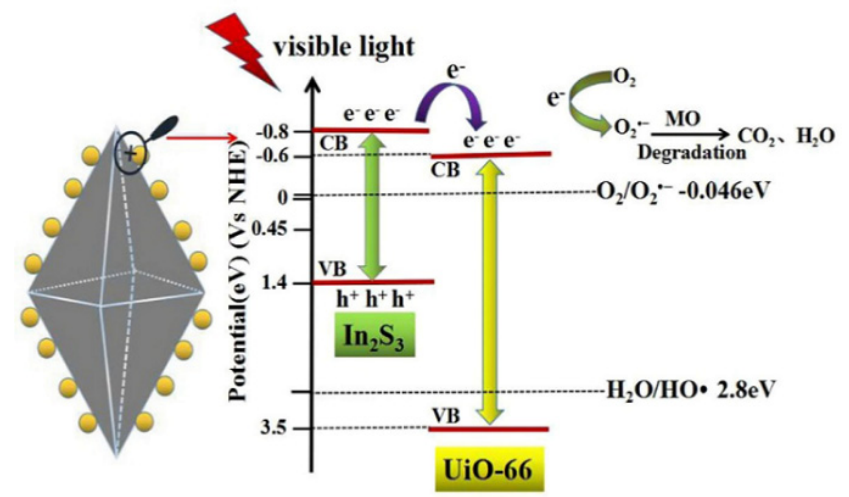

Fig. 40. Photocatalysis mechanism for the photodegradation of MO over ISU-40\%. Reprinted with permission from Ref. [281]. Copyright (2019) Elsevier. oxygen to generate $\mathrm{O}_{2}{ }^{-}$(Fig. 41). Many MOF-based photocatalytic materials have been reported to be used in the process of photocatalytic degradation of organic pollutant, and $\mathrm{O}_{2} \cdot-$ have transformed the main degradation effect [287-290].

\subsubsection{Oxidation induced degradation}

The degradation induced by the oxidation process is mainly dependent on $\mathrm{h}^{+}$and $\bullet \mathrm{OH}$. Holes are strong oxidants that can directly oxidize pollutants. Sometimes holes will react with $\mathrm{H}_{2} \mathrm{O}$ to generate $\bullet \mathrm{OH}$, and then $\bullet \mathrm{OH}$ will attack pollutants and degrade them into $\mathrm{CO}_{2}, \mathrm{H}_{2} \mathrm{O}$ and et al. Hence, the effective separation of electron-hole pairs and the number of $\bullet \mathrm{OH}$ become the key to the photodegradation efficiency. The specific process is as follows:

Organic pollutant + MOFs-based photocatalysts $\left(\mathrm{h}^{+\mathrm{VB}}\right)$
$\rightarrow$ Oxidation Products MOFs-based photocatalysts $\left(h^{+V B}\right)+\mathrm{H}_{2} \mathrm{O}$ $\rightarrow$ MOFs-based photocatalysts $+\mathrm{H}^{-}+\bullet \mathrm{OH}$

$\bullet \mathrm{OH}+$ Organic pollutant $\rightarrow$ Metabolites $\rightarrow \mathrm{CO}_{2}+\mathrm{H}_{2} \mathrm{O}+\ldots$ 


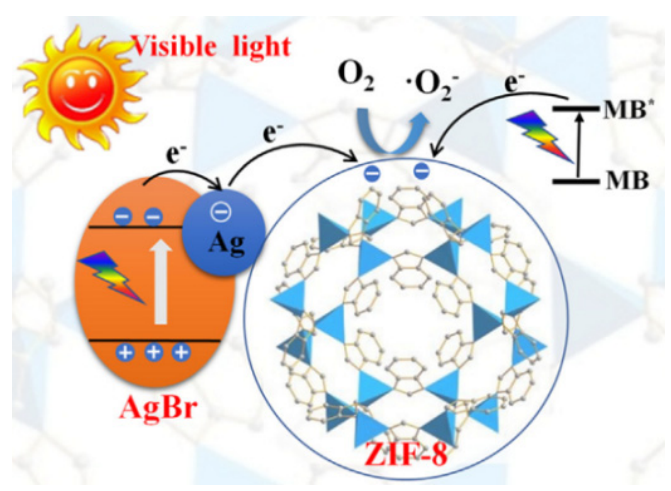

Fig. 41. Photocatalytic mechanism of AgBr/ZIF-8. Reprinted with permission from Ref. [286]. Copyright (2020) Elsevier.

Appropriate integration of MOF with carbonaceous material (graphene/carbonitride/ carbon quantum dots) will further facilitate interfacial contact, electron transport, photogenic electron/hole pairs, and provide additional catalytic sites for the target reaction. Yang and co-workers [291] synthesized MIL-68(In)- $\mathrm{NH}_{2} / \mathrm{GrO}$ by solvothermal, which could degrade 93\% amoxicillin (AMX) in 120 min. After the GrO modification, the MIL-68(In)- $\mathrm{NH}_{2} / \mathrm{GrO}$ had a higher valence band potential, which provided a higher photocatalytic oxidation capacity for the degradation of AMX. Utilizing the excellent electronic conductivity of $\pi$-conjugated g- $\mathrm{C}_{3} \mathrm{~N}_{4}$ can improve the degradation performance of MIL-68(In)- $\mathrm{NH}_{2}$ to IBP [292]. From the perspective of composite materials with different g- $\mathrm{C}_{3} \mathrm{~N}_{4}$ content, g- $\mathrm{C}_{3} \mathrm{~N}_{4} / \mathrm{MIL}-68(\mathrm{In})-\mathrm{NH}_{2}-3$ had the highest degradation rate for IBP. And the photocatalytic efficiency was maintained after the fifth operation. Good energy band structure matching made a heterojunction formed between $\mathrm{g}-\mathrm{C}_{3} \mathrm{~N}_{4}$ and MIL-68(In)- $\mathrm{NH}_{2}$, which significantly improved the separation efficiency of electron-hole pairs, thereby providing more $\mathrm{h}^{+}$for IBP degradation. Carbon quantum dots (CQDs) have the ability to collect near-infrared light and convert it into visible light. Wang et al. have reported that CQDs/ $\mathrm{NH}_{2}$-MIL-125, resulting in the removal of $100 \% \mathrm{RhB}$ [293]. This work affords insights for the construction of high-efficiency photocatalysts with broad-spectrum response.

MOF as a matrix for encapsulating noble metals is a hot spot of investigation. For example, Miao et al. prepared Pt/MIL-125(Ti) by solvothermal to establish the Schottky junction interface ( I ), and then introduced Ag onto the surface of Pt/MIL-125(Ti), forming an interface (II) with the surface plasmon resonance [132]. Pt/MIL-125(Ti)/Ag showed high photocatalytic activity for KP degradation. The Pt on the outermost surface of the catalyst had a stronger electron absorption capacity than oxygen, so $\mathrm{O}_{2}{ }^{\cdot-}$ cannot be generated at LUMO. On the contrary, the $\mathrm{h}^{+}$at HOMO reacted with $\mathrm{H}_{2} \mathrm{O}$ to form $\bullet \mathrm{OH}$, and the $\bullet \mathrm{OH}$ completed the degradation of $\mathrm{KP}$. It was reported that the efficient degradation of $\mathrm{MB}$ by $\mathrm{Ag}$ NPs@MIL-100(Fe)/GG was also caused by •OH [294]. It is a meaningful study to control charge flow by plasmonic effect. Huang and Liu synthesized Ag/AgCl@MIL-88A(Fe) (ACMA) through integrating the plasmon effect into MIL-88A(Fe) [295]. After $3.5 \mathrm{~h}$, ACMA-2 could completely degrade IBA and fol- lowed pseudo-first order kinetics. The electrons generated by $\mathrm{Ag}$ nanoparticles were transferred to the $\mathrm{CB}$ of $\mathrm{AgCl}$, while the photoexcited electrons of MIL-88A(Fe) combined with the $\mathrm{h}^{+}$of $\mathrm{Ag}$ to avoid the recombination of electron-hole pairs in MIL-88A(Fe). Therefore, the $\mathrm{h}^{+}$of MIL-88A(Fe) participated in the degradation of IBA.

Some researchers have tried to integrate metal oxides with semiconducting properties into MOFs nanostructures in order to achieve the goal of efficiently degrading pollutants [296-298]. $\mathrm{TiO}_{2}$ had been immobilized in the inner of

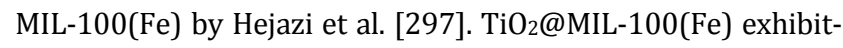
ed high photocatalytic decomposition of MB dye, which was much better than $\mathrm{TiO}_{2}$ and MIL-100(Fe). Another MIL-53(Al)/ZnO was design by Samy and co-workers through hydrothermal method [298], which achieved $93.5 \%$ TMP degradation in $240 \mathrm{~min}$.

Although Ui0-66 cannot be excited under visible light, its structure shows good hydrothermal and chemical stability, so researchers are committed to improving its performance so that it can play a role in photocatalytic degradation. UiO-66- $\mathrm{NH}_{2}$ has better visible light absorption than UiO-66, so there are more reports on UiO-66- $\mathrm{NH}_{2}$ composite materials. For instance, UiO-66- $\mathrm{NH}_{2} / \mathrm{Bi}_{2} \mathrm{WO}_{6}$ complex showed high photocatalytic activity for RhB degradation [299]. Although both $\mathrm{O}_{2}{ }^{--}$and $\mathrm{h}^{+}$were involved in the degradation process, the remaining $\mathrm{h}^{+}$in $\mathrm{Bi}_{2} \mathrm{WO}_{6}$ oxidized more $\mathrm{RhB}$ on account of sufficient positive VB potential. Subudhi constructed the p-n heterojunction utilizing the $\mathrm{Co} / \mathrm{Ti}-\mathrm{O}-\mathrm{N}$ bond between $\mathrm{CoTiO}_{3}$ and UiO-66- $\mathrm{NH}_{2}$ [300]. The $\mathrm{pH}$ of NFX in the solution was 6.8, and the surface of $\mathrm{CoTiO}_{3}$ / UiO-66- $\mathrm{NH}_{2}$ was cationic, so the electrostatic interaction enabled NFX to be quickly adsorbed on the catalyst surface, and the $\bullet \mathrm{OH}$ formed at the VB of catalyst played a key role in the photodegradation of NFX. It was also reported that the photocatalytic activities of the $\mathrm{NH}_{2}$-UiO-66/ZnIn $2 \mathrm{~S}_{4}$ [301] and MWCNT/N-TiO $2 / \mathrm{UiO}-66-\mathrm{NH}_{2}$ [302] composites were primarily affected by the $\mathrm{h}^{+}$or $\bullet \mathrm{OH}$.

The doping of metals may cause a new doping level between the LUMO and HOMO levels of the MOF, thus effectively separating electron hole pairs. Ao et al. confirmed this by $\mathrm{Cu}-\mathrm{NH}_{2}$-MIL-125(Ti) [303]. Improvement of Cu-NH2-MIL-125(Ti) performance was not only because of the improved light absorption capacity, but more importantly because the reduction potential of $\mathrm{Cu}^{+} / \mathrm{Cu}^{2+}$ was lower than the LUMO level of $\mathrm{NH}_{2}$-MIL-125. While photogenic electrons were captured through the $\mathrm{Cu}^{2+}$ doping site, the $\mathrm{h}^{+}$reacted with the adsorptive $\mathrm{H}_{2} \mathrm{O}$ to produce $\bullet \mathrm{OH}$ radical or directly taked part in the oxidation of pollutants.

In addition, there are some other examples where MOF and semiconductor materials have achieved effective separation of electron hole pairs, such as CdS/MIL-53(Fe) [304], $\mathrm{In}_{2} \mathrm{~S}_{3} / \mathrm{MIL}-100(\mathrm{Fe}) \quad[305], \quad \mathrm{Ag}_{3} \mathrm{VO}_{4} @ \mathrm{MIL}-125-\mathrm{NH}_{2} \quad$ [306], $\mathrm{Ag}_{3} \mathrm{PO}_{4} @ U M O F N s$ [307] and UMOFN/Ag $/ \mathrm{PO}_{4}$ [308] etc.

\section{Conclusions and perspective}

In conclusion, conversion technology of solar energy ground on MOFs-based photocatalysts play the leading role in settling 
environmental and energy problems. In the process of designing the MOF structure, we can consider the synthesis of the target MOF from the aspects of stability, band structure design, adsorption center, and conductivity. It is worth noting that the current research on pristine MOFs photocatalysts is mainly concentrated in a few "star" MOFs, such as PCN series, UiO series, MIL series and ZIF series. However, in general, the original MOF has no redox activity and can hardly respond to visible light. Therefore, more research has focused on the modification of MOFs: cocatalyst loading, construction of heterojunction, ligand or metal center modification.

When designing the structure of MOF, we should first consider the active sites of MOF, like metal nodes, organic ligands, and guest species. Based on the principle of regulating the photocatalytic ability of MOFs-based photocatalysts by adjusting their active sites, the functional design of MOFs photocatalysts can be carried out in the following three ways: (1) Selecting functional metal nodes or organic ligands as the activity Sites; (2) Introducing active sites into MOFs-based photocatalysts through direct synthesis or post-modification methods to design and adjust the structure and function; (3) Adding defects to MOF can provide characteristics such as porosity, active catalytic sites, and even charge transport. With the deepening of the research, more and more MOFs-based photocatalysts have been successfully put into use in photocatalytic degradation, photocatalytic water production to hydrogen/oxygen production, photocatalytic total water decomposition and photocatalytic $\mathrm{CO}_{2}$ reduction. However, there are many problems with MOFs as a photocatalyst. First of all, in previous reports, MOFs have been studied as semiconductors. In fact, MOFs, as an infinite network structure of alternating inorganic-organic arrangements, do not exhibit clear semiconductor properties in many aspects. At the same time, due to the large binding energy of excitons in pure organic semiconductors, electrons and holes are not easy to separate, so a large number of excitons and a significant exciton energy transfer process can be generated. The existence of a large number of organic ligands in MOFs-based photocatalysts makes the study of exciton effects in the photocatalytic process of MOFs require more attention. The structure composition of MOFs is relatively fixed. The organic ligands used by traditional MOFs materials are mostly aromatic carboxylate, imidazole and porphyrin macromolecules, etc., and the metal ions are mostly transition metal elements, lanthanide metals or main group metals. However, the metal nodes of MOFs-based photocatalysts mostly choose $\mathrm{Zr}$ and $\mathrm{Ti}$, and the organic ligands mostly choose porphyrin macromolecules. Therefore, when screening new MOFs photocatalyst materials, it is necessary to find new metal sites or organic ligands.

MOFs-based photocatalysts are characterized by structural complexity and diversity as well as high degree of functionalization, so it is challenging to establish the structure-activity relationship. At present, the research of MOF is developing towards the synthesis of MOF with more complex structure, stronger function and more stable and the performance research oriented to practical application. For example, the synthesis of MOF with the goal of $\mathrm{CO}_{2}$ capture not only pursues high selectivity and large working capacity, but also considers desorption energy of $\mathrm{CO}_{2}$ and water stability of materials. MOF with the same crystal structure but different connecting nodes have different properties. Although different MOF types have been studied, there is still space to study the interaction and activation of substrate by size, charge, electronegativity, etc. And providing homogeneous pore size and ordered mesoporous in the frame remains a challenge. Therefore, the current MOF synthesis has been closely combined with the application, and the performance research of MOF has become the focus. Meanwhile, it has become an important research field to find the application of MOF in practice.

The application of MOFs-based photocatalysts involved in this review focuses on photoreduction of $\mathrm{CO}_{2}$, photocatalytic water splitting, and degradation of organic pollutants. On the one hand, the degradation of organic pollution based on MOFs-based photocatalysts depends significantly on the optical absorption and charge separation efficiency and the number of catalytic sites, which are related to the central metal, the MOF structure, the degree of conjugation, the coordination environment and spatial steric around the active metal center. On the other hand, MOFs have been proven to be the general material for the hydrogen production and photoreduction of $\mathrm{CO}_{2}$. The photocatalytic efficiency of MOFs-based photocatalysts is affected by band gap, HOMO-LUMO band position, active site number and charge separation/transfer and light absorption in charge separation/transfer efficiency. The main product of MOF-based photocatalysts for photocatalytic $\mathrm{CO}_{2}$ reduction is $\mathrm{C} 1$ chemicals, rather than the more valuable $\mathrm{C} 2+$ products. It is very important to use situ characterization, such as in-situ Raman, in-situ XAFS, in-situ FT-IR, etc., to clarify the reaction mechanism. The systematic understanding of reaction path and reaction mechanism is helpful for the rational design of photocatalytic materials.

However, there are still some challenges in the design of MOFs-based photocatalysts, including: (1) In the semi-industrial scale production process of MOFs-based photocatalysts, high yield is guaranteed while the original structure of MOFs-based photocatalysts is maintained; (2) Considering that the size of nano MOFs-based photocatalysts has an important effect on catalytic activity, homogeneous nano MOFs-based photocatalysts with good monodispersity should be more developed; (3) One of the main factors limiting the practical application of MOFs-based photocatalysts is its stability. However, many so-called "stable MOFs" are not as stable as other inorganic or organic porous materials. Develop a MOFs-based photocatalysts that is stable under different conditions to better utilize the advantages of MOFs-based photocatalysts in the emerging potential applications; (4) How to accurately incorporate defects into MOFs-based photocatalysts, and how to comprehensively control the concentration of defects and the chemical properties of defects are also the focus of our future research.

\section{References}

[1] L. Jiao, Y. Wang, H. L. Jiang, Q. Xu, Adv. Mater., 2018, 30, 


\title{
Graphical Abstract
}

\author{
Chin. J. Catal., 2021, 42: 872-903 doi: 10.1016/S1872-2067(20)63715-9
}

Design of metal-organic frameworks (MOFs)-based photocatalyst for solar fuel production and photo-degradation of pollutants

Xiaoxue Zhao, Jinze Li, Xin Li, Pengwei Huo *, Weidong Shi * Jiangsu University

The design factors of MOFs-based photocatalysts and strategies to improve the activity of MOFs-based photocatalysts are discussed, and their application progress and challenges in reducing $\mathrm{CO}_{2}$, decomposing water and degrading organic pollutants are summarized.

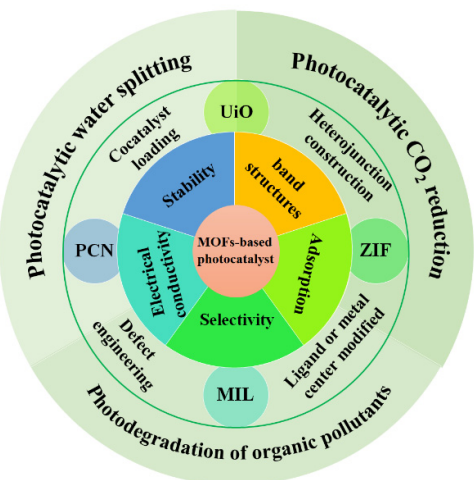

1703663-1703685.

[2] K. Huang, S. Guo, R. Y. Wang, S. Lin, N. Hussain, H. B. Wei, B. H. Deng, Y. Z. Long, M. Lei, H. L. Tang, H. Wu, Chin. J. Catal., 2020, 41, 1754-1760.

[3] W. Wang, X. Xu, W. Zhou, Z. Shao, Adv. Sci., 2017, 4, 1600371-1600391.

[4] S. N. Zhao, X. Z. Song, S. Y. Song, H. J. Zhang, Coord. Chem. Rev., 2017, 337, 80-96.

[5] C. Petit, Curr. Opin. Chem. Eng., 2018, 20, 132-142.

[6] J. R. Li, J. Sculley, H. C. Zhou, Chem. Rev., 2012, 112, 869-932.

[7] P. Horcajada, R. Gref, T. Baati, P. K. Allan, G. Maurin, P. Couvreur, G. Ferey, R. E. Morris, C. Serre, Chem. Rev., 2012, 112, 1232-1268.

[8] F. Y. Yi, D. Chen, M. K. Wu, L. Han, H. L. Jiang, ChemPlusChem, 2016, 81, 675-690.

[9] X. Yu, L. Wang, S. M. Cohen, CrystEngComm, 2017, 19, 4126-4136.

[10] K. Meyer, M. Ranocchiari, J. A. Van Bokhoven, Energy Environ. Sci., 2015, 8, 1923-1937.

[11] Y. Chen, D. Wang, X. Deng, Z. Li, Catal. Sci. Technol., 2017, 7, 4893-4904.

[12] X. Deng, Z. Li, H. Garcia, Chem. Eur. J., 2017, 23, 11189-11209.

[13] A. Dhakshinamoorthy, Z. Li, H. Garcia, Chem. Soc. Rev., 2018, 47, 8134-8172.

[14] M. Wen, G. Li, H. Liu, J. Chen, T. An, H. Yamashita, Environ. Sci. Nano, 2019, 6, 1006-1025.

[15] R. Li, W. Zhang, K. Zhou, Adv. Mater., 2018, 30, 1705512-1705542.

[16] M. Kalaj, K.C. Bentz, S. Ayala, Jr., J. M. Palomba, K. S. Barcus, Y. Katayama, S. M. Cohen, Chem. Rev., 2020, 120, 8267-8302.

[17] P. Horcajada, S. Surble, C. Serre, D. Y. Hong, Y. K. Seo, J. S. Chang, J. M. Greneche, I. Margiolaki, G. Ferey, Chem. Commun., 2007, 2820-2822.

[18] M. Eddaoudi, J. Kim, N. Rosi, D. Vodak, J. Wachter, M. Okeeffe, O. M. Yaghi, Science, 2002, 295, 469-472.

[19] B. Wang, A. P. Cote, H. Furukawa, M. O'Keeffe, O. M. Yaghi, Nature, 2008, 453, 207-211.

[20] P. S. Bárcia, D. Guimarães, P. A. P. Mendes, J. A. C. Silva, V. Guillerm, H. Chevreau, C. Serre, A. E. Rodrigues, Microporous Mesoporous Mater., 2011, 139, 67-73.

[21] D. Feng, Z. Y. Gu, J. R. Li, H. L. Jiang, Z. Wei, H. C. Zhou, Angew. Chem. Int. Ed., 2012, 51, 10307-10310.

[22] Y. C. Qiu, S. Yuan, X. X. Li, D. Y. Du, C. Wang, J. S. Qin, H. F. Drake, Y. Q. Lan, L. Jiang, H. C. Zhou, J. Am. Chem. Soc., 2019, 141,
13841-13848.

[23] C. G. Silva, I. Luz, F. X. Llabres i Xamena, A. Corma, H. Garcia, Chem. Eur. J., 2010, 16, 11133-11138.

[24] W. G. Lu, Z. W. Wei, Z. Y. Gu, T. F. Liu, J. Park, J. Y. Park, J. Tian, M. W. Zhang, Q. Zhang, T. Gentle, M. Bosch, H. C. Zhou, Chem. Soc. Rev., 2014, 43, 5561-5593.

[25] J. D. Evans, C. J. Sumby, C. J. Doonan, Chem. Soc. Rev., 2014, 43, 5933-5951.

[26] J. Hu, Y. Liu, J. Liu, C. Gu, D. Wu, Fuel, 2018, 226, 591-597.

[27] S. S. Chen, C. H. Wang, M. Zhang, W. X. Zhang, J. W. Qi, X. Y. Sun, L. J. Wang, J. S. Li, J. Hazard. Mater., 2020, 390, 122157-122164.

[28] Y. Y. Tong, Y. F. Li, L. Sun, R. Yang, S. Zhang, Y. Fu, L. Cao, R. Chen, Sep. Purif. Technol., 2020, 250, 117142-117150.

[29] L. Liu, W. Cui, C. Lu, A. Zain, W. Zhang, G. Shen, S. Hu, X. Qian, J. Environ. Manage., 2020, 268, 110630-110638.

[30] T. Matemb Ma Ntep, H. Breitzke, L. Schmolke, C. Schlüsener, B. Moll, S. Millan, N. Tannert, I. El Aita, G. Buntkowsky, C. Janiak, Chem. Mater., 2019, 31, 8629-8638.

[31] S. L. Xie, F. Li, S. X. Xu, J. Y. Li, W. Zeng, Chin. J. Catal., 2019, 40, 1205-1211.

[32] Z. H. Xiang, S. Y. Kang, X. Y. Feng, H. J. Mu, Y. X. Cai, Mater. Chem. Phys., 2020, 244, 122705-122709.

[33] K. Berijani, A. Morsali, J. Catal., 2019, 378, 28-35.

[34] K. D. Nguyen, S. Ehrling, I. Senkovska, V. Bon, S. Kaskel, J. Catal., 2020, 386, 106-116.

[35] A. M. Shultz, O. K. Farha, J. T. Hupp, S. T. Nguyen, J. Am. Chem. Soc., 2009, 131, 4204-4205.

[36] Y. Y. Liu, S. Y. Moon, J. T. Hupp, O. K. Farha, ACS Nano, 2015, 9, 12358-12364.

[37] P. Horcajada, S. Surble, C. Serre, D. Y. Hong, Y. K. Seo, J. S. Chang, J. M. Greneche, I. Margiolaki, G. Ferey, Chem. Commun., 2007, 2820-2822.

[38] M. Eddaoudi, J. Kim, N. Rosi, D. Vodak, J. Wachter, M. Okeeffe, O. M. Yaghi, Science, 2002, 295, 469-472.

[39] B. Wang, A. P. Cote, H. Furukawa, M. O'Keeffe, O. M. Yaghi, Nature, 2008, 453, 207-211.

[40] D. Zou, D. Liu, Mater. Today Chem., 2019, 12, 139-165.

[41] D. Feng, Z. Y. Gu, J. R. Li, H. L. Jiang, Z. Wei, H. C. Zhou, Angew. Chem. Int. Ed., 2012, 51, 10307-10310.

[42] Y. C. Qiu, S. Yuan, X. X. Li, D. Y. Du, C. Wang, J. S. Qin, H. F. Drake, Y. Q. Lan, L. Jiang, H. C. Zhou, J. Am. Chem. Soc., 2019, 141, 
13841-13848.

[43] C. Gomes Silva, I. Luz, F. X. Llabres i Xamena, A. Corma, H. Garcia, Chem. Eur. J., 2010, 16, 11133-11138.

[44] H. Dong, X. Zhang, Y. Lu, Y. Yang, Y. P. Zhang, H. L. Tang, F. M. Zhang, Z. D. Yang, X. Sun, Y. Feng, Appl. Catal. B, 2020, 276, 119173-119180.

[45] D. N. Jiang, Y. Zhu, M. Chen, B. B. Huang, G. M. Zeng, D. L. Huang, B. Song, L. Qin, H. Wang, W. Wei, Appl. Catal. B, 2019, 255, 117746-117757.

[46] M. Kalaj, K. C. Bentz, S. Ayala, Jr., J. M. Palomba, K. S. Barcus, Y. Katayama, S. M. Cohen, Chem. Rev., 2020, 120, 8267-8302.

[47] J. Hafizovic Cavka, S. Jakobsen, U. Olsbye, N. Guillou, C. Lamberti, S. Bordiga, K. P. Lillerud, J. Am. Chem. Soc., 2008, 130, 13850-13851.

[48] N. Zhang, X. Zhang, C. Gan, J. Zhang, Y. Liu, M. Zhou, C. Zhang, Y. Fang, J. Photochem. Photobiol. A, 2019, 376, 305-315.

[49] Y. Lee, S. Kim, J. K. Kang, S. M. Cohen, Chem. Commun., 2015, 51, 5735-5738.

[50] C. Yang, W. Huang, L. C. da Silva, K. A. I. Zhang, X. Wang, Chem. Eur. J., 2018, 24, 17454-17458.

[51] Y. P. Wei, Y. Liu, F. Guo, X. Y. Dao, W. Y. Sun, Dalton Trans., 2019, 48, 8221-8226.

[52] S. Li, S. Sun, H. Wu, C. Wei, Y. Hu, Catal. Sci. Technol., 2018, 8, 1696-1703.

[53] M. A. Nasalevich, M. van der Veen, F. Kapteijn, J. Gascon, CrystEngComm, 2014, 16, 4919-4926.

[54] X. Mu, J. Jiang, F. Chao, Y. Lou, J. Chen, Dalton Trans., 2018, 47, 1895-1902.

[55] I. Stassen, M. Styles, G. Grenci, H. V. Gorp, W. Vanderlinden, S. D. Feyter, P. Falcaro, D. D. Vos, P. Vereecken, R. Ameloot, Nat. Mater., 2016, 15, 304-310.

[56] M. Zhu, S. R. Venna, J. B. Jasinski, M. A. Carreon, Chem. Mater., 2011, 23, 3590-3592.

[57] Y. N. Wu, M. Zhou, B. Zhang, B. Wu, J. Li, J. Qiao, X. Guan, F. Li, Nanoscale, 2014, 6, 1105-1112.

[58] Y. Pan, Y. Liu, G. Zeng, L. Zhao, Z. Lai, Chem. Commun., 2011, 47, 2071-2073.

[59] H. Yang, X. W. He, F. Wang, Y. Kang, J. Zhang, J. Mater. Chem., 2012, 22, 21849-21851.

[60] H. Park, D. Amaranatha Reddy, Y. Kim, R. Ma, J. Choi, T. K. Kim, K. S. Lee, Solid State Sci., 2016, 62, 82-89.

[61] H. P. Jing, C. C. Wang, Y. W. Zhang, P. Wang, R. Li, RSC Adv., 2014, 4, 54454-54462.

[62] C. Yuan, P. Cheng, J. Li, X. Gao, X. Gao, X. Wang, M. Jin, R. Nötzel, G. Zhou, Z. Zhang, J. Liu, Microporous Mesoporous Mater., 2019, 285, 13-20.

[63] D. Li, Q. Zhu, C. Han, Y. Yang, W. Jiang, Z. Zhang, J. Hazard. Mater., 2015, 285, 398-408.

[64] J. J. Zhang, X. Liu, T. Ye, G. P. Zheng, X. C. Zheng, P. Liu, X. X. Guan, J. Alloys Compd., 2017, 698, 819-827.

[65] C. C. Wu, X. M. Zhang, H. Q. Li, Z. X. Xia, S. S. Yu, S. L. Wang, G. Q. Sun, Chin. J. Catal., 2021, 42, 637-647.

[66] T. Guo, K. Wang, G. K. Zhang, X. Y. Wu, Appl. Surf. Sci., 2019, 469, 331-339.

[67] D. Wang, M. Wang, Z. Li, ACS Catal., 2015, 5, 6852-6857.

[68] B. Xu, Z. Chen, B. Han, C. Li, Catal. Commun., 2017, 98, 112-115.

[69] N. M. Mahmoodi, J. Abdi, M. Oveisi, M. Alinia Asli, M. Vossoughi, Mater. Res. Bull., 2018, 100, 357-366.

[70] D. Wang, F. Jia, H. Wang, F. Chen, Y. Fang, W. Dong, G. Zeng, X. Li, Q. Yang, X. Yuan, J. Colloid Interface Sci., 2018, 519, 273-284.

[71] X. Y. Dao, J. H. Guo, Y. P. Wei, F. Guo, Y. Liu, W. Y. Sun, Inorg. Chem., 2019, 58, 8517-8524.

[72] M. Vinodh, F. H. Alipour, A. A. Mohamod, T. F. Al-Azemi, Molecules,
2012, 17, 11763-11799.

[73] H. L. Li, M. Eddaoudi, M. Okeeffe, O. M. Yaghi, Nature, 1999, 402, 276-279.

[74] S. Yuan, T. F. Liu, D. Feng, J. Tian, K. Wang, J. Qin, Q. Zhang, Y. P. Chen, M. Bosch, L. Zou, S. J. Teat, S. J. Dalgarno, H. C. Zhou, Chem. Sci., 2015, 6, 3926-3930.

[75] H. Q. Xu, J. Hu, D. Wang, Z. Li, Q. Zhang, Y. Luo, S. H. Yu, H. L. Jiang, J. Am. Chem. Soc., 2015, 137, 13440-13443.

[76] J. S. Qin, S. Yuan, L. Zhang, B. Li, D. Y. Du, N. Huang, W. Guan, H. F. Drake, J. Pang, Y. Q. Lan, A. Alsalme, H. C. Zhou, J. Am. Chem. Soc., 2019, 141, 2054-2060.

[77] C. M. Thompson, F. Li, R. A. Smaldone, Chem. Commun., 2014, 50, 6171-6173.

[78] A. A. K. Karunathilake, J. Chang, C. M. Thompson, C. U. Nguyen, D. Q. Nguyen, A. Rajan, A. Sridharan, M. Vyakaranam, N. Adegboyega, S. J. Kim, R. A. Smaldone, RSC Adv., 2016, 6, 65763-65769.

[79] H. L. Li, M. Eddaoudi, M. O'Keeffe, O. M. Yaghi, Nature, 1999, 402, 276-279.

[80] W. Morris, B. Volosskiy, S. Demir, F. Gandara, P. L. McGrier, H. Furukawa, D. Cascio, J. F. Stoddart, O. M. Yaghi, Inorg. Chem., 2012, 51, 6443-6445.

[81] K. Wang, X. L. Lv, D. Feng, J. Li, S. Chen, J. Sun, L. Song, Y. Xie, J. R. Li, H. C. Zhou, J. Am. Chem. Soc., 2016, 138, 914-919.

[82] H. Kim, S. Yang, S. R. Rao, S. Narayanan, E. A. Kapustin, H. Furukawa, A. S. Umans, O. M. Yaghi, E. N. Wang, Science, 2017, 356, 430-434.

[83] J. J. Low, A. I. Benin, P. Jakubczak, J. F. Abrahamian, S. A. Faheem, R. R. Willis, J. Am. Chem. Soc., 2009, 131, 15834-15842.

[84] Y. Bai, Y. Dou, L. H. Xie, W. Rutledge, J. R. Li, H. C. Zhou, Chem. Soc. Rev., 2016, 45, 2327-2367.

[85] B. Wang, Q. Yang, C. Guo, Y. Sun, L. H. Xie, J. R. Li, ACS Appl. Mater. Interfaces, 2017, 9, 10286-10295.

[86] Z. Chen, S. L. Hanna, L. R. Redfern, D. Alezi, T. Islamoglu, O. K. Farha, Coord. Chem. Rev., 2019, 386, 32-49.

[87] Y. Gao, J. Xia, D. Liu, R. Kang, G. Yu, S. Deng, Chem. Eng. J., 2019, $378,122118$.

[88] S. Lin, Y. Zhao, J. K. Bediako, C. W. Cho, A. K. Sarkar, C. R. Lim, Y. S. Yun, Chem. Eng. J., 2019, 362, 280-286.

[89] X. L. Lv, S. Yuan, L. H. Xie, H. F. Darke, Y. Chen, T. He, C. Dong, B. Wang, Y. Z. Zhang, J. R. Li, H. C. Zhou, J. Am. Chem. Soc., 2019, 141, 10283-10293.

[90] J. Hafizovic Cavka, S. Jakobsen, U. Olsbye, N. Guillou, C. Lamberti, S. Bordiga, K. P. Lillerud, J. Am. Chem. Soc., 2008, 130, 13850-3851.

[91] I. J. Kang, N. A. Khan, E. Haque, S. H. Jhung, Chem. Eur. J., 2011, 17, 6437-6442.

[92] H. Li, W. Shi, K. Zhao, H. Li, Y. Bing, P. Cheng, Inorg. Chem., 2012, 51, 9200-9207.

[93] T. Wu, L. Shen, M. Luebbers, C. Hu, Q. Chen, Z. Ni, R. I. Masel, Chem. Commun., 2010, 46, 6120-6122.

[94] C. Yang, U. Kaipa, Q. Z. Mather, X. Wang, V. Nesterov, A. F. Venero, M. A. Omary, J. Am. Chem. Soc., 2011, 133, 18094-18097.

[95] J. H. Wang, M. Li, D. Li, Chem. Eur. J., 2014, 20, 12004-12008.

[96] W. M. Liao, J. H. Zhang, Z. Wang, Y. L. Lu, S. Y. Yin, H. P. Wang, Y. N. Fan, M. Pan, C. Y. Su, Inorg. Chem., 2018, 57, 11436-11442.

[97] X. P. Wu, I. Choudhuri, D. G. Truhlar, Energy Environ. Mater., 2019, 2, 251-263.

[98] X. P. Wu, L. Gagliardi, D. G. Truhlar, J. Chem. Phys., 2019, 150, 041701-041708.

[99] C. C. Chueh, C. I. Chen, Y. A. Su, H. Konnerth, Y. J. Gu, C. W. Kung, K. C. W. Wu, J. Mater. Chem., 2019, 7, 17079-17095.

[100] U. Ryu, S. Jee, J. S. Park, I. K. Han, J. H. Lee, M. Park, K. M. Choi, ACS Nano, 2018, 12, 4968-4975. 
[101] H. Q. Pham, T. Mai, N.-N. Pham-Tran, Y. Kawazoe, H. Mizuseki, D. Nguyen-Manh, J. Phys. Chem. C, 2014, 118, 4567-4577.

[102] T. Musho, J. Li, N. Wu, Phys. Chem. Chem. Phys., 2014, 16, 23646-23653.

[103] C. H. Hendon, D. Tiana, M. Fontecave, C. Sanchez, L. D'Arras, C. Sassoye, L. Rozes, C. Mellot-Draznieks, A. Walsh, J. Am. Chem. Soc., 2013, 135, 10942-10945.

[104] O. K. Farha, I. Eryazici, N. C. Jeong, B. G. Hauser, C. E. Wilmer, A. A. Sarjeant, R. Q. Snurr, S. T. Nguyen, A. O. Yazaydin, J. T. Hupp, J. Am. Chem. Soc., 2012, 134, 15016-15021.

[105] J. R. Li, Y. G. Ma, M. C. McCarthy, J. Sculley, J. M. Yu, H.-K. Jeong, P. B. Balbuena, H. C. Zhou, Coord. Chem. Rev., 2011, 255, 1791-1823.

[106] Y. Fu, D. Sun, Y. Chen, R. Huang, Z. Ding, X. Fu, Z. Li, Angew. Chem. Int. Ed., 2012, 51, 3364-3367.

[107] D. Sun, Y. Fu, W. Liu, L. Ye, D. Wang, L. Yang, X. Fu, Z. Li, Chem. Eur. J., 2013, 19, 14279-14285.

[108] Y. Liu, Y. Yang, Q. Sun, Z. Wang, B. Huang, Y. Dai, X. Qin, X. Zhang, ACS Appl. Mater. Interfaces, 2013, 5, 7654-7658.

[109] X. C. Huang, Y. Y. Lin, J. P. Zhang, X. M. Chen, Angew. Chem. Int. Ed., 2006, 45, 1557-1559.

[110] X. Wang, J. Liu, S. Leong, X. Lin, J. Wei, B. Kong, Y. Xu, Z. X. Low, J. Yao, H. Wang, ACS Appl. Mater. Interfaces, 2016, 8, 9080-9087.

[111] L. Lin, T. Zhang, H. Liu, J. Qiu, X. Zhang, Nanoscale, 2015, 7, 7615-7623.

[112] C. H. Kuo, Y. Tang, L. Y. Chou, B. T. Sneed, C. N. Brodsky, Z. Zhao, C. K. Tsung, J. Am. Chem. Soc., 2012, 134, 14345-14348.

[113] S. Wang, Z. H. Zhu, A. Coomes, F. Haghseresht, G. Q. Lu, J. Colloid Interface Sci., 2005, 284, 440-446.

[114] M. Zeng, Z. Chai, X. Deng, Q. Li, S. Feng, J. Wang, D. Xu, Nano Res., 2016, 9, 2729-2734.

[115] C. Janiak, J. K. Vieth, New J. Chem., 2010, 34, 2366-2388.

[116] C. F. Leong, B. Chan, T. B. Faust, D. M. D'Alessandro, Chem. Sci., 2014, 5, 4724-4728.

[117] L. S. Xie, E. V. Alexandrov, G. Skorupskii, D. M. Proserpio, M. Dinca, Chem. Sci., 2019, 10, 8558-8565.

[118] L. S. Xie, L. Sun, R. Wan, S. S. Park, J. A. DeGayner, C. H. Hendon, M. Dinca, J. Am. Chem. Soc., 2018, 140, 7411-7414.

[119] Y. Kobayashi, B. Jacobs, M. D. Allendorf, J. R. Long, Chem. Mater., 2010, 22, 4120-4122.

[120] P. I. Scheurle, A. Mähringer, A. C. Jakowetz, P. Hosseini, A. F. Richter, G. Wittstock, D. D. Medina, T. Bein, Nanoscale, 2019, 11, 20949-20955.

[121] T. C. Narayan, T. Miyakai, S. Seki, M. Dinca, J. Am. Chem. Soc., 2012, 134, 12932-12935.

[122] L. Sun, C. H. Hendon, M. A. Minier, A. Walsh, M. Dinca, J. Am. Chem. Soc., 2015, 137, 6164-6167.

[123] Q. L. Zhu, Q. Xu, Chem. Soc. Rev., 2014, 43, 5468-5512.

[124] T. Toyao, M. Saito, Y. Horiuchi, K. Mochizuki, M. Iwata, H. Higashimura, M. Matsuoka, Catal. Sci. Technol., 2013, 3, 2092-2097.

[125] S. Bai, Y. Xiong, Chem. Commun., 2015, 51, 10261-10271.

[126] S. Bai, W. Jiang, Z. Li, Y. Xiong, ChemNanoMat, 2015, 1, 223-239.

[127] Q. Zhai, S. Xie, W. Fan, Q. Zhang, Y. Wang, W. Deng, Y. Wang, Angew. Chem. Int. Ed., 2013, 52, 5776-5779.

[128] S. Bai, X. Wang, C. Hu, M. Xie, J. Jiang, Y. Xiong, Chem. Commun., 2014, 50, 6094-6097.

[129] S. Chen, S. Shen, G. Liu, Y. Qi, F. Zhang, C. Li, Angew. Chem. Int. Ed., 2015, 54, 3047-3051.

[130] K. Rui, G. Zhao, M. Lao, P. Cui, X. Zheng, X. Zheng, J. Zhu, W. Huang, S. X. Dou, W. Sun, Nano Lett., 2019, 19, 8447-8453.

[131] A. Galin'ska, J. Walendziewski, Energy Fuels, 2005, 19,
1143-1147.

[132] S. Miao, H. Zhang, S. Cui, J. Yang, Chemosphere, 2020, 257, 127123-127133.

[133] J. Qiu, X. Zhang, K. Xie, X. F. Zhang, Y. Feng, M. Jia, J. Yao, J. Colloid Interface Sci., 2019, 538, 569-577.

[134] D. Sun, W. Liu, Y. Fu, Z. Fang, F. Sun, X. Fu, Y. Zhang, Z. Li, Chem. Eur. J., 2014, 20, 4780-4788.

[135] L. Shen, W. Wu, R. Liang, R. Lin, L. Wu, Nanoscale, 2013, 5, 9374-9382.

[136] L. Shen, L. Huang, S. Liang, R. Liang, N. Qin, L. Wu, RSC Adv., 2014, 4, 2546-2549.

[137] X. J. Wang, X. L. Zhao, D. Q. Zhang, G. S. Li, H. X. Li, Appl. Catal. B, 2018, 228, 47-53.

[138] R. Liang, L. Shen, F. Jing, N. Qin, L. Wu, ACS Appl. Mater. Interfaces, 2015, 7, 9507-9515.

[139] X. Li, Z. Le, X. Chen, Z. Li, W. Wang, X. Liu, A. Wu, P. Xu, D. Zhang, Appl. Catal. B, 2018, 236, 501-508.

[140] P. Karthik, R. Vinoth, P. Zhang, W. Choi, E. Balaraman, B. Neppolian, ACS Appl. Energy Mater., 2018, 1, 1913-1923.

[141] X. D. Du, X. H. Yi, P. Wang, J. G. Deng, C. C. Wang, Chin. J. Catal., 2019, 40, 70-79.

[142] S. J. A. Moniz, S. A. Shevlin, D. J. Martin, Z.-X. Guo, J. Tang, Energy Environ. Sci., 2015, 8, 731-759.

[143] H. Guo, H. Y. Niu, C. Liang, C. G. Niu, D. W. Huang, L. Zhang, N. Tang, Y. Yang, C. Y. Feng, G. M. Zeng, J. Catal., 2019, 370, 289-303.

[144] X. Zhang, Y. Yang, W. Huang, Y. Yang, Y. Wang, C. He, N. Liu, M. Wu, L. Tang, Mater. Res. Bull., 2018, 99, 349-358.

[145] W. Huang, N. Liu, X. Zhang, M. Wu, L. Tang, Appl. Surf. Sci., 2017, 425, 107-116.

[146] H. Jia, D. Ma, S. Zhong, L. Li, L. Li, L. Xu, B. Li, Chem. Eng. J., 2019, 368, 165-174.

[147] Y. Li, Y. Fang, Z. Cao, N. Li, D. Chen, Q. Xu, J. Lu, Appl. Catal. B, 2019, 250, 150-162.

[148] Y. Shiraishi, S. Kanazawa, Y. Kofuji, H. Sakamoto, S. Ichikawa, S. Tanaka, T. Hirai, Angew. Chem. Int. Ed., 2014, 53,13454-13459.

[149] L. Wang, P. Zheng, X. Zhou, M. Xu, X. Liu, J. Photochem. Photobiol. A, 2019, 376, 80-87.

[150] A. Crake, K. C. Christoforidis, A. Kafizas, S. Zafeiratos, C. Petit, Appl. Catal. B, 2017, 210, 131-140.

[151] C. Zhao, Z. Wang, X. Li, X. Yi, H. Chu, X. Chen, C. C. Wang, Chem. Eng. J., 2020, 389, 123431-123446.

[152] Y. C. Zhou, X. Y. Xu, P. Wang, H. Fu, C. Zhao, C. C. Wang, Chin. J. Catal., 2019, 40, 1912-1923.

[153] S. Subudhi, S. Mansingh, G. Swain, A. Behera, D. Rath, K. Parida, Inorg. Chem., 2019, 58, 4921-4934.

[154] B. B. Kale, J. O. Baeg, K. J. Kong, S. J. Moon, L. K. Nikam, K. R. Patil, J. Mater. Chem., 2011, 21, 2624-2631.

[155] Q. Chen, J. Li, L. Cheng, H. Liu, Chem. Eng. J., 2020, 379, 122389-122398.

[156] X. Li, Z. Zeng, G. Zeng, D. Wang, R. Xiao, Y. Wang, C. Zhou, H. Yi, S. Ye, Y. Yang, W. Xiong, J. Colloid Interface Sci., 2020, 561, 501-511.

[157] Q. Huang, Y. Hu, Y. Pei, J. Zhang, M. Fu, Appl. Catal. B, 2019, 259, 118106-118119.

[158] A. Iwase, Y. H. Ng, Y. Ishiguro, A. Kudo, R. Amal, J. Am. Chem. Soc., 2011, 133, 11054-11057.

[159] L. Xie, Z. Yang, W. Xiong, Y. Zhou, J. Cao, Y. Peng, X. Li, C. Zhou, R. Xu, Y. Zhang, Appl. Surf. Sci., 2019, 465, 103-115.

[160] C. Liang, C. G. Niu, X. J. Wen, S. F. Yang, M. C. Shen, G. M. Zeng, New J. Chem., 2017, 41, 5334-5346.

[161] Y. Pan, X. Yuan, L. Jiang, H. Wang, H. Yu, J. Zhang, Chem. Eng. J., 
2020, 384, 123310-123325.

[162] E. Akbarzadeh, H. Z. Soheili, M. Hosseinifard, M. R. Gholami, Mater. Res. Bull., 2020, 121, 110621-110627.

[163] J. Meng, Q. Chen, J. Lu, H. Liu, ACS Appl. Mater. Interfaces, 2019, $11,550-562$.

[164] Z. Wu, X. Huang, H. Zheng, P. Wang, G. Hai, W. Dong, G. Wang, Appl. Catal. B, 2018, 224, 479-487.

[165] C. Hu, Y. C. Huang, A. L. Chang, M. Nomura, J. Colloid Interface Sci., 2019, 553, 372-381.

[166] H. Huang, X. S. Wang, D. Philo, F. Ichihara, H. Song, Y. Li, D. Li, T. Qiu, S. Wang, J. Ye, Appl. Catal. B, 2020, 267, 118686-118692.

[167] D. Sun, W. Liu, M. Qiu, Y. Zhang, Z. Li, Chem. Commun., 2015, 51, 2056-2059.

[168] J. Tu, X. Zeng, F. Xu, X. Wu, Y. Tian, X. Hou, Z. Long, Chem. Commun., 2017, 53, 3361-3364.

[169] S. Wang, F. Meng, X. Sun, M. Bao, J. Ren, S. Yu, Z. Zhang, J. Ke, L. Zeng, Appl. Surf. Sci., 2020, 528, 147053-147063.

[170] H. Li, J. Zhang, Y. Yao, X. Miao, J. Chen, J. Tang, Environ. Pollut, 2019, 255, 113337-113345.

[171] S. Dissegna, K. Epp, W. R. Heinz, G. Kieslich, R. A. Fischer, Adv. Mater., 2018, 30, 1704501-1704523.

[172] Y. Fu, J. Wu, R. Du, K. Guo, R. Ma, F. Zhang, W. Zhu, M. Fan, RSC Adv., 2019, 9, 37733-37738.

[173] C. Avci, J. Arinez-Soriano, A. Carne-Sanchez, V. Guillerm, C. Carbonell, I. Imaz, D. Maspoch, Angew. Chem. Int. Ed., 2015, 54, 14417-14421.

[174] J. Koo, I. C. Hwang, X. Yu, S. Saha, Y. Kim, K. Kim, Chem. Sci., 2017, 8, 6799-6803.

[175] G. C. Shearer, S. Chavan, S. Bordiga, S. Svelle, U. Olsbye, K. P. Lillerud, Chem. Mater., 2016, 28, 3749-3761.

[176] H. Wu, Y. S. Chua, V. Krungleviciute, M. Tyagi, P. Chen, T. Yildirim, W. Zhou, J. Am. Chem. Soc., 2013, 135, 10525-10532.

[177] F. Vermoortele, B. Bueken, G. Le Bars, B. Van de Voorde, M. Vandichel, K. Houthoofd, A. Vimont, M. Daturi, M. Waroquier, V. Van Speybroeck, C. Kirschhock, D. E. De Vos, J. Am. Chem. Soc., 2013, 135, 11465-11468.

[178] E. Karamian, S. Sharifnia, J. $\mathrm{CO}_{2}$ Util., 2016, 16, 194-203.

[179] F. D. Meylan, V. Moreau, S. Erkman, J. $\mathrm{CO}_{2}$ Util., 2015, 12, 101-108.

[180] N. Shehzad, M. Tahir, K. Johari, T. Murugesan, M. Hussain, J. $\mathrm{CO}_{2}$ Util., 2018, 26, 98-122.

[181] G. R. Dey, J. Nat. Gas Chem., 2007, 16, 217-226.

[182] I. I. Alkhatib, C. Garlisi, M. Pagliaro, K. Al-Ali, G. Palmisano, Catal. Today, 2020, 340, 209-224.

[183] F. Fresno, I. J. Villar-Garcia, L. Collado, E. Alfonso-Gonzalez, P. Renones, M. Barawi, V. A. de la Pena O'Shea, J. Phys. Chem. Lett., 2018, 9, 7192-7204.

[184] J. Fu, K. Jiang, X. Qiu, J. Yu, M. Liu, Mater. Today, 2020, 32, 222-243.

[185] R. R. Rodrigues, C. M. Boudreaux, E. T. Papish, J. H. Delcamp, ACS Appl. Energy Mater., 2018, 2, 37-46.

[186] X. Chang, T. Wang, J. Gong, Energy Environ. Sci., 2016, 9, 2177-2196.

[187] Z. H. Yan, M. H. Du, J. Liu, S. Jin, C. Wang, G. L. Zhuang, X. J. Kong, L. S. Long, L. S. Zheng, Nat. Commun., 2018, 9, 3353-3360.

[188] M. Elcheikh Mahmoud, H. Audi, A. Assoud, T. H. Ghaddar, M. Hmadeh, J. Am. Chem. Soc., 2019, 141, 7115-7121.

[189] L. Li, S. Zhang, L. Xu, J. Wang, L. X. Shi, Z. N. Chen, M. Hong, J. Luo, Chem. Sci., 2014, 5, 3808-3813.

[190] J. Liu, Y. Z. Fan, X. Li, Z. Wei, Y. W. Xu, L. Zhang, C. Y. Su, Appl. Catal. B, 2018, 231, 173-181.

[191] D. Chen, H. Xing, C. Wang, Z. Su, J. Mater. Chem., 2016, 4,
$2657-2662$.

[192] L. Z. Dong, L. Zhang, J. Liu, Q. Huang, M. Lu, W. X. Ji, Y. Q. Lan, Angew. Chem. Int. Ed., 2020, 59, 2659-2663.

[193] Y. Lee, S. Kim, H. Fei, J. K. Kang, S. M. Cohen, Chem. Commun., 2015, 51, 16549-16552.

[194] Y. Liu, L. Deng, J. Sheng, F. Tang, K. Zeng, L. Wang, K. Liang, H. Hu, Y. N. Liu, Appl. Surf. Sci., 2019, 498, 143899-143906.

[195] H. Wang, D. Wu, C. Yang, H. Lu, Z. Gao, F. Xu, K. Jiang, J. CO ${ }_{2}$ Util., 2019, 34, 411-421.

[196] A. Zhou, Y. Dou, C. Zhao, J. Zhou, X. Q. Wu, J.-R. Li, Appl. Catal. B, 2020, 264, 118519-118526.

[197] Y. Xie, Z. Fang, L. Li, H. Yang, T. F. Liu, ACS Appl. Mater. Interfaces, 2019, 11, 27017-27023.

[198] X. K. Wang, J. Liu, L. Zhang, L. Z. Dong, S. L. Li, Y. H. Kan, D.-S. Li, Y. Q. Lan, ACS Catal., 2019, 9, 1726-1732.

[199] X. Y. Dao, X. F. Xie, J. H. Guo, X. Y. Zhang, Y. S. Kang, W. Y. Sun, ACS Appl. Energy Mater., 2020, 3, 3946-3954.

[200] D. Ding, Z. Jiang, J. Jin, J. Li, D. Ji, Y. Zhang, L. Zan, J. Catal., 2019, $375,21-31$.

[201] L. Ye, Y. Gao, S. Cao, H. Chen, Y. Yao, J. Hou, L. Sun, Appl. Catal. B, 2018, 227, 54-60.

[202] S. Wang, X. Wang, Appl. Catal. B, 2015, 162, 494-500.

[203] X. Gao, B. Guo, C. Guo, Q. Meng, J. Liang, J. Liu, ACS Appl. Mater. Interfacess, 2020, 12, 24059-24065.

[204] L. Wang, P. Jin, J. Huang, H. She, Q. Wang, ACS Sustainable Chem. Eng., 2019, 7, 15660-15670.

[205] L. Wang, P. Jin, S. Duan, H. She, J. Huang, Q. Wang, Sci. Bull., 2019, 64, 926-933.

[206] W. Zhu, C. Zhang, Q. Li, L. Xiong, R. Chen, X. Wan, Z. Wang, W. Chen, Z. Deng, Y. Peng, Appl. Catal. B, 2018, 238, 339-345.

[207] Q. Mu, W. Zhu, X. Li, C. Zhang, Y. Su, Y. Lian, P. Qi, Z. Deng, D. Zhang, S. Wang, X. Zhu, Y. Peng, Appl. Catal. B, 2020, 262, 118144-118122.

[208] S. S. Wang, H.H. Huang, M. Liu, S. Yao, S. Guo, J.W. Wang, Z. M. Zhang, T. B. Lu, Inorg. Chem., 2020, 59, 6301-6307.

[209] X. Chen, Q. Li, J. Li, J. Chen, H. Jia, Appl. Catal. B, 2020, 270, 118915-118925.

[210] H. J. Peng, L. Zhu, Y. L. Wang, H. Y. Chao, L. Jiang, Z. P. Qiao, Inorg. Chem. Commun., 2020, 117, 107943-107947.

[211] H. Zhao, X. S.Wang, J. F. Feng, Y. N. g Chen, X. Yang, S. Y. Gao, R. Cao, Catal. Sci. Technol, 2018, 8, 1288-1295.

[212] X. He, Z. Gan, S. Fisenko, D. Wang, H. M. El-Kaderi, W. N. Wang, ACS Appl. Mater. Interfaces, 2017, 9, 9688-9698.

[213] D. Li, M. Kassymova, X. Cai, S. Q. Zang, H. L. Jiang, Coord. Chem. Rev., 2020, 412, 213262-213277.

[214] S. N. Habisreutinger, L. Schmidt-Mende, J. K. Stolarczyk, Angew. Chem. Int. Ed., 2013, 52, 7372-7408.

[215] Y. Ma, Q. Tang, W. Y. Sun, Z. Y. Yao, W. Zhu, T. Li, J. Wang, Appl. Catal. B, 2020, 270, 118856-118864.

[216] J. Hu, J. Ding, Q. Zhong, J. Colloid Interface Sci., 2020, 560, 857-865.

[217] N. Sadeghi, S. Sharifnia, M. Sheikh Arabi, J. $\mathrm{CO}_{2}$ Util., 2016, 16, 450-457.

[218] Q. Huang, J. Liu, L. Feng, Q. Wang, W. Guan, L. Z. Dong, L. Zhang, L. K. Yan, Y. Q. Lan, H. C. Zhou, Natl. Sci. Rev., 2020, 7, 53-63.

[219] T. Takata, K. Domen, ACS Energy Lett., 2019, 4, 542-549.

[220] N. Xiao, S. S. Li, X. L. Li, L. Ge, Y. Q. Gao, N. Li, Chin. J. Catal., 2020, 41, 642-671.

[221] G. Colón, Appl. Catal. A, 2016, 518, 48-59.

[222] K. M. And, K. Domen, J. Phys. Chem. C, 2007, 111, 7851-7861.

[223] N. M. Gupta, Renewable Sustainable Energy Rev., 2017, 71, 585-601. 
[224] Y. An, Y. Liu, P. An, J. Dong, B. Xu, Y. Dai, X. Qin, X. Zhang, M. H. Whangbo, B. Huang, Angew. Chem. Int. Ed., 2017, 56, 3036-3040.

[225] S. Remiro-Buenamañana, M. Cabrero-Antonino, M. Martínez-Guanter, M. Álvaro, S. Navalón, H. García, Appl. Catal. B, 2019, 254, 677-684.

[226] A. Melillo, M. Cabrero-Antonino, S. Navalón, M. Álvaro, B. Ferrer, H. García, Appl. Catal. B, 2020, 278, 119345-119355.

[227] S. Subudhi, G. Swain, S. P. Tripathy, K. Parida, Inorg. Chem., 2020, 59, 9824-9837.

[228] G. Liu, P. Niu, L. Wang, G. Q. Lu, H.-M. Cheng, Catal. Sci. Technol., 2011, 1, 222-225.

[229] F. Zhang, B. Zhang, J. Feng, X. Tan, L. Liu, L. Liu, B. Han, L. Zheng, J. Zhang, J. Tai, J. Zhang, ACS Appl. Energy Mater., 2019, 2, 4964-4970.

[230] Y. An, Y. Liu, H. Bian, Z. Wang, P. Wang, Z. Zheng, Y. Dai, M. H. Whangbo, B. Huang, Sci. Bull., 2019, 64, 1502-1509.

[231] B. Zhang, J. Zhang, X. Tan, D. Shao, J. Shi, L. Zheng, J. Zhang, G. Yang, B. Han, ACS Appl. Mater. Interfaces, 2018, 10, 16418-16423.

[232] L. Sun, Y. Yuan, F. Wang, Y. Zhao, W. Zhan, X. Han, Nano Energy, 2020, 74, 104909-104916.

[233] H. Liu, J. Zhang, D. Ao, Appl. Catal. B, 2018, 221, 433-442.

[234] M. Naguib, M. Kurtoglu, V. Presser, J. Lu, J. Niu, M. Heon, L. Hultman, Y. Gogotsi, M. W. Barsoum, Adv. Mater., 2011, 23, 4248-4253.

[235] M. Naguib, O. Mashtalir, J. Carle, V. Presser, J. Lu, L. Hultman, Y. Gogotsi, M. W. Barsoum, ACS Nano, 2012, 6, 1322-1331.

[236] K. Nakamura, Y. Oaki, H. Imai, J. Am. Chem. Soc., 2013, 135, 4501-4508.

[237] S. Cong, Y. Tian, Q. Li, Z. Zhao, F. Geng, Adv. Mater., 2014, 26, 4260-4267.

[238] Z. Chen, L. Li, S. Cong, J. Xuan, D. Zhang, F. Geng, T. Zhang, Z. Zhao, Nano Lett., 2017, 17, 355-361.

[239] M. A. Lukowski, A. S. Daniel, F. Meng, A. Forticaux, L. Li, S. Jin, J. Am. Chem. Soc., 2013, 135, 10274-10277.

[240] P. Tian, X. He, L. Zhao, W. Li, W. Fang, H. Chen, F. Zhang, Z. Huang, H. Wang, Sol. Energy, 2019, 188, 750-759.

[241] P. Tian, X. He, L. Zhao, W. Li, W. Fang, H. Chen, F. Zhang, Z. Huang, H. Wang, Int. J. Hydrogen Energy, 2019, 44, 788-800.

[242] S. Mao, Y. Zou, G. Sun, L. Zeng, Z. Wang, D. Ma, Y. Guo, Y. Cheng, C. Wang, J. W. Shi, J. Colloid Interface Sci., 2021, 581, 1-10.

[243] C. Zhao, H. Jiang, Q. Liang, M. Zhou, Y. Zhang, Z. Li, S. Xu, Sol. Energy, 2020, 207, 599-608.

[244] Z. Jin, Z. Wang, H. Yuan, F. Han, Int. J. Hydrogen Energy, 2019, 44, 19640-19649.

[245] J. Guo, Y. Liang, L. Liu, J. Hu, H. Wang, W. An, W. Cui, Appl. Surf. Sci., 2020, 522, 146356-146367.

[246] G. J. Lee, Y. W. Chien, S. Anandan, C. Lv, J. Dong, J. J. Wu, Int. J. Hydrogen Energy, 2020, DOI: 10.1016/j.ijhydene.2020.03.254.

[247] M. Jin, X. Qian, J. Gao, J. Chen, D. K. Hensley, H. C. Ho, R. J. Percoco, C. M. Ritzi, Y. Yue, Inorg. Chem., 2019, 58, 8332-8338.

[248] A. Cao, L. Zhang, Y. Wang, H. Zhao, H. Deng, X. Liu, Z. Lin, X. Su, F. Yue, ACS Sustainable Chem. Eng., 2018, 7, 2492-2499.

[249] L. Cui, X. Zou, Y. Liu, X. Li, L. Jiang, C. Li, L. Yang, M. Yu, Y. Wang, J. Colloid Interface Sci., 2020, 577, 233-241.

[250] H. Gong, X. Zhang, G. Wang, Y. Liu, Y. Li, Z. Jin, Mol. Catal., 2020, 485, 110832-220842.

[251] G. Zhou, M. F. Wu, Q. J. Xing, F. Li, H. Liu, X. B. Luo, J. P. Zou, J. M. Luo, A. Q. Zhang, Appl. Catal. B, 2018, 220, 607-614.

[252] J. D. Xiao, Q. C. Shang, Y. J. Xiong, Q. Zhang, Y. Luo, S. H. Yu, H. L. Jiang, Angew. Chem. Int. Ed., 2016, 55, 9389-9393.

[253] F. Dai, Y. Wang, X. Zhou, R. Zhao, J. Han, L. Wang, Appl. Surf. Sci.,
2020, 517, 146161-146166.

[254] Y. Xiao, X. Guo, J. Liu, L. Liu, F. Zhang, C. Li, Chin. J. Catal., 2019, $40,1339-1344$

[255] L. Tian, X. Yang, Q. Liu, F. Qu, H. Tang, Appl. Surf. Sci., 2018, 455, 403-409.

[256] X. Wang, X. Zhang, W. Zhou, L. Liu, J. Ye, D. Wang, Nano Energy, 2019, 62, 250-258.

[257] R. Bibi, H. Huang, M. Kalulu, Q. Shen, L. Wei, O. Oderinde, N. Li, J. Zhou, ACS Sustainable Chem. Eng., 2018, 7, 4868-4877.

[258] F. Li, D. Wang, Q. J. Xing, G. Zhou, S. S. Liu, Y. Li, L. L. Zheng, P. Ye, J. P. Zou, Appl. Catal. B, 2019, 243, 621-628.

[259] Y. Liang, R. Shang, J. Lu, W. An, J. Hu, L. Liu, W. Cui, IInt. J. Hydrogen Energy, 2019, 44, 2797-2810.

[260] Z. Gao, L. Wang, L. Wang, J. Huang, H. She, Q. Wang, IInt. J. Hydrogen Energy, 2019, 44, 24407-24417.

[261] J. J. Zhou, R. Wang, X. L. Liu, F. M. Peng, C. H. Li, F. Teng, Y. P. Yuan, Appl. Surf. Sci., 2015, 346, 278-283.

[262] X. Liu, P. Fan, L. Xiao, J. Weng, Q. Xu, J. Xu, J. Energy Chem., 2021, 53, 185-191.

[263] L. Shen, M. Luo, Y. Liu, R. Liang, F. Jing, L. Wu, Appl. Catal. B, 2015, 166-167, 445-453.

[264] F. Mu, Q. Cai, H. Hu, J. Wang, Y. Wang, S. Zhou, Y. Kong, Chem. Eng. J., 2020, 384, 123352-123364.

[265] S. Zhang, M. Du, Z. Xing, Z. Li, K. Pan, W. Zhou, Appl. Catal. B, 2020, 262, 118202-118212.

[266] Y. F. Chen, L. L. Tan, J. M. Liu, S. Qin, Z. Q. Xie, J. F. Huang, Y. W. Xu, L. M. Xiao, C. Y. Su, Appl. Catal. B, 2017, 206, 426-433.

[267] Y. P. Yuan, L. S. Yin, S. W. Cao, G. S. Xu, C. H. Li, C. Xue, Appl. Catal. $B$, 2015, 168-169, 572-576.

[268] G. Xu, X. Lin, Y. Tong, H. Du, L. Gu, Y. Yuan, Mater. Lett., 2019 , 255, 126593-126596.

[269] Z. Wang, Z. Jin, H. Yuan, G. Wang, B. Ma, J. Colloid Interface Sci., 2018, 532, 287-299.

[270] J. Li, H. Huang, P. Liu, X. Song, D. Mei, Y. Tang, X. Wang, C. Zhong, J. Catal., 2019, 375, 351-360.

[271] Y. Zhang, Z. Jin, J. Phys. Chem. C, 2019, 123, 18248-18263.

[272] Z. Wang, Z. Jin, G. Wang, B. Ma, Int. J. Hydrogen Energy, 2018, 43, 13039-13050.

[273] X. Hao, Z. Jin, H. Yang, G. Lu, Y. Bi, Appl. Catal. B, 2017, 210, 45-56.

[274] N. Serpone, A. V. Emeline, J. Phys. Chem. Lett., 2012, 3, 673-677.

[275] M. Wen, K. Mori, Y. Kuwahara, T. An, H. Yamashita, Chem. Asian J., 2018, 13, 1767-1779.

[276] B. Yu, F. Wang, W. Dong, J. Hou, P. Lu, J. Gong, Mater. Lett., 2015, 156, 50-53.

[277] Y. Pi, X. Li, Q. Xia, J. Wu, Y. Li, J. Xiao, Z. Li, Chem. Eng. J., 2018, 337, 351-371.

[278] H. L. Nguyen, T. T. Vu, D. Le, T. L.H. Doan, V. Q. Nguyen, N. T. S. Phan, ACS Catal., 2016, 7, 338-342.

[279] S. H. Khan, B. Pathak, Environmental Nanotechnology, Monitoring \& Management, 2020, 13, 100290-100304.

[280] W. He, H. K. Kim, W. G. Wamer, D. Melka, J. H. Callahan, J. J. Yin, J. Am. Chem. Soc., 2014, 136, 750-757.

[281] X. Zhang, N. Zhang, C. Gan, Y. Liu, L. Chen, C. Zhang, Y. Fang, Mater. Sci. Semicond. Process., 2019, 91, 212-221.

[282] Y. X. Li, X. Wang, C. C. Wang, H. Fu, Y. Liu, P. Wang, C. Zhao, J. Hazard. Mater., 2020, 399, 123085-123098.

[283] G. Zhu, S. Feng, J. Chao, W. Zheng, C. Shao, Ceram. Int., 2020, 46, 2530-2537.

[284] H. Ramezanalizadeh, F. Manteghi, J. Cleaner Prod., 2018, 172, 2655-2666.

[285] R. Li, W. Li, C. Jin, Q. He, Y. Wang, J. Alloys Compd., 2020, 825, 
154008-154017.

[286] Y. M. He, L. Zeng, Z. Feng, Q. L. Zhang, X. Y. Zhao, S. F. Ge, X. Hu, H. J. Lin, Adv. Powder Technol, 2020, 31, 439-477.

[287] Q. Hu, J. Di, B. Wang, M. Ji, Y. Chen, J. Xia, H. Li, Y. Zhao, Appl. Surf. Sci., 2019, 466, 525-534.

[288] L. Hu, G. Deng, W. Lu, S. Pang, X. Hu, Appl. Surf. Sci., 2017, 410, 401-413.

[289] M. Salimi, A. Esrafili, A. Jonidi Jafari, M. Gholami, H. R. Sobhi, M. Nourbakhsh, B. Akbari-Adergani, Colloids Surf. A, 2019, 582, 123874-123884.

[290] Y. Tang, X. Yin, M. Mu, Y. Jiang, X. Li, H. Zhang, T. Ouyang, Colloids Surf. A, 2020, 596, 124745-124756.

[291] C. Yang, X. You, J. Cheng, H. Zheng, Y. Chen, Appl. Catal. B, 2017, 200, 673-680.

[292] W. Cao, Y. Yuan, C. Yang, S. Wu, J. Cheng, Chem. Eng. J., 2020, 391, 123608-123619.

[293] Q. Wang, G. Wang, X. Liang, X. Dong, X. Zhang, Appl. Surf. Sci., 2019, 467-468, 320-327.

[294] C. Duan, C. Liu, X. Meng, K. Gao, W. Lu, Y. Zhang, L. Dai, W. Zhao, C. Xiong, W. Wang, Y. Liu, Y. Ni, Carbohydr. Polym., 2020, 230, 115642-115650.

[295] W. Huang, C. Jing, X. Zhang, M. Tang, L. Tang, M. Wu, N. Liu, Chem. Eng. J., 2018, 349, 603-612.

[296] J. Chen, X. Zhang, X. Shi, F. Bi, Y. Yang, Y. Wang, J. Colloid Interface Sci., 2020, 579, 37-49.
[297] R. Hejazi, A. R. Mahjoub, A. H. C. Khavar, Z. Khazaee, J. Photochem. Photobiol. A, 2020, 400, 112644-112655.

[298] M. Samy, M. G. Ibrahim, M. Gar Alalm, M. Fujii, Sep. Purif. Technol,, 2020, 249, 117173-117183.

[299] G. Li, Y. Wang, R. Huang, Y. Hu, J. Guo, S. Zhang, Q. Zhong, Colloids Surf. A, 2020, 603, 125256-125264.

[300] S. Subudhi, L. Paramanik, S. Sultana, S. Mansingh, P. Mohapatra, K. Parida, J. Colloid Interface Sci., 2020, 568, 89-105.

[301] C. Zhao, Y. Zhang, H. Jiang, J. Chen, Y. Liu, Q. Liang, M. Zhou, Z. Li, Y. Zhou, J. Phys. Chem. C, 2019, 123, 18037-18049.

[302] J. Sun, S. Feng, S. Feng, Inorg. Chem. Commun., 2020, 111, 107669-107678.

[303] D. Ao, J. Zhang, H. Liu, J. Photochem. Photobiol. A, 2018, 364, 524-533.

[304] G. Chaturvedi, A. Kaur, S. K. Kansal, J. Phys. Chem. C, 2019, 123, 16857-16867.

[305] Y. He, W. Dong, X. Li, D. Wang, Q. Yang, P. Deng, J. Huang, J. Colloid Interface Sci., 2020, 574, 364-376.

[306] H. E. Emam, H. B. Ahmed, E. Gomaa, M. H. Helal, R. M. Abdelhameed, J. Photochem. Photobiol. A, 2019, 383, 111986-111997.

[307] Y. Liang, R. Shang, J. Lu, L. Liu, J. Hu, W. Cui, ACS Appl. Mater. Interfaces, 2018, 10, 8758-8769.

[308] T. Kusutaki, H. Katsumata, I. Tateishi, M. Furukawa, S. Kaneco, ACS Omega, 2019, 4, 15975-15984.

\title{
金属有机框架(MOFs)基光催化剂的设计及其在太阳能燃料生产和污染物降解 领域的研究进展
}

\author{
赵小雪，李金择，李 金霍鹏伟", 施伟东 ${ }^{*}$ \\ 江苏大学化学化工学院/绿色化学与化工技术研究院, 江苏镇江 212013
}

摘要: 金属有机骨架(MOFs)具有较高的比表面积, 丰富的金属/有机物种, 较大的孔体积以及结构和成分可调节的特性, 因 此在太阳能燃料生产和污染物的光降解领域具有广泛的应用. 根据其结构特点, 研究者们主要从有机配体和孔道结构两 方面对MOFs进行调控: (1)对有机配体进行修饰, 如将杂原子、羟基、卤素原子、金属离子、生物大分子等引入MOFs结构; (2)将无机纳米粒子引入MOFs孔道内, 如将贵金属、金属氧化物、多金属氧酸盐等纳米粒子封装在MOFs的孔道内. 这些策 略可有效增强MOFs的导电性、稳定性等, 并进一步提高MOFs基催化剂的光催化性能.

本文首先概述了四种经典MOFs 类型, 即 $\mathrm{UiO}, \mathrm{ZIF}, \mathrm{MIL}$ 和PCN系列的结构特点和催化性能. 其次, 总结了在设计MOFs 基光催化材料过程中, 根据不同类型MOFs特点着重考虑的五方面因素, 即稳定性、能带结构、吸附作用、选择性和电导性. 再次, 讨论了提高MOFs基光催化剂活性的策略, 如助催化剂修饰、构建异质结、配体或金属中心修饰和缺陷工程. 最后, 总 结了MOFs基光催化材料在催化还原 $\mathrm{CO}_{2}$ 、分解水制氢和降解有机污染物反应中的应用进展及影响其催化性能的主要因素.

尽管MOFs 基光催化材料研究已经取得了令人瞩目的进展, 但对MOFs基光催化剂进行可控设计制备仍然存在挑战. 如何实现纳米MOFs基光催化材料的制备与规模化生产、可调缺陷MOFs基光催化材料的精准设计、开发高稳定性的MOFs 基光催化材料等仍需进一步探索. 因此, 未来需要从MOFs的纳米化合成、复合材料界面结构的精准调控、催化活性机制 与稳定性关系等方面对MOFs基光催化材料进行深入的研究.

关键词: 设计; 金属有机骨架; 光催化性能; 降解有机污染物; $\mathrm{CO}_{2}$ 还原; 产氢

收稿日期: 2020-08-18. 接受日期: 2020-09-21. 上网日期: 2020-11-22.

*通讯联系人. 电话/传真: (0511)88790885; 电子信箱: huopw@mail.ujs.edu.cn

\#通讯联系人. 电子信箱: swd1978@ujs.edu.cn

基金来源: 国家自然科学基金(22078131, 21776117).

本文的电子版全文由Elsevier出版社在ScienceDirect上出版(http://www.sciencedirect.com/science/journal/18722067). 